\title{
Computer model of unstirred layer and intracellular pH changes. Determinants of unstirred layer pH
}

\author{
Roger Marrannes
}

Received: 10 August 2012 / Accepted: 19 February 2013 / Published online: 7 April 2013

(C) Springer Science+Business Media Dordrecht 2013

\begin{abstract}
Transmembrane acid-base fluxes affect the intracellular $\mathrm{pH}$ and unstirred layer $\mathrm{pH}$ around a superfused biological preparation. In this paper the factors influencing the unstirred layer $\mathrm{pH}$ and its gradient are studied. An analytical expression of the unstirred layer $\mathrm{pH}$ gradient in steady state is derived as a function of simultaneous transmembrane fluxes of (weak) acids and bases with the dehydration reaction of carbonic acid in equilibrium. Also a multicompartment computer model is described consisting of the extracellular bulk compartment, different unstirred layer compartments and the intracellular compartment. With this model also transient changes and the influence of carbonic anhydrase (CA) can be studied. The analytical expression and simulations with the multicompartment model demonstrate that in steady state the unstirred layer $\mathrm{pH}$ and its gradient are influenced by the size and type of transmembrane flux of acids and bases, their dissociation constant and diffusion coefficient, the concentration, diffusion coefficient and type of mobile buffers and the activity and location of CA. Similar principles contribute to the amplitude of the unstirred layer $\mathrm{pH}$ transients. According to these models an immobile buffer does not influence the steady-state $\mathrm{pH}$, but reduces the amplitude of $\mathrm{pH}$ transients especially when these are fast. The unstirred layer $\mathrm{pH}$ provides useful information about transmembrane acid-base fluxes. This paper gives more insight how the unstirred layer $\mathrm{pH}$ and its transients can be interpreted. Methodological issues are discussed.
\end{abstract}

Keywords Computer model $\cdot$ Unstirred layer $\mathrm{pH} \cdot$ Intracellular $\mathrm{pH} \cdot$ Proton transport • Buffer $\cdot$ Carbonic anhydrase $\cdot$ Disequilibrium $\mathrm{pH} \cdot \mathrm{pH}$

The author is a former scientist in Department of Physiology and Physiopathology, Ghent University, De Pintelaan 185, 9000 Ghent, Belgium and in Department of Neuroscience, Johnson and Johnson Pharmaceutical Research and Development, Division of Janssen Pharmaceutica N.V., Turnhoutseweg 30, 2340 Beerse, Belgium (Retired).

R. Marrannes $(\varangle)$

Kongostraat 135, 2300 Turnhout, Belgium

e-mail: roger.marrannes@telenet.be 


\section{Introduction}

Many physiological properties are influenced by $\mathrm{pH}$, such as protein conformation and activity of enzymes, ion channels and transporters. Chemical reactions and transmembrane fluxes of acids and bases tend to affect the intracellular $\mathrm{pH}$ and unstirred layer $\mathrm{pH}$ close to the cell membrane. The intracellular $\mathrm{pH}$ is regulated by acid extrusion pumps, transporters, buffering and carbonic anhydrase [1-3]. Development of small $\mathrm{pH}$-sensitive microelectrodes and $\mathrm{pH}$-sensitive dyes has greatly advanced our insight in intracellular $\mathrm{pH}$ changes [4-6].

A method to study intracellular $\mathrm{pH}$ regulation is implemented by imposing an acid or alkaline load on the cell by transmembrane diffusion of weak acids or weak bases or by direct acid injection into the cell [7-9]. In a seminal paper, some important principles of intracellular $\mathrm{pH}$ regulation after transmembrane fluxes of $\mathrm{CO}_{2} / \mathrm{HCO}_{3}{ }^{-}$or $\mathrm{NH}_{4}{ }^{+} / \mathrm{NH}_{3}$ have been demonstrated and modeled with a two-compartment computer model [10].

However, simultaneously with the intracellular $\mathrm{pH}$ changes, the transmembrane fluxes of (weak) acids and bases can also induce extracellular $\mathrm{pH}$ changes in the surrounding unstirred layer, which affect the electrophysiological activity of the biological preparation [11-13]. The amplitude of these unstirred layer $\mathrm{pH}$ changes depends not only on the rate of the transmembrane fluxes of acids and bases, but also on the extracellular buffer capacity and carbonic anhydrase activity [11-15]. The uncatalyzed reaction $\mathrm{H}_{2} \mathrm{CO}_{3} \leftrightarrows$ $\mathrm{H}_{2} \mathrm{O}+\mathrm{CO}_{2}$ is rather slow and can be rate limiting [16]. Carbonic anhydrase (CA), which catalyses this reaction, has been found in many tissues. Metabolic production of $\mathrm{CO}_{2}$ and lactic acid can also induce a steady-state $\mathrm{pH}$ gradient in the extracellular unstirred layer $[14,17]$.

Measurement of the extracellular unstirred layer $\mathrm{pH}$ can provide important information on transmembrane acid-base fluxes [13, 18, 19]. Therefore it is useful to study more precisely the relationship between the unstirred layer $\mathrm{pH}$ and these transmembrane fluxes.

In this paper, first analytical expressions are derived to calculate the steady-state $\mathrm{pH}$ gradient in the extracellular unstirred layer as a function of simultaneous acid-base fluxes, when the reaction of $\mathrm{H}_{2} \mathrm{CO}_{3} \leftrightarrows \mathrm{H}_{2} \mathrm{O}+\mathrm{CO}_{2}$ is in equilibrium. Thereafter a multicompartment computer model is described, which also enables transient changes to be simulated. This model contains an extracellular bulk compartment, a freely chosen number of unstirred layer compartments and an intracellular compartment. The absence or degree of catalysis of the carbonic anhydrase reaction can be chosen in each compartment individually. These tools were applied to study in more detail how the unstirred layer $\mathrm{pH}$ profile is influenced by different types of transmembrane fluxes of acids and bases, by carbonic anhydrase and the type of buffering. The model can be used to analyze and predict different experimental situations.

\section{Methods}

\subsection{Calculation of the $\mathrm{pH}$ gradient in the unstirred layer in steady state}

Consider a preparation covered by an unstirred layer with thickness $d$. Let us assume that there is an abrupt transition from the stirred region (the bulk of the solution) to the unstirred region. The unstirred layer can be divided into thin sheets with thickness $\mathrm{d} x$ and surface $S$. It is assumed that the surface of each such sheet is homogeneous in all properties, such as diffusion coefficients and concentration gradients of all solutes. A constant flux 
of one or more acid-base solutes through the membrane of the preparation will create a concentration and $\mathrm{pH}$ gradient from the bulk to the membrane. Expressions will be derived that allow these gradients to be calculated and that show how the different factors influence these gradients.

The $\mathrm{x}$-axis is chosen perpendicular to the preparation and is directed from the bulk towards the preparation. Fluxes are considered positive in the direction of the x-axis. Let us consider a simultaneous diffusion of $\mathrm{H}^{+}, \mathrm{OH}^{-}$, the monoprotic acid-base systems HA/A and $\mathrm{HB} / \mathrm{B}$, and a diprotic acid-base system $\mathrm{H}_{2} \mathrm{C} / \mathrm{HC} / \mathrm{C}$ through the unstirred layer. $\mathrm{H}_{2} \mathrm{C}, \mathrm{HC}$ and $\mathrm{C}$ stand for $\mathrm{CO}_{2}{ }^{\prime}\left(=\mathrm{CO}_{2}+\mathrm{H}_{2} \mathrm{CO}_{3}\right)$, bicarbonate and carbonate, respectively. For these derivations, the reaction $\mathrm{CO}_{2}+\mathrm{H}_{2} \mathrm{O} \leftrightarrows \mathrm{H}_{2} \mathrm{CO}_{3}$ is assumed to be in equilibrium, so that $K_{1}^{\prime}=K_{C O 2^{\prime}}=[\mathrm{H}][\mathrm{HC}] /\left[\mathrm{H}_{2} \mathrm{C}\right]=10^{-6.12}[20]$. The signs indicating the charge of the solutes will be omitted in the equations. $\mathrm{HA}$ is a weak acid and $\mathrm{A}$ its corresponding weak base. $\mathrm{HA} / \mathrm{A}$ can thus be e.g., lactic acid/lactate or $\mathrm{NH}_{4}{ }^{+} / \mathrm{NH}_{3}$. The same applies to $\mathrm{HB}$ and $\mathrm{B}$, which can be a non- $\mathrm{CO}_{2}$ buffer like HEPES.

$$
\begin{aligned}
{\left[T_{H A}\right] } & =[\mathrm{HA}]+[\mathrm{A}] ;\left[T_{H B}\right]=[\mathrm{HB}]+[\mathrm{B}] ; \\
{\left[T_{H 2 C}\right] } & =\left[\mathrm{H}_{2} \mathrm{C}\right]+[\mathrm{HC}]+[\mathrm{C}] \text { at distance } x .
\end{aligned}
$$

A condition for steady state is that in the whole unstirred layer $\left[T_{H A}\right],\left[T_{H B}\right]$ and $\left[T_{H 2 C}\right]$ are constant over time. For $\left[T_{H A}\right]$ this means that the sum of the amounts of HA and A, which diffuse through all parallel surfaces of the unstirred layer per second, are equal and are also equal to the total amount that migrates through the membrane surface $\left(S_{m}\right)$ of the preparation, so that

$$
\left(J_{H A}+J_{A}\right) S=\left(J_{m H A}+J_{m A}\right) S_{m}
$$

where $J_{X}$ is the flux of solute $X$ through a surface $S$ of the unstirred layer and $J_{m X}$ the flux of solute $X$ through the outer membrane area of the preparation. For HB/B:

$$
\left(J_{H B}+J_{B}\right) S=\left(J_{m H B}+J_{m B}\right) S_{m}
$$

For $\mathrm{H}_{2} \mathrm{C} / \mathrm{HC} / \mathrm{C}$ :

$$
\left(J_{H 2 C}+J_{H C}+J_{C}\right) S=\left(J_{m H 2 C}+J_{m H C}+J_{m C}\right) S_{m}
$$

Another condition for the steady state is that through all these surface areas the same amount of protons migrates, bound or not to their respective bases. For these proton movements the flux of a hydroxyl anion is practically equivalent to a flux of a proton in the opposite direction. Consequently, in steady state:

$$
\begin{aligned}
& \left(J_{H}-J_{O H}+J_{H A}+J_{H B}+2 J_{H 2 C}+J_{H C}\right) S \\
& \quad=\left(J_{m H}-J_{m O H}+J_{m H A}+J_{m H B}+2 J_{m H 2 C}+J_{m H C}\right) S_{m}
\end{aligned}
$$


Because the potential gradient measured over the unstirred layer is quite small [17], this can be neglected. Then the diffusion of all solutes through the unstirred layer can be described by Fick's first law of diffusion:

$$
\begin{gathered}
J_{H}=-U D_{H} \frac{\mathrm{d}[\mathrm{H}]}{\mathrm{d} x}=U D_{H} \ln (10)[\mathrm{H}] \frac{\mathrm{dpH}}{\mathrm{d} x}=U D_{H} \beta_{H} \frac{\mathrm{dpH}}{\mathrm{d} x} \\
J_{O H}=-U D_{O H} \frac{\mathrm{d}[\mathrm{OH}]}{\mathrm{d} x}=-U D_{O H} \ln (10)[\mathrm{OH}] \frac{\mathrm{dpH}}{\mathrm{d} x}=-U D_{O H} \beta_{O H} \frac{\mathrm{dpH}}{\mathrm{d} x}
\end{gathered}
$$

where $D_{X}$ is the diffusion coefficient of solute $X ; \beta_{H}$ and $\beta_{O H}$ are the buffer capacities of $\mathrm{H}^{+}$and $\mathrm{OH}^{-}$, respectively. $U$ is a unit conversion factor. In this paper $U=1000$, because the SI unit system is used but concentrations and buffer capacities are expressed in $\mathrm{M}\left(\right.$ mole $\left.\mathrm{dm}^{-3}\right)$. If $\mathrm{m}$ was used consistently as unit of distance and concentrations were expressed in mole $\mathrm{m}^{-3}$, then $U$ would be 1 .

Let $f_{H A}$ be the fraction of $\left[T_{H A}\right]$ as HA. Thus $f_{H A}=[\mathrm{HA}] /\left[T_{H A}\right]$ and $f_{A}=[\mathrm{A}] /\left[T_{H A}\right]$.

$$
f_{H 2 C}=\left[\mathrm{H}_{2} \mathrm{C}\right] /\left[T_{H 2 C}\right] ; f_{H C}=[\mathrm{HC}] /\left[T_{H 2 C}\right] ; f_{C}=[\mathrm{C}] /\left[T_{H 2 C}\right]
$$

The other fluxes through the unstirred layer can be expressed as:

$$
\begin{aligned}
J_{H A}=-U D_{H A} \frac{\mathrm{d}[\mathrm{HA}]}{\mathrm{d} x} & =-U D_{H A} \frac{\mathrm{d} f_{H A}\left[T_{H A}\right]}{\mathrm{d} x}=-U D_{H A}\left(f_{H A} \frac{\mathrm{d}\left[T_{H A}\right]}{\mathrm{d} x}+\left[T_{H A}\right] \frac{\mathrm{d} f_{H A}}{\mathrm{~d} x}\right) \\
J_{A}=-U D_{A} \frac{\mathrm{d}[\mathrm{A}]}{\mathrm{d} x} & =-U D_{A} \frac{\mathrm{d} f_{A}\left[T_{H A}\right]}{\mathrm{d} x}=-U D_{A}\left(f_{A} \frac{\mathrm{d}\left[T_{H A}\right]}{\mathrm{d} x}+\left[T_{H A}\right] \frac{\mathrm{d} f_{A}}{\mathrm{~d} x}\right) \\
J_{H 2 C} & =-U D_{H 2 C} \frac{\mathrm{d}[\mathrm{H} 2 \mathrm{C}]}{\mathrm{d} x}=-U D_{H 2 C} \frac{\mathrm{d} f_{H 2 C}\left[T_{H 2 C}\right]}{\mathrm{d} x} \\
& =-U D_{H 2 C}\left(f_{H 2 C} \frac{\mathrm{d}\left[T_{H 2 C}\right]}{\mathrm{d} x}+\left[T_{H 2 C}\right] \frac{\mathrm{d} f_{H 2 C}}{\mathrm{~d} x}\right)
\end{aligned}
$$

where $D_{H 2 C}$ is the weighted average diffusion coefficient of $\mathrm{CO}_{2}$ and $\mathrm{H}_{2} \mathrm{CO}_{3}$

$$
\begin{aligned}
& J_{H C}=-U D_{H C} \frac{\mathrm{d}[\mathrm{HC}]}{\mathrm{d} x}=-U D_{H C} \frac{\mathrm{d} f_{H C}\left[T_{H 2 C}\right]}{\mathrm{d} x}=-U D_{H C}\left(f_{H C} \frac{\mathrm{d}\left[T_{H 2 C}\right]}{\mathrm{d} x}+\left[T_{H 2 C}\right] \frac{\mathrm{d} f_{H C}}{\mathrm{~d} x}\right) \\
& J_{C}=-U D_{C} \frac{\mathrm{d}[\mathrm{C}]}{\mathrm{d} x}=-U D_{C} \frac{\mathrm{d} f_{C}\left[T_{H 2 C}\right]}{\mathrm{d} x}=-U D_{C}\left(f_{C} \frac{\mathrm{d}\left[T_{H 2 C}\right]}{\mathrm{d} x}+\left[T_{H 2 C}\right] \frac{\mathrm{d} f_{C}}{\mathrm{~d} x}\right)
\end{aligned}
$$

For HA/A:

$$
f_{H A}=\frac{[\mathrm{HA}]}{\left[T_{H A}\right]}=\frac{[\mathrm{HA}]}{([\mathrm{HA}]+[\mathrm{A}])}=\frac{[\mathrm{H}]}{\left([\mathrm{H}]+K_{H A}\right)}
$$


where $K_{H A}=[\mathrm{H}][\mathrm{A}] /[\mathrm{HA}]$

$$
f_{A}=\frac{[\mathrm{A}]}{\left[T_{H A}\right]}=\frac{[\mathrm{A}]}{([\mathrm{HA}]+[\mathrm{A}])}=\frac{K_{H A}}{\left([\mathrm{H}]+K_{H A}\right)}=1-f_{H A}
$$

Derivation of $f_{A}$ yields:

$$
\frac{\mathrm{d} f_{A}}{\mathrm{~d} x}=\ln (10) \frac{[\mathrm{H}] K_{H A}}{\left([\mathrm{H}]+K_{H A}\right)^{2}} \frac{\mathrm{dpH}}{\mathrm{d} x}
$$

For HA/A, the buffer capacity for a closed system [21, 22] is:

$$
\beta_{H A}=\ln (10) f_{H A} f_{A}\left[T_{H A}\right]=\ln (10) \frac{[\mathrm{H}] K_{H A}}{\left([\mathrm{H}]+K_{H A}\right)^{2}}\left[T_{H A}\right]
$$

Combination of (14) and (15) gives:

$$
\frac{\mathrm{d} f_{A}}{\mathrm{~d} x}=\frac{\beta_{H A}}{\left[T_{H A}\right]} \frac{\mathrm{dpH}}{\mathrm{d} x}
$$

Because $f_{H A}=1-f_{A}$,

$$
\frac{\mathrm{d} f_{H A}}{\mathrm{~d} x}=-\frac{\beta_{H A}}{\left[T_{H A}\right]} \frac{\mathrm{dpH}}{\mathrm{d} x}
$$

Combination of (1), (7), (8), (16) and (17) gives:

$$
\frac{\mathrm{d}\left[T_{H A}\right]}{\mathrm{d} x}=\frac{\frac{-\left(J_{m H A}+J_{m A}\right) S_{m}}{S U}+\left(D_{H A}-D_{A}\right) \beta_{H A} \frac{\mathrm{dpH}}{\mathrm{d} x}}{f_{H A} D_{H A}+f_{A} D_{A}}
$$

Substitution of $\frac{\mathrm{d}\left[T_{H A}\right]}{\mathrm{d} x}$ from (18) and $\frac{\mathrm{d} f_{H A}}{\mathrm{~d} x}$ from (17) into (7) gives:

$$
J_{H A}=\frac{\frac{f_{H A} D_{H A}\left(J_{m H A}+J_{m A}\right) S_{m}}{S}+U D_{H A} D_{A} \beta_{H A} \frac{\mathrm{dpH}}{\mathrm{d} x}}{f_{H A} D_{H A}+f_{A} D_{A}}
$$

Substitution of $\frac{\mathrm{d}\left[T_{H A}\right]}{\mathrm{d} x}$ from (18) and $\frac{\mathrm{d} f_{A}}{\mathrm{~d} x}$ from (16) into (8) gives:

$$
\begin{gathered}
J_{A}=\frac{\frac{f_{A} D_{A}\left(J_{m H A}+J_{m A}\right) S_{m}}{S}-U D_{H A} D_{A} \beta_{H A} \frac{\mathrm{dpH}}{\mathrm{d} x}}{f_{H A} D_{H A}+f_{A} D_{A}} \\
K_{2}=[\mathrm{H}][\mathrm{C}] /[\mathrm{HC}]=\left[\mathrm{H}^{+}\right]\left[\mathrm{CO}_{3}^{2-}\right] /\left[\mathrm{HCO}_{3}^{-}\right]=10^{-10.277}
\end{gathered}
$$

For $\mathrm{H}_{2} \mathrm{C} / \mathrm{HC} / \mathrm{C}$, it can be derived easily that:

$$
\begin{gathered}
f_{H 2 C}=\frac{[\mathrm{H}]^{2}}{[\mathrm{H}]^{2}+[\mathrm{H}] K_{1}^{\prime}+K_{1}^{\prime} K_{2}} \\
f_{H C}=\frac{[\mathrm{H}] K_{1}^{\prime}}{[\mathrm{H}]^{2}+[\mathrm{H}] K_{1}^{\prime}+K_{1}^{\prime} K_{2}} \\
f_{C}=\frac{K_{1}^{\prime} K_{2}}{[\mathrm{H}]^{2}+[\mathrm{H}] K_{1}^{\prime}+K_{1}^{\prime} K_{2}}
\end{gathered}
$$




$$
\begin{aligned}
& \frac{\mathrm{d} f_{H 2 C}}{\mathrm{~d} x}=\frac{\mathrm{d} f_{H 2 C}}{\mathrm{dpH}} \frac{\mathrm{dpH}}{\mathrm{d} x}=-\frac{\ln (10)[\mathrm{H}]^{2} K_{1}^{\prime}\left([\mathrm{H}]+2 K_{2}\right)}{\left([\mathrm{H}]^{2}+[\mathrm{H}] K_{1}^{\prime}+K_{1}^{\prime} K_{2}\right)^{2}} \frac{\mathrm{dpH}}{\mathrm{d} x} \\
& \frac{\mathrm{d} f_{H C}}{\mathrm{~d} x}=\frac{\mathrm{d} f_{H C}}{\mathrm{dpH}} \frac{\mathrm{dpH}}{\mathrm{d} x}=-\frac{\ln (10)[\mathrm{H}] K_{1}^{\prime}\left(K_{1}^{\prime} K_{2}-[\mathrm{H}]^{2}\right)}{\left([\mathrm{H}]^{2}+[\mathrm{H}] K_{1}^{\prime}+K_{1}^{\prime} K_{2}\right)^{2}} \frac{\mathrm{dpH}}{\mathrm{d} x}
\end{aligned}
$$

Substitution of $J_{H 2 C}, J_{H C}, J_{C}, f_{H 2 C}, f_{H C}$ and $f_{C}$ from (9), (10), (11), (21), (22) and (23), respectively into (3), grouping of terms containing $\mathrm{dpH} / \mathrm{d} x$ and isolation of $\mathrm{d}\left[T_{H 2 C}\right] / \mathrm{d} x$ gives:

$\frac{\mathrm{d}\left[T_{H 2 C}\right]}{\mathrm{d} x}$

$=\frac{-\left(J_{m H 2 C}+J_{m H C}+J_{m C}\right) \frac{S_{m}}{S U}+\frac{\ln (10)[\mathrm{H}] K_{1}^{\prime}\left(D_{H 2 C}\left([\mathrm{H}]^{2}+2[\mathrm{H}] K_{2}\right)+D_{H C}\left(K_{1}^{\prime} K_{2}-[\mathrm{H}]^{2}\right)-D_{C}\left(2[\mathrm{H}] K_{2}+K_{1}^{\prime} K_{2}\right)\right)\left[T_{H 2 C}\right]}{\left([\mathrm{H}]^{2}+[\mathrm{H}] K_{1}^{\prime}+K_{1}^{\prime} K_{2}\right)^{2}} \frac{\mathrm{dpH}}{\mathrm{d} x}}{f_{H 2 C} D_{H 2 C}+f_{H C} D_{H C}+f_{C} D_{C}}$

Substitution of $\mathrm{d}\left[T_{H_{2} C}\right] / \mathrm{d} x$ from (26) and $\mathrm{d} f_{\mathrm{H}_{2} \mathrm{C}} / \mathrm{d} x$ from (24) into (9) gives:

$$
J_{H 2 C}=\frac{f_{H 2 C} D_{H 2 C}\left(J_{m H 2 C}+J_{m H C}+J_{m C}\right) \frac{S_{m}}{S}+\frac{U \ln (10)[\mathrm{H}] K_{1}^{\prime} D_{H 2 C}\left([\mathrm{H}]^{2} D_{H C}+2[\mathrm{H}] K_{2} D_{C}\right)\left[T_{H 2 C}\right]}{\left([\mathrm{H}]^{2}+[\mathrm{H}] K_{1}^{\prime}+K_{1}^{\prime} K_{2}\right)^{2}} \frac{\mathrm{dpH}}{\mathrm{d} x}}{f_{H 2 C} D_{H 2 C}+f_{H C} D_{H C}+f_{C} D_{C}}
$$

Substitution of $\mathrm{d}\left[T_{H 2 C}\right] / \mathrm{d} x$ from (26) and $\mathrm{d} f_{H C} / \mathrm{d} x$ from (25) into (10) gives:

$$
J_{H C}=\frac{f_{H C} D_{H C}\left(J_{m H 2 C}+J_{m H C}+J_{m C}\right) \frac{S_{m}}{S}+\frac{U \ln (10)[\mathrm{H}] K_{1}^{\prime} D_{H C}\left(K_{1}^{\prime} K_{2} D_{C}-[\mathrm{H}]^{2} D_{H 2 C}\right)\left[T_{H 2 C}\right]}{\left([\mathrm{H}]^{2}+[\mathrm{H}] K_{1}^{\prime}+K_{1}^{\prime} K_{2}\right)^{2}} \frac{\mathrm{dpH}}{\mathrm{d} x}}{f_{H 2 C} D_{H 2 C}+f_{H C} D_{H C}+f_{C} D_{C}}
$$

Equations analogous to (7), (8), (12), (13), (14), (15), (16), (17), (18), (19), and (20) can be written for HB/B. Substitution of $J_{H}, J_{O H}, J_{H A}, J_{H B}, J_{H 2 C}$ and $J_{H C}$ from (5), (6), (19) (and an analogous equation for $J_{H B}$ ), (27) and (28) into (4), grouping of terms in $\mathrm{dpH} / \mathrm{d} x$ and isolation of $\mathrm{dpH} / \mathrm{d} x$ yields:

$$
\frac{\mathrm{dpH}}{\mathrm{d} x}=\frac{F_{1}}{U F_{2}}
$$

where

$$
F_{1}=\left[\begin{array}{c}
J_{m H}-J_{m O H}+\frac{J_{m H A} f_{A} D_{A}-J_{m A} f_{H A} D_{H A}}{f_{H A} D_{H A}+f_{A} D_{A}}+\frac{J_{m H B} f_{B} D_{B}-J_{m B} f_{H B} D_{H B}}{f_{H B} D_{H B}+f_{B} D_{B}} \\
+\frac{J_{m H 2 C}\left(f_{H C} D_{H C}+2 f_{C} D_{C}\right)+J_{m H C}\left(f_{C} D_{C}-f_{H 2 C} D_{H 2 C}\right)-J_{m C}\left(2 f_{H 2 C} D_{H 2 C}+f_{H C} D_{H C}\right)}{f_{H 2 C} D_{H 2 C}+f_{H C} D_{H C}+f_{C} D_{C}}
\end{array}\right] \frac{S_{m}}{S}
$$




$$
F_{2}=\left[\begin{array}{c}
D_{H} \beta_{H}+D_{O H} \beta_{O H}+\frac{D_{H A} D_{A} \beta_{H A}}{f_{H A} D_{H A}+f_{A} D_{A}}+\frac{D_{H B} D_{B} \beta_{H B}}{f_{H B} D_{H B}+f_{B} D_{B}}+ \\
\frac{\left(\frac{\ln (10)[\mathrm{H}] K_{1}^{\prime}\left(D_{H 2 C} D_{H C}[\mathrm{H}]^{2}+D_{H 2 C} D_{C} 4[\mathrm{H}] K_{2}+D_{H C} D_{C} K_{1}^{\prime} K_{2}\right)\left[T_{H 2 C}\right]}{\left([\mathrm{H}]^{2}+[\mathrm{H}] K_{1}^{\prime}+K_{1}^{\prime} K_{2}\right)^{2}}\right)}{f_{H 2 C} D_{H 2 C}+f_{H C} D_{H C}+f_{C} D_{C}}
\end{array}\right]
$$

To explain the physical meaning of (29b):

Because $f_{H A}+f_{A}=1, \quad f_{H B}+f_{B}=1$ and $f_{H 2 C}+f_{H C}+f_{C}=1, \quad\left(f_{H A} D_{H A}+f_{A} D_{A}\right)$ in Eq. (29b) is the weighted average diffusion coefficient of the system HA/A, $\left(f_{H B} D_{H B}+f_{B} D_{B}\right)$ is the weighted average diffusion coefficient of the system $\mathrm{HB} / \mathrm{B}$ and $\left(f_{H 2 C} D_{H 2 C}+f_{H C} D_{H C}+f_{C} D_{C}\right)$ is the weighted average diffusion coefficient of the system $\mathrm{H}_{2} \mathrm{C} / \mathrm{HC} / \mathrm{C}$.

If there is a transmembrane flux of HA $\left(J_{m H A}\right)$, a fraction $f_{A}$ will dissociate to A and $\mathrm{H}^{+}$and thus $J_{m H A}$ will induce a flux of A and an equal flux of $\mathrm{H}^{+}$through surface $S$ of the unstirred layer. The magnitude of this flux is $J_{m H A}\left(f_{A} D_{A} /\left(f_{H A} D_{H A}+f_{A} D_{A}\right)\right) S_{m} / S$ and depends very much on $f_{A}$. If $D_{H A}=D_{A}$, this flux equals $J_{m H A} f_{A} S_{m} / S$. However, in the extreme case that $D_{A}=0$, then this flux becomes zero, because then the amount of HA (determined by $J_{m H A}$ ) can only diffuse through the unstirred layer as HA. In the other extreme case that $D_{H A}=0$, this flux is equal to $J_{m H A} S_{m} / S$, because then all HA coming from $J_{m H A}$ has to move through the unstirred layer via A. This shows that this flux is modulated by $D_{H A}$ and $D_{A}$. If there is a transmembrane flux of A $\left(J_{m A}\right)$, a fraction $f_{H A}$ will associate with $\mathrm{H}^{+}$to HA and $J_{m A}$ will induce a flux of $\mathrm{HA}$ and a flux of $\mathrm{H}^{+}$in the opposite direction through surface $S$ of the unstirred layer, equal to $-J_{m A}\left(f_{H A} D_{H A} /\left(f_{H A} D_{H A}+f_{A} D_{A}\right)\right) S_{m} / S$. If there is a transmembrane flux of $\mathrm{H}_{2} \mathrm{C}\left(J_{m H 2 C}\right)$, the fraction that dissociates to HC induces a proton flux of $J_{m H 2 C}\left(f_{H C} D_{H C} /\left(f_{H 2 C} D_{H 2 C}+f_{H C} D_{H C}+f_{C} D_{C}\right)\right) S_{m} / S$ and the fraction that dissociates further to $\mathrm{C}$ induces a proton flux of $J_{m H 2 C}\left(2 f_{C} D_{C} /\left(f_{H 2 C} D_{H 2 C}+f_{H C} D_{H C}+\right.\right.$ $\left.\left.f_{C} D_{C}\right)\right) S_{m} / S$, etc.

In (29a) $F_{1}$ is thus the net proton flux (due to all these transmembrane fluxes after dissociation and association reactions in the unstirred layer) through $S$, which has to be transported by the mobile buffers. $F_{2}$ is the proton transport capacity of the mobile buffers in this sheet of the unstirred layer (29c) and depends on the concentration and buffer capacity of the mobile buffers and on their diffusion coefficients. According to (29a), the $\mathrm{pH}$ gradient will thus be larger when the above net proton flux through $S$ is larger and the proton transport capacity of the mobile buffers is smaller.

In the simpler case that $D_{H A}=D_{A}, D_{H B}=D_{B}$ and $D_{H 2 C}=D_{H C}=D_{C}$, (29a) reduces to:

$\frac{\mathrm{dpH}}{\mathrm{d} x}=$

$\underline{\left[J_{m H}-J_{m O H}+f_{A} J_{m H A}-f_{H A} J_{m A}+f_{B} J_{m H B}-f_{H B} J_{m B}+\left(f_{H C}+2 f_{C}\right) J_{m H 2 C}+\left(f_{C}-f_{H 2 C}\right) J_{m H C}-\left(2 f_{H 2 C}+f_{H C}\right) J_{m C}\right] \frac{S_{m}}{S}}$ $U\left(D_{H} \beta_{H}+D_{O H} \beta_{O H}+D_{H A} \beta_{H A}+D_{H B} \beta_{H B}+D_{H 2 C} \beta_{H 2 C}\right)$

where $\beta_{H 2 C}$ is the buffer capacity of $\mathrm{H}_{2} \mathrm{C} / \mathrm{HC} / \mathrm{C}$ for a closed system $[23,24]$ :

$$
\beta_{H 2 C}=\ln (10)[\mathrm{H}] K_{1}^{\prime} \frac{[\mathrm{H}]^{2}+4[\mathrm{H}] K_{2}+K_{1}^{\prime} K_{2}}{\left([\mathrm{H}]^{2}+[\mathrm{H}] K_{1}^{\prime}+K_{1}^{\prime} K_{2}\right)^{2}}\left[T_{H 2 C}\right]
$$


This demonstrates how closely the buffer capacity for a closed system (multiplied with the diffusion coefficient) is related to the proton transport capacity, not only for monoprotic but also for diprotic acid-base systems. Equations (29c) and (30) also show that only the mobile buffers $\left(D_{X}>0\right)$ contribute to the reduction of the steady-state $\mathrm{pH}$-gradient in the unstirred layer.

Equations (29a), (26), (18) (and analogue equation for HB/B) can be integrated numerically from the bulk solution $(x=0)$ to the cell membrane $(x=d)$. This makes it possible to plot the $\mathrm{pH}$ and concentrations of these solutes in the unstirred layer versus $x$. For maximal accuracy the integration step has to be small enough (for example $\mathrm{d} x=d / 10,000$ ).

In these derivations and equations it was assumed that the reaction $\mathrm{H}_{2} \mathrm{CO}_{3} \leftrightarrows$ $\mathrm{H}_{2} \mathrm{O}+\mathrm{CO}_{2}$ is in equilibrium. If this is not the case, a disequilibrium $\mathrm{pH}$ difference will be superimposed on this $\mathrm{pH}$-gradient. This more general case can be calculated with the multicompartment model given below.

\subsection{Multicompartment model for transient changes in $\mathrm{pH}$ and concentration}

\subsubsection{Compartments}

The model consists of an extracellular bulk compartment (0), one or more unstirred layer compartments $(1$ to $N)$ and an intracellular compartment $(N+1$ or $i)$. In reality, the $\mathrm{pH}$ and concentrations in the unstirred layer change gradually between the bulk compartment and the cell membrane. However, to facilitate the calculations the unstirred layer is subdivided into $N$ compartments; it is assumed that each compartment is homogeneous for all concentrations and that the diffusion resistance through extracellular compartment $j$ is concentrated in a diffusion barrier located at the interface between compartment $j$ and compartment $j-1$. The error due to this simplification is small when $N$ is sufficiently large (see also Section 3.5).

\subsubsection{Passive fluxes}

Let us assume that there is no electrical potential difference between the different extracellular compartments. Then Fick's law governs the passive flux of charged and uncharged solutes over the diffusion barriers between the extracellular compartments according to the equation:

$$
J_{X, j}=-U P_{X, j}\left([X]_{j}-[X]_{j-1}\right)
$$

where $J_{X, j}$ is the flux of solute $X$ from compartment $j-1$ to compartment $j . P_{X, j}$ is the permeability of the diffusion barrier between both compartments and $[X]_{j}$ is the concentration of solute $X$ in compartment $j$.

Fick's law can also be used for the passive fluxes of the uncharged solutes over the cell membrane. In that case $P_{X, j}$ is the membrane permeability to $X$ and $j=N+1$ or $i$. $U$ is the unit conversion factor $(=1000)$.

The GHK constant field equation $[25,26]$ is assumed to govern the passive transmembrane fluxes of the charged solutes:

$$
J_{X, i}=-U P_{X, i} \frac{z F E}{R T} \frac{\left([X]_{N}-[X]_{i} \varepsilon\right)}{(1-\varepsilon)}
$$


where $\varepsilon$ represents $\exp (z F E / R T), E$ the membrane potential, $z$ the valence of the solute, $F$ the Faraday constant, $R$ the gas constant, $T$ the absolute temperature, $[X]_{N}$ and $[X]_{i}$ are the concentration of solute $X$ in compartment $N$ close to the cell membrane and in the intracellular compartment, respectively.

\subsubsection{Rate of change in total concentrations}

The rate of change of the intracellular $\left[T_{H A}\right]_{i}$ is equal to

$$
\frac{\mathrm{d}\left[T_{H A}\right]_{i}}{\mathrm{~d} t}=\frac{\left(J_{H A, i}+J_{A, i}\right) \rho_{p, i}}{U}+M_{H A}
$$

where $t$ is time. $\rho_{p, i}$ is the surface-to-volume ratio of the intracellular compartment. $M_{H A}$ represents the metabolic production of HA (e.g., lactic acid) by the cell in mole $\mathrm{dm}^{-3} \mathrm{~s}^{-1}$.

It is assumed that there is no metabolic production of HA in the unstirred layer. The rate of change of $\left[T_{H A}\right]$ in an unstirred layer compartment $j$ is:

$$
\frac{\mathrm{d}\left[T_{H A}\right]_{j}}{\mathrm{~d} t}=\frac{\left(J_{H A, j}+J_{A, j}\right) \rho_{p, j}-\left(J_{H A, j+1}+J_{A, j+1}\right) \rho_{n, j}}{U}
$$

where $\rho_{p, j}$ and $\rho_{n, j}$ are the surface-to-volume ratios of compartment $j . \rho_{p, j}$ is the surface of the previous compartment $(j-1)$ divided by the volume of compartment $j$ and $\rho_{n, j}$ is the surface of the next compartment $(j+1)$ divided by the volume of compartment $j$.

Although the computer model is developed for three simultaneous mobile acid-base systems $\mathrm{HA} / \mathrm{A}, \mathrm{HB} / \mathrm{B}$, and $\mathrm{CO}_{2} / \mathrm{H}_{2} \mathrm{CO}_{3} / \mathrm{HCO}_{3}{ }^{-} / \mathrm{CO}_{3}{ }^{2-}$, the terms in $\mathrm{HB}$ and $\mathrm{B}$ will be omitted from the equations for the sake of brevity. The treatment is completely analogous to that for HA/A.

For the system $\mathrm{CO}_{2} / \mathrm{H}_{2} \mathrm{CO}_{3} / \mathrm{HCO}_{3}{ }^{-} / \mathrm{CO}_{3}{ }^{2-}$ the hydration reaction of $\mathrm{CO}_{2}$ has to be taken into account. For the intracellular compartment

$$
\begin{gathered}
\frac{\mathrm{d}\left[T_{\mathrm{H} 2 \mathrm{CO} 3}\right]_{i}}{\mathrm{~d} t}=\frac{\left(J_{\mathrm{H} 2 \mathrm{CO}, i}+J_{\mathrm{HCO}, i}+J_{\mathrm{CO}, i}\right) \rho_{p, i}}{U}+M_{\mathrm{H} 2 \mathrm{CO} 3}-D_{\text {ehydr }, i} \\
\frac{\mathrm{d}\left[\mathrm{CO}_{2}\right]_{i}}{\mathrm{~d} t}=\frac{J_{\mathrm{CO}, i} \rho_{p, i}}{U}+M_{\mathrm{CO} 2}+D_{\text {ehydr }, i}
\end{gathered}
$$

where $\left[T_{\mathrm{H}_{2} \mathrm{CO} 3}\right]_{i}=\left(\left[\mathrm{H}_{2} \mathrm{CO}_{3}\right]_{i}+\left[\mathrm{HCO}_{3}{ }^{-}\right]_{i}+\left[\mathrm{CO}_{3}{ }^{2-}\right]_{i}\right) \cdot M_{\mathrm{H} 2 \mathrm{CO} 3}$ and $M_{\mathrm{CO} 2}$ are the intracellular rates of metabolic production (in mole $\mathrm{dm}^{-3} \mathrm{~s}^{-1}$ ) of $\mathrm{H}_{2} \mathrm{CO}_{3}$ and $\mathrm{CO}_{2}$, respectively. The model incorporates both $\mathrm{M}_{22 \mathrm{CO} 3}$ and $\mathrm{M}_{\mathrm{CO} 2}$ to leave open the possibility that either $\mathrm{H}_{2} \mathrm{CO}_{3}$ or $\mathrm{CO}_{2}$ would be produced by metabolism. In the shown calculations, it is assumed that only $\mathrm{CO}_{2}$ is produced by metabolism and that $M_{H 2 C O 3}=0$. The term $D_{\text {ehydr,i }}$ is the intracellular rate of $\mathrm{CO}_{2}$ production (in mole $\mathrm{dm}^{-3} \mathrm{~s}^{-1}$ ) by both the uncatalyzed and the catalyzed dehydration reaction. The uncatalyzed reaction can occur via two pathways:

$$
\begin{gathered}
\mathrm{CO}_{2}+\mathrm{H}_{2} \mathrm{O} \underset{k_{1}}{\stackrel{k_{-1}}{\leftrightarrows}} \mathrm{H}_{2} \mathrm{CO}_{3} \quad \text { or } \\
\mathrm{CO}_{2}+\mathrm{OH}^{-} \underset{k_{4}}{\leftrightarrows} \mathrm{HCO}_{3}^{-}
\end{gathered}
$$

where $k_{-1}, k_{1}, k_{-4}$ and $k_{4}$ are the corresponding velocity constants. 
The first reaction contributes most at physiological $\mathrm{pH}$ [16]. To investigate the influence of catalysis of the dehydration reaction a simplified equation is used for each compartment $j$ :

$$
\begin{aligned}
D_{e h y d r, j}= & {\left[C_{a t a, j}\left(k_{-1}\left[\mathrm{H}_{2} \mathrm{CO}_{3}\right]_{j}-k_{1}\left[\mathrm{H}_{2} \mathrm{O}\right]\left[\mathrm{CO}_{2}\right]_{j}\right)\right.} \\
& \left.+C_{a t b, j}\left(k_{-4}\left[\mathrm{HCO}_{3}^{-}\right]_{j}-k_{4}\left[\mathrm{OH}^{-}\right]_{j}\left[\mathrm{CO}_{2}\right]_{j}\right)\right]
\end{aligned}
$$

where $C_{a t a, j}$ represents the degree of catalysis (or catalysis factor) of the first reaction in compartment $j$. When this reaction is uncatalyzed then $C_{a t a, j}=1$, otherwise $C_{a t a, j}$ takes larger values. $C_{a t b, j}$ represents the degree of catalysis of the second reaction in compartment $j$. In the calculations $C_{a t b, j}$ is set to 1 but the program allows to test the situation in which $C_{a t a, j}=1$ and $C_{a t b, j}>1$. The value of $C_{a t a, j}$ ( or $C_{a t b, j}$ ) can be made different in different compartments. In (38) the activity of water is considered as equal to 1.

In analogy to (36) and (37), one can write for an unstirred layer compartment $j$ :

$$
\begin{aligned}
& \frac{\mathrm{d}\left[T_{\mathrm{H} 2 \mathrm{CO}}\right]_{j}}{\mathrm{~d} t}
\end{aligned}
$$

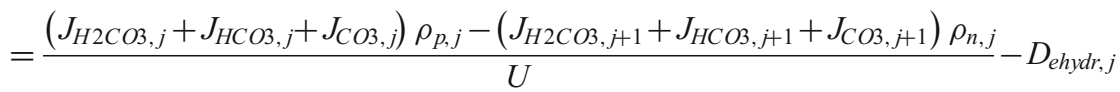

$$
\frac{\mathrm{d}\left[\mathrm{CO}_{2}\right]_{j}}{\mathrm{~d} t}=\frac{J_{C O 2, j} \rho_{p, j}-J_{C O 2, j+1} \rho_{n, j}}{U}+D_{e h y d r, j}
$$

where $\left[T_{\mathrm{H}_{2} \mathrm{CO} 3}\right]_{j}=\left(\left[\mathrm{H}_{2} \mathrm{CO}_{3}\right]_{j}+\left[\mathrm{HCO}_{3}{ }^{-}\right]_{j}+\left[\mathrm{CO}_{3}{ }^{2-}\right]_{j}\right)$. In contrast to the hydrationdehydration reaction of $\mathrm{CO}_{2}$, the acid-base reactions are very fast and are assumed here to be in equilibrium.

\subsubsection{Rate of change in $\mathrm{pH}$}

$$
\begin{gathered}
f_{H A, j}=[\mathrm{HA}]_{j} /\left[T_{H A}\right]_{j} ; f_{A, j}=[\mathrm{A}]_{j} /\left[T_{H A}\right]_{j} . \\
f_{H 2 C O 3, j}=\left[\mathrm{H}_{2} \mathrm{CO}_{3}\right]_{j} /\left[T_{\mathrm{H} 2 \mathrm{CO}}\right]_{j} ; f_{\mathrm{HCO}, j}=\left[\mathrm{HCO}_{3}{ }^{-}\right]_{j} /\left[T_{\left.\mathrm{H}_{2 C O}\right]_{j}} ;\right. \\
f_{\mathrm{CO}, j}=\left[\mathrm{CO}_{3}{ }^{2-}\right]_{j} /\left[T_{\mathrm{H} 2 \mathrm{CO} 3}\right]_{j} .
\end{gathered}
$$

To calculate these fractions, one has to use $K_{1}\left(K_{1}=\left[\mathrm{H}^{+}\right]\left[\mathrm{HCO}_{3}{ }^{-}\right] /\left[\mathrm{H}_{2} \mathrm{CO}_{3}\right]=10^{-3.46}\right)$ instead of $K_{1}^{\prime}$ :

$$
\begin{gathered}
f_{H 2 C O 3, j}=\frac{[\mathrm{H}]_{j}^{2}}{[\mathrm{H}]_{j}^{2}+[\mathrm{H}]_{j} K_{1}+K_{1} K_{2}} \\
f_{H C O 3, j}=\frac{[\mathrm{H}]_{j} K_{1}}{[\mathrm{H}]_{j}^{2}+[\mathrm{H}]_{j} K_{1}+K_{1} K_{2}} \\
f_{C O 3, j}=\frac{K_{1} K_{2}}{[\mathrm{H}]_{j}^{2}+[\mathrm{H}]_{j} K_{1}+K_{1} K_{2}}
\end{gathered}
$$


The protons, weak acids, and bases that enter or leave a compartment can induce a $\mathrm{pH}$ change. To be able to calculate $\mathrm{dpH}_{j}$ after simultaneous addition and removal of $\mathrm{H}^{+}, \mathrm{OH}^{-}$, $\mathrm{HA}, \mathrm{A}, \mathrm{CO}_{2}, \mathrm{H}_{2} \mathrm{CO}_{3}, \mathrm{HCO}_{3}{ }^{-}$and $\mathrm{CO}_{3}{ }^{2-}$, one can split this complex event conceptually into two consecutive steps:

1) In a first step, one allows all solutes simultaneously to enter or leave the compartment during an infinitesimally small time period $\mathrm{d} t$ via

a) the cell membrane or the diffusion barrier between the unstirred layer compartments

b) a metabolic production of $\mathrm{HA}, \mathrm{CO}_{2}$ or $\mathrm{H}_{2} \mathrm{CO}_{3}$

c) the hydration-dehydration reaction of $\mathrm{CO}_{2}$.

During this first step one also allows $\mathrm{HA}, \mathrm{H}_{2} \mathrm{CO}_{3}$ and $\mathrm{HCO}_{3}{ }^{-}$to dissociate and $\mathrm{A}$, $\mathrm{HCO}_{3}{ }^{-}$and $\mathrm{CO}_{3}{ }^{2-}$ to associate with protons (according to the equilibrium $f_{H A, j}, f_{A, j}$, $\left.f_{\mathrm{H} 2 \mathrm{CO}}, j, f_{\mathrm{HCO}}, j, f_{\mathrm{CO}}, j\right)$ but one considers $\mathrm{pH}_{j}$ to remain constant by conceptually setting aside the net amount of entered or dissociated protons.

2) In a timeless second step, one conceptually closes the system, preventing further addition or removal of solutes via the above pathways. Then one adds the amount of protons, which was set aside during the first step, to the system. The resultant $\mathrm{pH}$ change in compartment $j$ equals

$$
\mathrm{dpH}_{j}=-\mathrm{d} Q_{T, j} / \beta_{T, j}
$$

where $\mathrm{d} Q_{T, j}$ is the total proton load or the net total concentration of protons that were set aside during the first step in compartment $j$ at constant $\mathrm{pH} j . \beta_{T, j}$ is the total buffer capacity in compartment $j$, averaged over the $\mathrm{pH}$ interval $\mathrm{dpH}_{j}$. When $\mathrm{d} t$ and $\mathrm{dpH} j$ are infinitesimally small, then

$$
\beta_{T, j}=\beta^{\prime}{ }_{j}+\beta_{H A, j}+\beta_{H 2 C O 3, j}
$$

The buffer capacities for a closed system of $\mathrm{HA} / \mathrm{A}$ and $\mathrm{H}_{2} \mathrm{CO}_{3} / \mathrm{HCO}_{3}{ }^{-} / \mathrm{CO}_{3}{ }^{2-}$ in compartment $j$ are:

$$
\begin{gathered}
\beta_{H A, j}=\ln (10) \frac{[\mathrm{H}]_{j} K_{H A}}{\left([\mathrm{H}]_{j}+K_{H A}\right)^{2}}\left[T_{H A}\right]_{j}=\ln (10) f_{H A, j} f_{A, j}\left[T_{H A}\right]_{j} \\
\beta_{H 2 C O 3, j}=\ln (10)[\mathrm{H}]_{j} K_{1} \frac{[\mathrm{H}]_{j}^{2}+4[\mathrm{H}]_{j} K_{2}+K_{1} K_{2}}{\left([\mathrm{H}]_{j}^{2}+[\mathrm{H}]_{j} K_{1}+K_{1} K_{2}\right)^{2}}\left[T_{H 2 C O 3}\right]_{j}
\end{gathered}
$$

where $\beta_{j}^{\prime}$ is the intrinsic buffer capacity made up by the other buffers in compartment $j$. This intrinsic buffer capacity can be a function of $\mathrm{pH}_{j}[7,27]$.

When the $\mathrm{pH}$ remains constant (first step) and HA is added to the system (e.g., via $J_{H A}$ ) the fraction that dissociates to A gives off protons and this fraction corresponds to $f_{A}$. If $\mathrm{A}$ is added, the fraction that will associate to HA $\left(f_{H A}\right)$ will take up protons. In the case of an influx of a diprotic acid, such as $\mathrm{H}_{2} \mathrm{CO}_{3}$, the fraction that dissociates to $\mathrm{HCO}_{3}{ }^{-}\left(f_{\mathrm{HCO}}\right)$ will give off protons, but the fraction that dissociates further to $\mathrm{CO}_{3}{ }^{2-}\left(f_{\mathrm{CO} 3}\right)$ gives off twice as much protons per $\mathrm{H}_{2} \mathrm{CO}_{3}$, etc. 
Consequently, the total rate of intracellular proton load during $\mathrm{d} t$ at constant $\mathrm{pH}_{i}$ equals: $\frac{\mathrm{d} Q_{T, i}}{\mathrm{~d} t}$

$=\left[\begin{array}{l}\frac{\left(J_{H, i}-J_{O H, i}+f_{A, i} J_{H A, i}-f_{H A, i} J_{A, i}+\left(f_{H C O 3, i}+2 f_{C O 3, i}\right) J_{H 2 C O 3, i}+\left(f_{C O 3, i}-f_{H 2 C O 3, i}\right) J_{H C O 3, i}-\left(2 f_{H 2 C O 3, i}+f_{H C O}, i\right) J_{C O 3, i}\right) \rho_{p, i}}{U} \\ +f_{A, i} M_{H A}+\left(f_{H C O 3, i}+2 f_{C O 3, i}\right)\left(M_{H 2 C O 3}-D_{\text {ehydr }, i}\right)\end{array}\right]$

In the above equation, each flux can be the sum of a passive transmembrane flux and the flux via a pump or transporter. For example, $J_{H, i}$ can be the sum of the passive transmembrane flux of $\mathrm{H}^{+}$and other proton fluxes, such as the proton flux generated by an acid extrusion pump, a $\mathrm{Na}^{+} / \mathrm{H}^{+}$or $\mathrm{K}^{+} / \mathrm{H}^{+}$antiporter or a $\mathrm{H}^{+} / \mathrm{Cl}^{-}$symporter. $J_{\mathrm{HCO}, i}$ can be the sum of the passive flux of $\mathrm{HCO}_{3}{ }^{-}$and other $\mathrm{HCO}_{3}{ }^{-}$fluxes, such as those via the $\mathrm{Cl}^{-} / \mathrm{HCO}_{3}{ }^{-}$exchanger or a $\mathrm{Na}^{+} / \mathrm{HCO}_{3}{ }^{-}$cotransporter, etc.

The contribution of addition of HA to the rate of intracellular total proton load at constant $\mathrm{pH}_{\mathrm{i}}$ equals

$$
f_{A, i}\left(\frac{J_{H A, i} \rho_{p, i}}{U}+M_{H A}\right)
$$

where $\frac{J_{H A, i} \rho_{p, i}}{U}$ is the total concentration of HA added per time via the cell membrane before dissociation.

Note that in (48) $\mathrm{CO}_{2}$ does not cause a direct proton load. It participates only indirectly to the proton load via the amount of $\mathrm{H}_{2} \mathrm{CO}_{3}$, which is generated by hydration of $\mathrm{CO}_{2}$.

The total rate of proton load in the unstirred layer compartment $j$ is equal to

$$
\frac{\mathrm{d} Q_{T, j}}{\mathrm{~d} t}=\frac{\left(F_{3}+F_{4}\right) \rho_{p, j}-\left(F_{5}+F_{6}\right) \rho_{n, j}}{U}-\left(f_{H C O 3, j}+2 f_{C O 3, j}\right) D_{\text {ehydr }, j}
$$

where

$$
\begin{gathered}
F_{3}=J_{H, j}-J_{O H, j}+f_{A, j} J_{H A, j}-f_{H A, j} J_{A, j} \\
F_{4}=\left(f_{H C O 3, j}+2 f_{C O 3, j}\right) J_{H 2 C O 3, j}+\left(f_{C O 3, j}-f_{H 2 C O 3, j}\right) J_{H C O 3, j}-\left(2 f_{H 2 C O 3, j}+f_{H C O 3, j}\right) J_{C O 3, j}
\end{gathered}
$$

$$
F_{5}=J_{H, j+1}-J_{O H, j+1}+f_{A, j} J_{H A, j+1}-f_{H A, j} J_{A, j+1}
$$

$$
\begin{aligned}
F_{6}= & \left(f_{\mathrm{HCO}, j}+2 f_{\mathrm{CO} 3, j}\right) J_{\mathrm{H} 2 \mathrm{CO}, j+1}+\left(f_{\mathrm{CO} 3, j}-f_{\mathrm{H} 2 \mathrm{CO}, j}\right) J_{\mathrm{HCO}, j+1} \\
& -\left(2 f_{\mathrm{H} 2 \mathrm{CO}, j}+f_{\mathrm{HCO} 3, j}\right) J_{\mathrm{CO} 3, j+1}
\end{aligned}
$$

The rates of change of $\mathrm{pH}$ in the intracellular and unstirred layer compartments are thus equal to:

$$
\begin{aligned}
\frac{\mathrm{dpH}_{i}}{\mathrm{~d} t} & =-\frac{\mathrm{d} Q_{T, i}}{\mathrm{~d} t} \frac{1}{\beta_{T, i}} \\
\frac{\mathrm{dpH}}{\mathrm{d} t} & =-\frac{\mathrm{d} Q_{T, j}}{\mathrm{~d} t} \frac{1}{\beta_{T, j}}
\end{aligned}
$$




\subsubsection{Compartments with 'infinite catalysis'}

To simulate a situation in which the dehydration reaction of $\mathrm{H}_{2} \mathrm{CO}_{3}$ is strongly catalyzed one can use a very large value for $C_{a t a, j}\left(\right.$ or $C_{a t b, j}$ ) in (38). However, this necessitates the use of a very small time increment during the numerical integration of these equations to prevent inaccuracy and oscillation of the calculated values. To circumvent this practical problem, alternative equations can be used for the compartments in which the dehydration reaction is strongly catalyzed. For these compartments one can assume that the dehydration reaction is so rapid that it reaches chemical equilibrium at all times. Then the ratio $\left[\mathrm{H}_{2} \mathrm{CO}_{3}\right]_{j} /\left[\mathrm{CO}_{2}\right]_{j}$ is assumed to be constant and equal to $k_{1} / k_{-1}$ and $\mathrm{CO}_{2}$ and $\mathrm{H}_{2} \mathrm{CO}_{3}$ can be lumped to a single particle $\mathrm{CO}_{2}^{\prime}$ with $K_{\mathrm{CO}_{2}}{ }^{\prime}$ or $K_{1}{ }^{\prime}$ as first dissociation constant $\left(K_{1}{ }^{\prime}=10^{-6.12}\right)$.

$\left[T_{\mathrm{CO}^{\prime}}\right]_{j}=\left(\left[\mathrm{CO}_{2}^{\prime}\right]_{j}+\left[\mathrm{HCO}_{3}{ }^{-}\right]_{j}+\left[\mathrm{CO}_{3}{ }^{2-}\right]_{j}\right)=\left(\left[\mathrm{H}_{2} \mathrm{C}\right]_{j}+[\mathrm{HC}]_{j}+[\mathrm{C}]_{j}\right)=\left[T_{\mathrm{H}_{2} \mathrm{C}}\right]_{j}$ $f_{H 2 C, j}=\left[H_{2} C\right]_{j} /\left[T_{H 2 C}\right]_{j} ; f_{H C, j}=[H C]_{j} /\left[T_{H 2 C}\right]_{j} ; f_{C, j}=[C]_{j} /\left[T_{H 2 C}\right]_{j}$, see (21)-(23).

If the dehydration reaction is in equilibrium in the intracellular compartment, then (36) and (37) are replaced by

$$
\frac{\mathrm{d}\left[T_{C O 2^{\prime}}\right]_{i}}{\mathrm{~d} t}=\frac{\left(J_{\mathrm{CO} 2, i}+J_{\mathrm{H} 2 \mathrm{CO}, i}+J_{\mathrm{HCO}, i}+J_{\mathrm{CO}, i}\right) \rho_{p, i}}{U}+M_{\mathrm{CO} 2}+M_{\mathrm{H} 2 \mathrm{CO} 3}
$$

and (48) is replaced by

$$
\begin{aligned}
& \frac{\mathrm{d} Q_{T, i}}{\mathrm{~d} t} \\
& =\left[\begin{array}{l}
\frac{\left(J_{H, i}-J_{O H, i}+f_{A, i} J_{H A, i}-f_{H A, i} J_{A, i}+\left(f_{H C, i}+2 f_{C, i}\right)\left(J_{C O 2, i}+J_{H 2 C O 3, i}\right)+\left(f_{C, i}-f_{H 2 C, i}\right) J_{H C O 3, i}-\left(2 f_{H 2 C, i}+f_{H C, i}\right) J_{C O 3, i}\right) \rho_{p, i}}{U} \\
+f_{A, i} M_{H A}+\left(f_{H C, i}+2 f_{C, i}\right)\left(M_{C O 2}+M_{H 2 C O 3}\right)
\end{array}\right]
\end{aligned}
$$

If the dehydration reaction is in equilibrium in the unstirred layer, then (39) and (40) are replaced by

$$
\begin{aligned}
& \frac{\mathrm{d}\left[T_{\left.\mathrm{CO}^{\prime}\right]_{j}}\right.}{\mathrm{d} t} \\
& =\frac{\left(J_{\mathrm{CO} 2, j}+J_{\mathrm{H} 2 \mathrm{CO}, j}+J_{\mathrm{HCO}, j}+J_{\mathrm{CO}, j}\right) \rho_{p, j}-\left(J_{\mathrm{CO} 2, j+1}+J_{H 2 C O 3, j+1}+J_{H C O 3, j+1}+J_{C O 3, j+1}\right) \rho_{n, j}}{U}
\end{aligned}
$$

and (49a) is replaced by

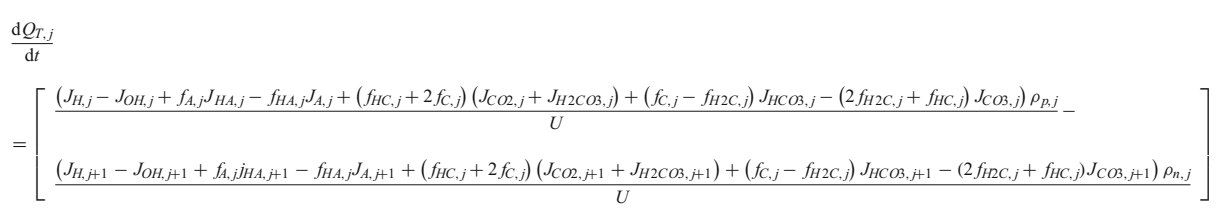

Equation (45) is then replaced by

$$
\beta_{T, j}=\beta_{j}^{\prime}+\beta_{H A, j}+\beta_{H 2 C, j}
$$




$$
\beta_{H 2 C, j}=\ln (10)[\mathrm{H}]_{j} K_{1}^{\prime} \frac{[\mathrm{H}]_{j}^{2}+4[\mathrm{H}]_{j} K_{2}+K_{1}^{\prime} K_{2}}{\left([\mathrm{H}]_{j}^{2}+[\mathrm{H}]_{j} K_{1}^{\prime}+K_{1}^{\prime} K_{2}\right)^{2}}\left[T_{C O 2^{\prime}}\right]_{j}
$$

If $\left[\mathrm{CO}_{2}\right]_{j}$ and $\left[\mathrm{H}_{2} \mathrm{CO}_{3}\right]_{j}$ are assumed to be in equilibrium in a compartment $j$ and lumped to $\left[\mathrm{CO}_{2}{ }^{\prime}\right]$, one has thus to use $K_{1}{ }^{\prime}\left(=10^{-6.12}\right)$ to calculate $f_{H 2 C, j}, f_{H C, j}, f_{C, j}$ and $\beta_{H 2 C, j}$ instead of $K_{1}\left(=10^{-3.46}\right)$.

It is also possible to calculate the intracellular rate of $\mathrm{CO}_{2}$ formation via the dehydration reaction $\left(D_{\text {ehydr, }}\right)$ in the case of infinitely rapid equilibration of the dehydration reaction. According to (37):

$$
D_{\text {ehydr }, i}=\frac{\mathrm{d}\left[\mathrm{CO}_{2}\right]_{i}}{\mathrm{~d} t}-\frac{J_{C O 2, i} \rho_{p, i}}{U}-M_{C O 2}
$$

In the case of infinitely rapid equilibration of the dehydration reaction

$$
\left[\mathrm{CO}_{2}\right]_{i}=\left[\mathrm{CO}_{2}^{\prime}\right]_{i} \frac{k_{-1}}{\left(k_{-1}+k_{1}\right)}
$$

Hence, the rate of change of the intracellular $\mathrm{CO}_{2}$ concentration equals

$$
\begin{aligned}
\frac{\mathrm{d}\left[\mathrm{CO}_{2}\right]_{i}}{\mathrm{~d} t} & =\frac{k_{-1}}{\left(k_{-1}+k_{1}\right)} \frac{\mathrm{d}\left[\mathrm{CO}_{2}{ }^{\prime}\right]_{i}}{\mathrm{~d} t} \\
\frac{\mathrm{d}\left[\mathrm{CO}_{2}{ }^{\prime}\right]_{i}}{\mathrm{~d} t}=\frac{\mathrm{d}\left(f_{\mathrm{H} 2 C}\left[T_{\mathrm{CO}^{\prime}}\right]_{i}\right)}{\mathrm{d} t} & =f_{\mathrm{H} 2 \mathrm{C}, i} \frac{\mathrm{d}\left[T_{\mathrm{CO}^{\prime}}\right]_{i}}{\mathrm{~d} t}+\left[T_{C O 2^{\prime}}\right]_{i} \frac{\mathrm{d} f_{\mathrm{H} 2 C, i}}{\mathrm{dpH} \mathrm{H}_{i}} \frac{\mathrm{dp}_{i}}{\mathrm{~d} t}
\end{aligned}
$$

and thus (see (24)) :

$$
\frac{\mathrm{d}\left[\mathrm{CO}_{2}{ }^{\prime}\right]_{i}}{\mathrm{~d} t}=f_{\mathrm{H} 2 C, i} \frac{\mathrm{d}\left[T_{C O 2^{\prime}}\right]_{i}}{\mathrm{~d} t}-\frac{\left[T_{C O 2^{\prime}}\right]_{i} \ln (10)[\mathrm{H}]_{i}{ }^{2} K_{1}^{\prime}\left([\mathrm{H}]_{i}+2 K_{2}\right)}{\left([\mathrm{H}]_{i}{ }^{2}+[\mathrm{H}]_{i} K_{1}^{\prime}+K_{1}^{\prime} K_{2}\right)^{2}} \frac{\mathrm{dpH}}{\mathrm{d} t}
$$

Combination of (58), (59) and (61) yields that, in the case of infinitely rapid equilibration of the dehydration reaction, the intracellular rate of $\mathrm{CO}_{2}$ production via the dehydration reaction equals

$$
\begin{aligned}
D_{e h y d r, i}= & \frac{k_{-1}}{\left(k_{-1}+k_{1}\right)}\left(f_{H 2 C, i} \frac{\mathrm{d}\left[T_{C O 2^{\prime}}\right]_{i}}{\mathrm{~d} t}-\frac{\left[T_{C O 2^{\prime}}\right]_{i} \ln (10)[\mathrm{H}]_{i}{ }^{2} K_{1}^{\prime}\left([\mathrm{H}]_{i}+2 K_{2}\right)}{\left([\mathrm{H}]_{i}{ }^{2}+[\mathrm{H}]_{i} K_{1}^{\prime}+K_{1}^{\prime} K_{2}\right)^{2}} \frac{\mathrm{dpH}}{\mathrm{d} t}\right) \\
& -\frac{J_{C O 2, i} \rho_{p, i}}{U}-M_{C O 2}
\end{aligned}
$$

Similarly for the unstirred layer compartment $j$ :

$$
\begin{aligned}
D_{e h y d r, j}= & \frac{k_{-1}}{\left(k_{-1}+k_{1}\right)}\left(f_{H 2 C, j} \frac{\mathrm{d}\left[T_{C O 2^{\prime}}\right]_{j}}{\mathrm{~d} t}-\frac{\left[T_{C O 2^{\prime}}\right]_{j} \ln (10)[\mathrm{H}]_{j}^{2} K_{1}^{\prime}\left([\mathrm{H}]_{j}+2 K_{2}\right)}{\left([\mathrm{H}]_{j}^{2}+[\mathrm{H}]_{j} K_{1}^{\prime}+K_{1}^{\prime} K_{2}\right)^{2}} \frac{\mathrm{dpH}}{\mathrm{d} t}\right) \\
& -\frac{\left(J_{C O 2, j} \rho_{p, j}-J_{C O 2, j+1} \rho_{n, j}\right)}{U}
\end{aligned}
$$


Table 1 Influence of CA on the steady-state unstirred layer $\mathrm{pH}$ during simulated efflux of different types of particles, in a bicarbonate buffered extracellular solution

\begin{tabular}{|c|c|c|c|c|c|}
\hline \multirow[t]{2}{*}{ Particle } & \multicolumn{2}{|l|}{$\mathrm{pH}_{\mathrm{N}}$} & \multicolumn{2}{|l|}{$\mathrm{pH}_{\mathrm{N}}-7.4$} & \multirow[t]{2}{*}{ Disequil. $\mathrm{pH}_{\mathrm{N}}$} \\
\hline & No catalysis & Catalysis & No catalysis & Catalysis & \\
\hline$\overline{\mathrm{H}^{+}}$ & 7.27429 & 7.35772 & -0.12571 & -0.04228 & -0.08343 \\
\hline HA & 7.27504 & 7.35785 & -0.12496 & -0.04215 & -0.08281 \\
\hline $\mathrm{A}$ & 7.40041 & 7.40013 & 0.00041 & 0.00013 & 0.00028 \\
\hline HB & 7.35147 & 7.38133 & -0.04853 & -0.01867 & -0.02986 \\
\hline B & 7.46556 & 7.42444 & 0.06556 & 0.02444 & 0.04112 \\
\hline $\mathrm{H}_{2} \mathrm{CO}_{3}$ & 7.27830 & 7.36167 & -0.12170 & -0.03833 & -0.08337 \\
\hline $\mathrm{CO}_{2}$ & 7.36237 & 7.36167 & -0.03763 & -0.03833 & 0.00070 \\
\hline $\mathrm{CO}_{2}{ }^{\prime}$ & 7.36217 & 7.36167 & -0.03783 & -0.03833 & 0.00050 \\
\hline $\mathrm{HCO}_{3}{ }^{-}$ & 7.40378 & 7.40391 & 0.00378 & 0.00391 & -0.00013 \\
\hline $\mathrm{CO}_{3}{ }^{2-}$ & 7.55769 & 7.44974 & 0.15769 & 0.04974 & 0.10795 \\
\hline
\end{tabular}

The extracellular bulk solution was buffered with $25 \mathrm{mM}$ bicarbonate at $\mathrm{pH}$ 7.4. The unstirred layer was subdivided into $8(=N)$ compartments. The transmembrane flux of each particle (first column) was $-10^{-6}$ mole $\mathrm{m}^{-2} \mathrm{~s}^{-1}$, see Fig. 1. Second column: steady-state $\mathrm{pH}$ in the unstirred layer compartment closest to the cell membrane $\left(\mathrm{pH}_{\mathrm{N}}\right)$ without catalysis of the Deh reaction in the unstirred layer. Third column: steadystate $\mathrm{pH}_{\mathrm{N}}$ during infinite catalysis of the Deh reaction in compartment $N$. Fourth and fifth column: difference with the bulk $\mathrm{pH}$ (7.4). Sixth column: disequilibrium $\mathrm{pH}_{\mathrm{N}}\left(=\mathrm{pH}_{\mathrm{N}}\right.$ in the absence $-\mathrm{pH}_{\mathrm{N}}$ in presence of infinite catalysis in compartment $N$ )

Thus (62) and (63) make it possible to calculate and plot $D_{e h y d r}$ in the case of infinitely rapid equilibration of the dehydration reaction of $\mathrm{H}_{2} \mathrm{CO}_{3}$.

\subsubsection{Other concentration changes}

If one wants to take into account transmembrane flux components via transporters, equations expressing the rate of change in concentration of the ions involved in the transport (e.g., $\mathrm{Na}^{+}, \mathrm{K}^{+}, \mathrm{Cl}^{-}$etc.) have also to be included in the model and in the numerical integration.

Table 2 Influence of CA on the steady-state unstirred layer pH during simulated efflux of different types of particles, in a solution buffered with bicarbonate and HEPES

\begin{tabular}{|c|c|c|c|c|c|}
\hline \multirow[t]{2}{*}{ Particle } & \multicolumn{2}{|l|}{$\mathrm{pH}_{\mathrm{N}}$} & \multicolumn{2}{|l|}{$\mathrm{pH}_{\mathrm{N}}-7.4$} & \multirow[t]{2}{*}{ Disequil. $\mathrm{pH}_{\mathrm{N}}$} \\
\hline & No catalysis & Catalysis & No catalysis & Catalysis & \\
\hline $\mathrm{H}^{+}$ & 7.33159 & 7.35157 & -0.06841 & -0.04843 & -0.01998 \\
\hline HA & 7.33183 & 7.35173 & -0.06817 & -0.04827 & -0.01990 \\
\hline A & 7.40020 & 7.40015 & 0.00020 & 0.00015 & 0.00006 \\
\hline $\mathrm{HB}$ & 7.37078 & 7.37888 & -0.02922 & -0.02112 & -0.00809 \\
\hline B & 7.43723 & 7.42717 & 0.03723 & 0.02717 & 0.01006 \\
\hline $\mathrm{H}_{2} \mathrm{CO}_{3}$ & 7.33487 & 7.35622 & -0.06513 & -0.04378 & -0.02135 \\
\hline $\mathrm{CO}_{2}$ & 7.36954 & 7.35622 & -0.03046 & -0.04378 & 0.01332 \\
\hline $\mathrm{CO}_{2}$ & 7.36947 & 7.35622 & -0.03053 & -0.04378 & 0.01325 \\
\hline $\mathrm{HCO}_{3}^{-}$ & 7.40299 & 7.40439 & 0.00299 & 0.00439 & -0.00140 \\
\hline $\mathrm{CO}_{3}^{2-}$ & 7.47298 & 7.45484 & 0.07298 & 0.05484 & 0.01814 \\
\hline
\end{tabular}

The extracellular bulk solution was buffered with $12.5 \mathrm{mM}$ bicarbonate and $5 \mathrm{mM}$ HEPES at $\mathrm{pH}$ 7.4. See legend to analogous Table 1 for further explanation 


\subsubsection{Calculation process}

In the simulations shown in this paper, the permeability of the diffusion barrier between unstirred layer compartments $j-1$ and $j$ for solute $X$ was calculated with

$$
P_{X, j}=\frac{N D_{X}}{d}
$$

where $N$ is the number of unstirred layer compartments and $d$ the thickness of the unstirred layer.

The calculation of the transient $\mathrm{pH}$ and concentration changes (or the steady state) can be done as follows: first the fractions $f_{\mathrm{HA}}, f_{A}, f_{\mathrm{H} 2 \mathrm{CO}}, f_{\mathrm{HCO} 3}, f_{\mathrm{CO} 3}$ (or $f_{\mathrm{H} 2 \mathrm{C}}, f_{\mathrm{HC}}, f_{\mathrm{C}}$ in case of equilibrium of the dehydration reaction) are calculated from the corresponding $\mathrm{pK}$ and the $\mathrm{pH}$ for all compartments. Then the concentration of all solutes is calculated

Table 3 Combinations of small transmembrane fluxes

\begin{tabular}{|c|c|c|c|c|}
\hline \multirow[t]{2}{*}{ Particles } & \multicolumn{2}{|l|}{$\mathrm{pH}_{\mathrm{N}}$} & \multicolumn{2}{|l|}{ Difference } \\
\hline & No catalysis & Catalysis & No catalysis & Catalysis \\
\hline \multicolumn{5}{|c|}{ A) $25 \mathrm{mM}$ bicarbonate buffer at $\mathrm{pH}_{0} 7.4$} \\
\hline $\mathbf{H}^{+}$ & 7.274293 & 7.357718 & & \\
\hline $\mathrm{H}_{2} \mathrm{CO}_{3}-\mathrm{HCO}_{3}^{-}$ & 7.274293 & 7.357718 & 0.000232 & 0.000046 \\
\hline $\mathrm{CO}_{2}-\mathrm{HCO}_{3}^{-}$ & 7.358520 & 7.357718 & 0.000072 & 0.000046 \\
\hline $\mathbf{H A}-\mathbf{C O}_{2}$ & 7.307383 & 7.396184 & 0.005482 & -0.000008 \\
\hline $\mathrm{HB}-\mathrm{CO}_{2}$ & 7.385753 & 7.420620 & 0.003541 & -0.000968 \\
\hline
\end{tabular}

B) $12.5 \mathrm{mM}$ bicarbonate $+5 \mathrm{mM}$ HEPES buffer at $\mathrm{pH}_{0} 7.4$

\begin{tabular}{llllr}
\hline $\mathbf{H}^{+}$ & 7.331590 & 7.351569 & & \\
$\mathbf{H}_{2} \mathbf{C O}_{3}-\mathbf{H C O}_{3}^{-}$ & 7.331590 & 7.351569 & 0.000290 & 0.000260 \\
$\mathbf{C O}_{2}-\mathbf{H C O}_{3}^{-}$ & 7.366398 & 7.351569 & 0.000152 & 0.000260 \\
$\mathbf{H A}-\mathbf{C O}_{2}{ }^{2}$ & 7.361945 & 7.395691 & 0.000414 & -0.000187 \\
$\mathbf{H B}-\mathbf{C O}_{2}$, & 7.400351 & 7.422984 & 0.000962 & -0.000330 \\
\hline
\end{tabular}

These tables show the effect of combinations of two different transmembrane fluxes on the steady-state $\mathrm{pH}_{\mathrm{N}}(N=8)$ and compare this to the result of addition of the effect of the individual fluxes (from Tables 1 and 2). In the rows labeled with $\mathrm{H}^{+}$in the left column there was a transmembrane proton efflux of $-10^{-6}$ mole $\mathrm{m}^{-2} \mathrm{~s}^{-1}$, for comparison with the flux combination in the row below. $\mathrm{H}_{2} \mathrm{CO}_{3}-\mathrm{HCO}_{3}-$ in the left column means a combination of a transmembrane efflux of $\mathrm{H}_{2} \mathrm{CO}_{3}\left(-10^{-6} \mathrm{~mole} \mathrm{~m}^{-2} \mathrm{~s}^{-1}\right)$ with an influx of $\mathrm{HCO}_{3}^{-}\left(10^{-6}\right.$ mole $\left.\mathrm{m}^{-2} \mathrm{~s}^{-1}\right)$. The meaning of the next combinations is analogous. $\mathrm{HA}-\mathrm{CO}_{2}$ ' means an efflux of HA $\left(-10^{-6}\right.$ mole $\left.\mathrm{m}^{-2} \mathrm{~s}^{-1}\right)$ combined with an influx of $\mathrm{CO}_{2},\left(10^{-6}\right.$ mole $\left.\mathrm{m}^{-2} \mathrm{~s}^{-1}\right)$, wherein $\mathrm{CO}_{2}$ and $\mathrm{H}_{2} \mathrm{CO}_{3}$ are in equilibrium. Second column: steady-state $\mathrm{pH}_{\mathrm{N}}$ without catalysis of the Deh reaction in the unstirred layer. Third column: $\mathrm{pH}_{\mathrm{N}}$ with infinite catalysis of the Deh reaction in compartment $N$. The correct $\mathrm{pH}_{\mathrm{N}}$ results in the second and third column are obtained directly from simulations with the multicompartment model with these flux combinations. The fourth and fifth column show the error (in $\mathrm{pH}$ units) made if $\mathrm{pH}_{\mathrm{N}}$ with these flux combinations is calculated with the following approximate formula:

$$
\text { pH } H_{\text {Napprox }}=\mathrm{pH}_{0}+\left(\mathrm{pH}_{\mathrm{N} 1}-\mathrm{pH}_{0}\right)+\left(\mathrm{pH}_{\mathrm{N} 2}-\mathrm{pH}_{0}\right) J_{2} / J_{1}
$$

where $\mathrm{pH}_{\mathrm{N} 1}$ and $\mathrm{pH}_{\mathrm{N} 2}$ are the steady-state $\mathrm{pH}_{\mathrm{N}}$ (calculated with the multicompartment model) with the first or second transmembrane flux of the row alone, respectively. $J_{2} / J_{1}$ is the ratio of the second to the first flux of the combination. In the examples of this table, this ratio equals -1 . The values in the fourth column are thus the difference between $\mathrm{pH}_{\text {Napprox }}$ without catalysis and the correct $\mathrm{pH}_{\mathrm{N}}$ without catalysis, given in the second column. If the combined transmembrane fluxes are small, this error (difference) is thus relatively small

A: extracellular bulk solution buffered with $25 \mathrm{mM}$ bicarbonate at $\mathrm{pH}_{0}$ 7.4. B: bulk solution buffered with $12.5 \mathrm{mM}$ bicarbonate and $5 \mathrm{mM}$ HEPES at $\mathrm{pH}_{0} 7.4$ 
using these fractions and the total acid concentrations such as $\left[T_{H A}\right]$. Thereafter, the fluxes through all diffusion barriers of the unstirred layer and through the cell membrane are calculated. If the dehydration reaction of $\mathrm{H}_{2} \mathrm{CO}_{3}$ is not equilibrating infinitely rapid, Dehydr, $j$ is calculated with (38), else with (62) and (63). Thereafter all rates of change in $\mathrm{pH}$, total concentrations and $\mathrm{CO}_{2}$ concentration are calculated for all compartments. In the simulations, these differential equations were integrated numerically with the fourth order Runge-Kutta method with adaptive step size control [28]. The computer program allows to calculate the transients according to the above equations. It also allows to clamp the transmembrane fluxes to chosen values or to clamp the intracellular concentrations.

It is recommended to start the calculation of the $\mathrm{pH}$ and concentration transients from a steady-state situation. The steady-state $\mathrm{pH}$ and total concentration in all compartments can be found by letting the calculations go on for a long time with the same parameters. The computer program provides also a much faster algorithm to calculate the steady state very accurately by means of the Newton-Raphson method for nonlinear systems of equations with multidimensional root finding [28]. The results in Tables 1, 2, and 3 were calculated with this method.

The documented simulation program, written in Pascal, can be obtained at no cost from R. Marrannes.

Graphs of simulations were exported as Igor Text files and plotted with Igor Pro (WaveMetrics, Lake Oswego, USA).

\section{Model calculations and discussion}

For the sake of brevity I shall call the net sum of the reactions $\mathrm{H}_{2} \mathrm{CO}_{3} \leftrightarrows \mathrm{CO}_{2}+\mathrm{H}_{2} \mathrm{O}$ and $\mathrm{HCO}_{3}{ }^{-} \leftrightarrows \mathrm{CO}_{2}+\mathrm{OH}^{-}$the Deh reaction, independent on whether these reactions go in the direction of dehydration or hydration and whether they are catalyzed or not. The analytical expression of (29a) shows how the steady-state $\mathrm{pH}$ gradient in the unstirred layer is related to the transmembrane fluxes, the $\mathrm{pK}$ of the weak acids or bases (via $f_{X}$ ), diffusion coefficients and concentration of mobile buffers, if it is assumed that the Deh reaction is infinitely catalyzed or in equilibrium.

To study the steady-state $\mathrm{pH}$ in the unstirred layer also in situations where the Deh reaction is not in equilibrium, the multicompartment model was used in the following simulations. For optimal comparability with (29a) the simulations were first done in the flux clamp mode (transmembrane fluxes were clamped to chosen values). The surface area $S$ of the unstirred layer was then kept constant and the surface to volume ratios of the unstirred layer compartments were calculated with:

$$
\rho_{p, j}=\frac{N}{d} \quad \text { and } \quad \rho_{n, j}=\frac{N}{d}
$$

The value of $200 \mu \mathrm{m}$ was used as thickness of the unstirred layer [17, 29-31]. In the first simulations the unstirred layer was subdivided into 8 compartments $(N=8)$.

\subsection{Steady-state $\mathrm{pH}$ in unstirred layer with multicompartment model and equilibrium of Deh reaction}

The steady-state $\mathrm{pH}$ profile of the unstirred layer $(\mathrm{pH}$ as a function of unstirred layer compartment number), calculated with the multicompartment model when the Deh reaction is infinitely catalyzed in all unstirred layer compartments, is the same as the $\mathrm{pH}$ profile 
predicted by numerical integration of (29a), (26), (18) (and analogue for HB/B) from the bulk solution $(x=0)$ to the cell membrane $(x=d)$.

When in the simulation the Deh reaction is infinitely catalyzed in compartment $N$ (closest to the cell membrane), but not catalyzed in the other unstirred layer compartments (1 to $N-1)$, the steady-state $\mathrm{pH}$ in compartment $N\left(\mathrm{pH}_{N}\right)$ is exactly the same as when the Deh reaction is infinitely catalyzed in all unstirred layer compartments (see Appendix). Then the value of $\mathrm{pH}_{N}$ can thus also be predicted by integration of (29a) (together with (26), (18)
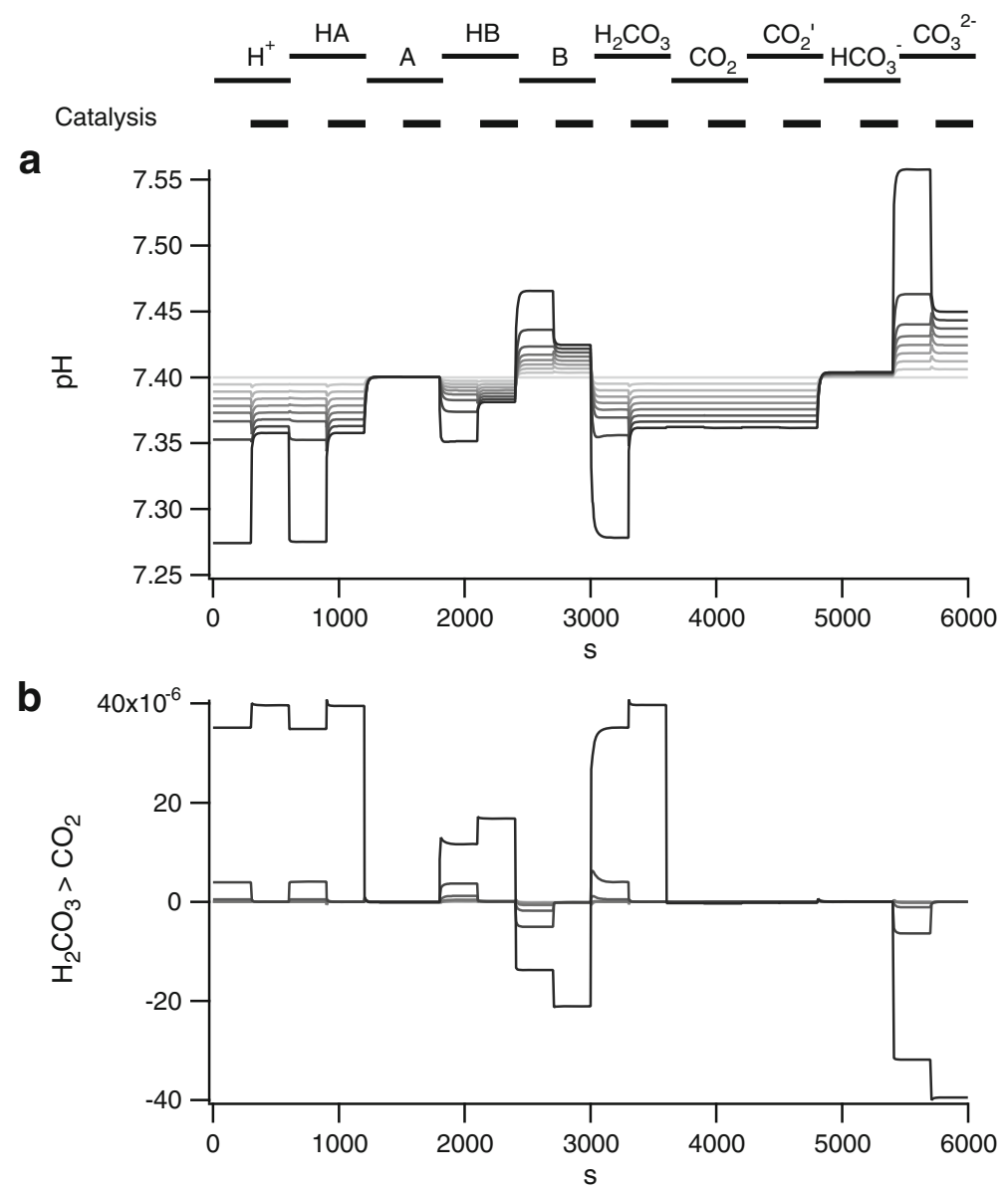

Fig. 1 Influence of type of particle efflux and catalysis on the unstirred layer buffered with bicarbonate. The extracellular bulk solution was buffered with $25 \mathrm{mM}$ bicarbonate at $\mathrm{pH}$ 7.4. There was no transmembrane flux, except the efflux $\left(-10^{-6}\right.$ mole $\left.\mathrm{m}^{-2} \mathrm{~s}^{-1}\right)$ of consecutively different types of particles, indicated with the upper horizontal bars. The unstirred layer was subdivided into 8 compartments. For each particle this was simulated first without catalysis of the Deh reaction in the unstirred layer and thereafter with infinite catalysis (or equilibrium) of the Deh reaction in the unstirred layer compartment $N(=8)$ closest to the cell membrane, but without catalysis in the other unstirred layer compartments (lower thick horizontal bars). During $\mathrm{CO}_{2}$ ' application the total efflux of $\mathrm{CO}_{2}+\mathrm{H}_{2} \mathrm{CO}_{3}$ was $-10^{-6}$ mole $\mathrm{m}^{-2} \mathrm{~s}^{-1}$ but their concentrations were in equilibrium. $p K_{H A}=4.87, p K_{H B}=7.5, p K_{H 2 C O 3}=3.46$ and $p K_{C O 2}{ }^{\prime}=6.12$. See Table 4 for the other parameters. a: calculated $\mathrm{pH}$ in the bulk compartment and in the different unstirred layer compartments, plotted versus simulation time. The darker color corresponds to a higher compartment number. b: Rate of dehydration (of $\mathrm{H}_{2} \mathrm{CO}_{3}$ and $\mathrm{HCO}_{3}{ }^{-}$) or $D_{\text {ehydr, } j}$ in each compartment $j$ 
and analogue for $\mathrm{HB} / \mathrm{B})$. This situation with infinite catalysis in compartment $N$ imitates a strong catalysis by extracellular membrane-bound carbonic anhydrase.

\subsection{Influence of type of transmembrane flux}

The influence of different types of transmembrane flux (different solutes) on the unstirred layer $\mathrm{pH}$ was simulated in the absence or presence of catalysis of the Deh reaction in the unstirred layer. This was done first with an extracellular bulk solution buffered with bicarbonate/ $\mathrm{CO}_{2}$ (Fig. 1) and thereafter with a bulk solution buffered with both a bicarbonate and a non-bicarbonate buffer (Fig. 2).

\subsubsection{Efflux in a bicarbonate/CO $\mathrm{C}_{2}$ buffered unstirred layer}

The extracellular bulk solution was buffered with $25 \mathrm{mM} \mathrm{HCO}_{3}{ }^{-}$at $\mathrm{pH}$ 7.4. The $\mathrm{CO}_{2}$ concentration in the bulk solution was calculated to obtain $\mathrm{pH} 7.4$ with this bicarbonate
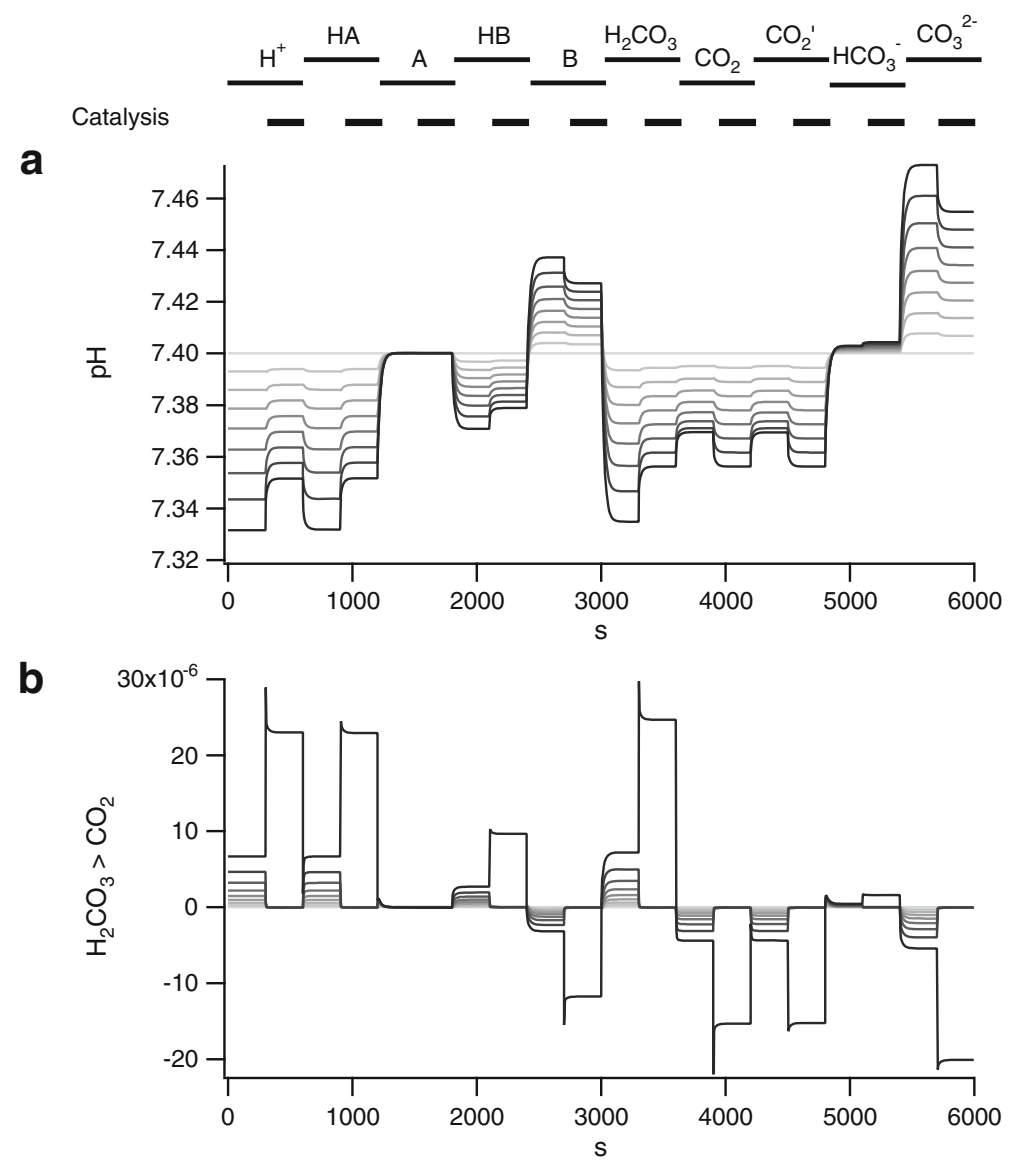

Fig. 2 Influence of type of particle efflux and catalysis on the unstirred layer buffered with both bicarbonate and HEPES. The extracellular bulk solution was buffered with $12.5 \mathrm{mM}$ bicarbonate and $5 \mathrm{mM}$ HEPES at $\mathrm{pH}$ 7.4. See legend to analogous Fig. 1 for further explanation 
concentration. The transmembrane fluxes $\left(-10^{-6}\right.$ mole $\left.\mathrm{m}^{-2} \mathrm{~s}^{-1}\right)$ were consecutively a $\mathrm{H}^{+}, \mathrm{HA}, \mathrm{A}, \mathrm{HB}, \mathrm{B}, \mathrm{H}_{2} \mathrm{CO}_{3}, \mathrm{CO}_{2}, \mathrm{CO}_{2}{ }^{\prime}\left(=\mathrm{CO}_{2}+\mathrm{H}_{2} \mathrm{CO}_{3}\right.$ in equilibrium), $\mathrm{HCO}_{3}{ }^{-}$or $\mathrm{CO}_{3}{ }^{2-}$ efflux. Their effect on the unstirred layer $\mathrm{pH}$ gradient is quite different (Fig. 1a). The detailed results are given in Table 1.

In the case of infinite catalysis in compartment $N$ (thick horizontal bars in Fig. 1), the steady-state $\mathrm{pH}$ of the unstirred layer closest to the cell membrane $\left(\mathrm{pH}_{N}\right)$ can be predicted by integration of (29a) (together with (26), (18) and analogue for $\mathrm{HB} / \mathrm{B}$ ).

The membrane efflux of the acids $\mathrm{H}^{+}, \mathrm{HA}, \mathrm{HB}, \mathrm{H}_{2} \mathrm{CO}_{3}, \mathrm{CO}_{2}$ or $\mathrm{CO}_{2}$ ' decreases $\mathrm{pH}_{N}$, but to a different extent. A proton efflux causes the largest acidification of $\mathrm{pH}_{N}$. An efflux of HA has a larger effect than an efflux of HB mainly by the different $\mathrm{pK}$ value (4.87 vs. 7.5 , respectively) which influences $f_{H A}, f_{A}, f_{H B}$ and $f_{B}$ (see (29b) or (30)). Because of the higher $\mathrm{pK}$ of $\mathrm{HB}$, a smaller fraction of the efflux of $\mathrm{HB}$ will dissociate to $\mathrm{B}$ and $\mathrm{H}^{+}$, and thus a smaller proton flux has to be transported by the mobile buffers and consequently the unstirred layer $\mathrm{pH}$-gradient will be smaller with an efflux of $\mathrm{HB}$ than with an efflux of HA. Since the $\mathrm{pK}$ of lactic acid is low compared to the bulk $\mathrm{pH}$, the effect of a cellular efflux of lactic acid on $\mathrm{pH}_{\mathrm{N}}$ can be expected to approach that of a proton efflux of the same size. If the Deh reaction is infinitely catalyzed, the effect of an efflux of $\mathrm{H}_{2} \mathrm{CO}_{3}, \mathrm{CO}_{2}$ and $\mathrm{CO}_{2}{ }^{\prime}$ on $\mathrm{pH}_{\mathrm{N}}$ is the same (because then $\left[\mathrm{H}_{2} \mathrm{CO}_{3}\right]$ and $\left[\mathrm{CO}_{2}\right]$ are in equilibrium). During their efflux a large fraction will dissociate $\left(K_{1}{ }^{\prime}=10^{-6.12}\right)$ to bicarbonate and protons and at physiological $\mathrm{pH}$ only a small fraction will further dissociate to carbonate and all these protons have to be transported.

A membrane efflux of the bases $\mathrm{A}, \mathrm{B}, \mathrm{HCO}_{3}{ }^{-}$and $\mathrm{CO}_{3}{ }^{2-}$ increases $\mathrm{pH}_{\mathrm{N}}$. During their membrane efflux they will take up protons and this causes an opposite flux of protons to be transported by the mobile buffers. Because of the difference in $\mathrm{pK}$, an efflux of A makes $\mathrm{pH}_{\mathrm{N}}$ less alkaline than an efflux of B (see (29b) or (30)). During an efflux of bicarbonate the $\mathrm{pH}$ gradient in the unstirred layer is small, because only a small fraction will associate to $\mathrm{H}_{2} \mathrm{CO}_{3}$ (most of which will dehydrate) and thus take up a proton and an even smaller fraction will dissociate to $\mathrm{CO}_{3}{ }^{2-}$. However, during a steady-state $\mathrm{CO}_{3}{ }^{2-}$ efflux $\mathrm{pH}_{N}$ is clearly increased, because after association to $\mathrm{HCO}_{3}{ }^{-}$and also partly to $\mathrm{H}_{2} \mathrm{CO}_{3}$ a larger opposite proton flux has then to be transported.

When the Deh reaction is not catalyzed, the difference between $\mathrm{pH}_{N}$ and the bulk $\mathrm{pH}$ is larger for different types of fluxes (Fig. 1a and Table 1), but for other fluxes catalysis makes little or no difference. Figure $1 \mathrm{~b}$ displays the simultaneous rate of the dehydration reaction in the different compartments $\left(D_{\text {ehydr }, j}\right)$. Comparing Fig. 1a with b shows that for those types of fluxes, whereby the rate of the Deh reaction is small, the absence of catalysis has little effect on $\mathrm{pH}_{N}$ (= the absolute value of the disequilibrium $\mathrm{pH}$ is then small). Then the $\mathrm{CO}_{2}$ and $\mathrm{H}_{2} \mathrm{CO}_{3}$ concentrations must be nearly in equilibrium, even if there is no catalysis of the Deh reaction.

A proton efflux from the cell membrane, in an extracellular unstirred layer containing only a bicarbonate/ $\mathrm{CO}_{2}$ buffer, decreases $\mathrm{pH}_{N}$ much more when the Deh reaction is not catalyzed (Fig. 1a). These protons move through the unstirred layer via different parallel pathways, such as diffusion of $\mathrm{H}^{+}$, and $\mathrm{OH}^{-}$(via a $\mathrm{OH}^{-} / \mathrm{H}_{2} \mathrm{O}$ shuttle) and is facilitated by the bicarbonate $/ \mathrm{CO}_{2}$ buffer (Fig. 3). If the Deh reaction is not catalyzed, $\mathrm{H}_{2} \mathrm{CO}_{3}$ generated by the proton transport accumulates, which causes a disequilibrium $\mathrm{pH}$. The same is seen with an efflux of HA, which induces a rate of proton transport which is not much smaller. An efflux of $\mathrm{HB}$, which (because of a smaller $f_{B}$ ) induces a smaller rate of proton transport, also induces a smaller disequilibrium $\mathrm{pH}$. In equilibrium the ratio $\left[\mathrm{H}_{2} \mathrm{CO}_{3}\right] /\left(\left[\mathrm{H}_{2} \mathrm{CO}_{3}\right]+\right.$ $\left[\mathrm{CO}_{2}\right]$ ) equals 0.0022 . Consequently, during an efflux of $\mathrm{H}_{2} \mathrm{CO}_{3}$ the Deh reaction is initially 


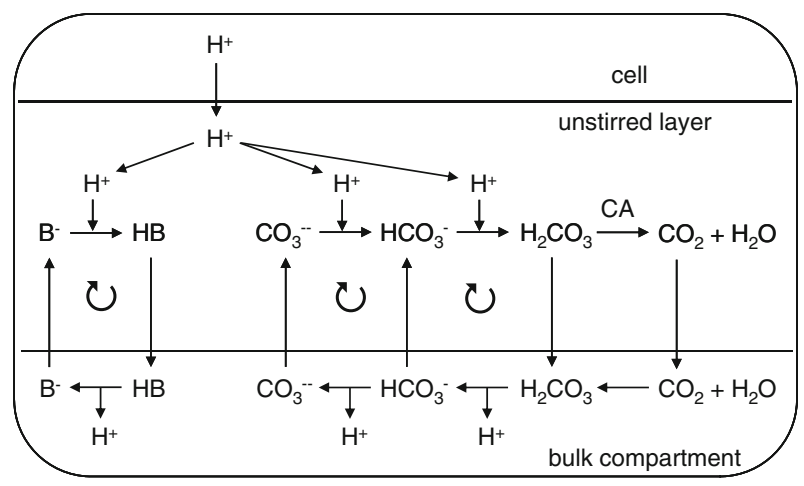

Fig. 3 Proton transport through the unstirred layer. If there is a mobile HB/B buffer in the unstirred layer, a shuttle movement of $\mathrm{HB}$ and $\mathrm{B}$ facilitates the transport of protons through the unstirred layer. If the unstirred layer is buffered with a bicarbonate/ $\mathrm{CO}_{2}$ buffer, the scheme illustrates how proton transport is facilitated by this buffer and by carbonic anhydrase (CA). The proton transport by the bicarbonate/ $\mathrm{CO}_{2}$ buffer can also be considered as the sum of a $\mathrm{CO}_{3}{ }^{2-} / \mathrm{HCO}_{3}{ }^{-}$shuttle and a $\mathrm{HCO}_{3}{ }^{-} /\left(\mathrm{H}_{2} \mathrm{CO}_{3}+\mathrm{CO}_{2}\right)$ shuttle. The given example is for a proton efflux from the cell, but these reactions are reversible

far from equilibrium and thus the increase in $\left[\mathrm{H}_{2} \mathrm{CO}_{3}\right]_{N}$ causes the disequilibrium $\mathrm{pH}$. In contrast, in equilibrium the ratio $\left[\mathrm{CO}_{2}\right] /\left(\left[\mathrm{H}_{2} \mathrm{CO}_{3}\right]+\left[\mathrm{CO}_{2}\right]\right)$ equals 0.9978 . Consequently, during an efflux of $\mathrm{CO}_{2}$ the Deh reaction is close to its equilibrium and will thus be very slow. During an efflux of $\mathrm{HCO}_{3}{ }^{-}$in a solution which contains no other buffers the Deh reaction will also be activated very little. Only a small fraction $\left(f_{\mathrm{H}_{2} \mathrm{CO} 3}\right)$ will associate with a proton to $\mathrm{H}_{2} \mathrm{CO}_{3}$ and a very small fraction $\left(f_{\mathrm{CO} 3}\right)$ will dissociate to $\mathrm{CO}_{3}{ }^{2-}$ and most of the bicarbonate will simply diffuse to the bulk solution. However, during an efflux of $\mathrm{CO}_{3}{ }^{2-}$ the largest fraction associates with $\mathrm{H}^{+}$to bicarbonate, which induces a proton transport through the unstirred layer, and results in a large disequilibrium $\mathrm{pH}$.

Figure $4 \mathrm{a}$ displays the corresponding $\mathrm{pH}$ profiles. For the same type of efflux, the deviation between the full line and the dashed line shows the compartments in which the Deh reaction is out of equilibrium when the Deh reaction is not catalyzed. This also indicates that in the compartments closer to the bulk solution the Deh reaction approaches equilibrium.

\subsubsection{Efflux in an unstirred layer buffered with both a bicarbonate and a non-bicarbonate buffer}

The extracellular bulk solution was buffered with $12.5 \mathrm{mM} \mathrm{HCO}_{3}{ }^{-}$and $5 \mathrm{mM}$ HEPES at pH 7.4 (Fig. 2 and Table 2). For the other parameters the simulation was similar to that in Fig. 1.

When the extracellular buffer solution contains also a non-bicarbonate buffer, on the one hand catalysis of the Deh reaction in compartment $N$ on $\mathrm{pH}_{\mathrm{N}}$ is smaller for an efflux of $\mathrm{H}^{+}$, $\mathrm{HA}, \mathrm{A}, \mathrm{HB}, \mathrm{B}, \mathrm{H}_{2} \mathrm{CO}_{3}$ and $\mathrm{CO}_{3}{ }^{2-}$ than in Fig. 1, because the Deh reaction has then not to work so rapidly in compartment $N$ (Fig. 2b) since part of the proton flux goes via shuttle movements of the acid and basic form of HEPES. On the other hand catalysis has a larger effect for an efflux of $\mathrm{CO}_{2}, \mathrm{CO}_{2}{ }^{\prime}$ and $\mathrm{HCO}_{3}{ }^{-}$in the presence of HEPES, because these fluxes then activate the Deh reaction. 

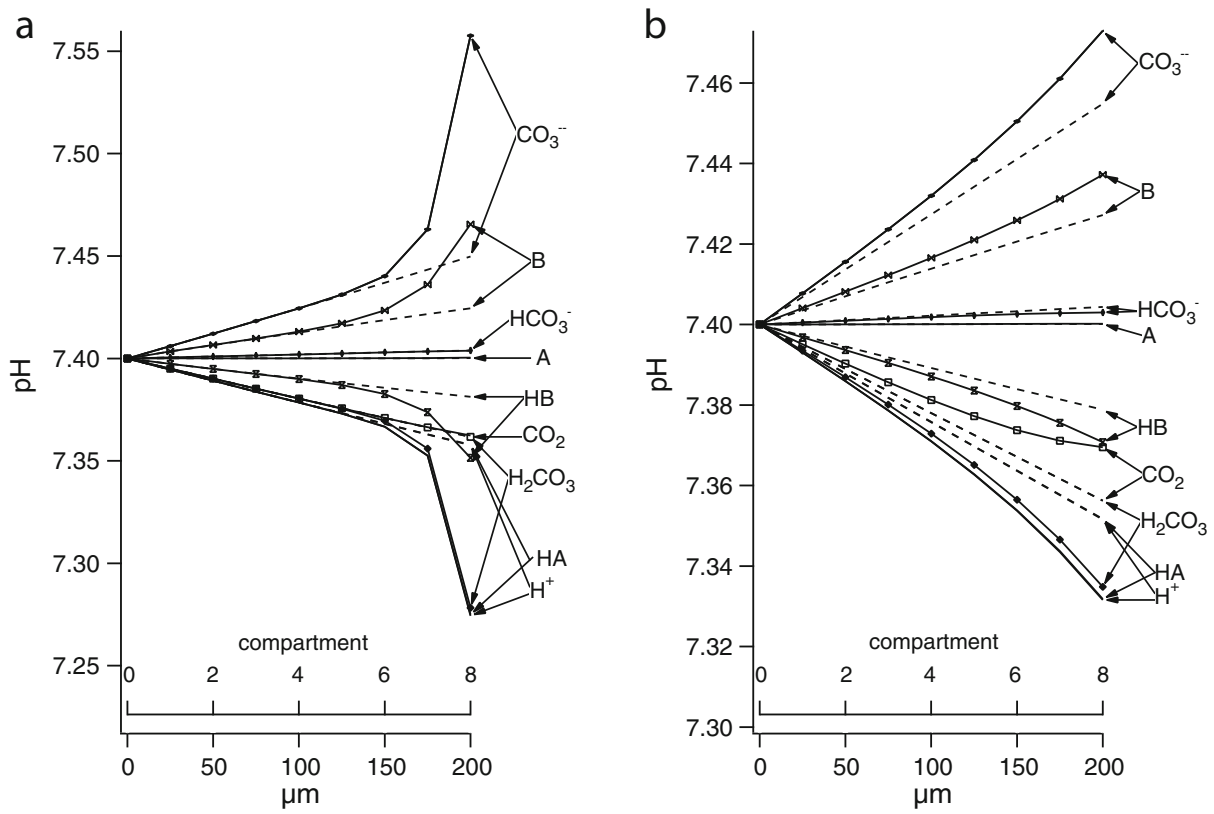

Fig. 4 Steady-state $\mathrm{pH}$ profiles in the unstirred layer. The unstirred layer is subdivided into eight compartments. The $\mathrm{pH}$ is plotted versus the compartment number during an efflux $\left(-10^{-6} \mathrm{~mole} \mathrm{~m}^{-2} \mathrm{~s}^{-1}\right)$ of the particles indicated with the arrows. Full lines: no catalysis of the Deh reaction. Dashed lines: infinite catalysis of the Deh reaction in compartment $N$. At the bottom of the graph, a distance scale is also given from the extracellular bulk compartment $(0 \mu \mathrm{m})$ to the cell membrane $(200 \mu \mathrm{m})$. The distance equals $200 * j / N \mu \mathrm{m}$, where $j$ is the compartment number and $N$ the total number of unstirred layer compartments, and is thus the distance at the interface between compartment $j$ and compartment $j+1$. a Extracellular bulk solution buffered with $25 \mathrm{mM} \mathrm{HCO}_{3}{ }^{-}$at $\mathrm{pH} 7.4$, same simulation as Fig. 1. b Extracellular bulk solution buffered with $12.5 \mathrm{mM} \mathrm{HCO}_{3}{ }^{-}$and $5 \mathrm{mM}$ HEPES at $\mathrm{pH}$ 7.4, same simulation as Fig. 2

In addition, in the presence of HEPES for each efflux type the $\mathrm{pH}$ profile curve in the absence of catalysis (full line) remains separated for all unstirred layer compartments from the curve with infinite catalysis (dashed line), compare Fig. 4b with Fig. 4a. This can be explained as follows: in the case of a proton efflux, a fraction of these protons is transported through the unstirred layer by bicarbonate/ $\mathrm{CO}_{2}$ (Fig. 3) and a large fraction is also transported by the HEPES shuttle. In each unstirred layer compartment part of the protons transported by HEPES will leave the HEPES shuttle (due to the $\mathrm{pH}$ gradient in the unstirred layer) and go into the reaction: $\mathrm{H}^{+}+\mathrm{HCO}_{3}^{-} \rightarrow \mathrm{H}_{2} \mathrm{CO}_{3} \rightarrow \mathrm{CO}_{2}+\mathrm{H}_{2} \mathrm{O}$, which induces disequilibrium of the Deh reaction in that unstirred layer compartment, if the Deh reaction is not infinitely catalyzed. A similar explanation can be given for the efflux of $\mathrm{HA}, \mathrm{A}, \mathrm{HB}, \mathrm{B}, \mathrm{H}_{2} \mathrm{CO}_{3}, \mathrm{HCO}_{3}{ }^{-}$and $\mathrm{CO}_{3}{ }^{2-}$ in a combined bicarbonate and HEPES buffer. Each of these types of solute efflux generates a net proton flux through the unstirred layer partly via the HEPES shuttle and this also causes a disequilibrium of the Deh reaction in all unstirred layer compartments in the absence of catalysis (Fig. 4b). An efflux of $\mathrm{CO}_{2}$ acidifies the unstirred layer $\mathrm{pH}$ less in the absence of catalysis, because then the reaction $\mathrm{H}^{+}+\mathrm{HCO}_{3}{ }^{-} \leftarrow \mathrm{H}_{2} \mathrm{CO}_{3} \leftarrow \mathrm{CO}_{2}+\mathrm{H}_{2} \mathrm{O}$ is slowed down. The protons released by this reaction are then taken away partly by the HEPES shuttle, which draws the above 
reaction to the left and also induces disequilibrium of the Deh reaction in all unstirred layer compartments.

This demonstrates that, during a solute efflux through the cell membrane, a shuttle movement of protons by an acid-base system like that of HEPES spreads the disequilibrium of the Deh reaction all over the unstirred layer.

\subsection{Combinations of transmembrane fluxes}

If the fluxes are small (e.g., $-10^{-6}$ mole $\mathrm{m}^{-2} \mathrm{~s}^{-1}$ ), one can have an approximate idea of the $\mathrm{pH}$ effect of the fluxes in the opposite direction by inverting the effects shown in Figs. 1 and 2 . Normally different types of transmembrane acid-base fluxes occur simultaneously. If small clamped fluxes are combined, the resulting effect can be predicted approximately by adding the effect of the individual fluxes on $\left(\mathrm{pH}_{\mathrm{N}}-\mathrm{pH}_{0}\right)$, see Table 3 and $(29 \mathrm{~b})$. However, this simple addition method is not valid for large $\mathrm{pH}$ changes in which the proton transport capacity changes very much (29c). For accurate results, one has to use (29a) or the multicompartment model.

\subsection{Influence of the buffer concentration}

The buffer concentration in the bulk of the extracellular solution affects the concentration of the mobile buffers in the unstirred layer. Decreasing this buffer concentration increases the $\mathrm{pH}$ gradient if the Deh reaction is infinitely catalyzed ((29a) and Fig. 5a). Similar effects are seen when the Deh reaction is not catalyzed. The rate of the Deh reaction is little influenced by decreasing the mobile buffer concentration (Fig. 5b), but the $\mathrm{pH}$ gradient is increased, because the effect of the same transmembrane fluxes is distributed over a smaller amount of mobile buffer.

However, if in the multicompartment model the intrinsic buffer capacity of the unstirred layer is changed, which in the model behaves as an immobile buffer, this has no influence on the steady-state $\mathrm{pH}$ in the unstirred layer. Immobile buffers do have an influence on transient changes in unstirred layer $\mathrm{pH}$ (see Section 3.13).

It has been shown experimentally that mobile buffers facilitate proton transport and reduce the $\mathrm{pH}$-gradient in the unstirred layer [11, 12, 14, 18, 32-38].

In Fig. 5a there is a transient alkalinization of the unstirred layer $\mathrm{pH}$ when the bicarbonate and $\mathrm{CO}_{2}$ concentrations are decreased in the bulk solution. This is because a larger unstirred layer permeability was used for $\mathrm{CO}_{2}$ than for bicarbonate (Table 4 and (64)). When in another simulation the same values were used for both permeabilities, such initial $\mathrm{pH}$ transients were absent (results not shown).

\subsection{Influence of the number of unstirred layer compartments}

In the previous simulations the number of unstirred layer compartments $(N)$ was limited to 8 , to allow distinction of the results from individual compartments in the graphs. In order to test whether the number of compartments, into which the unstirred layer is subdivided, influences the calculated steady-state unstirred layer $\mathrm{pH}$ close to the membrane, $N$ was varied from 1 to 32 (Fig. 6). The thickness of the unstirred layer (d) was kept constant. The permeabilities and surface to volume ratios of the unstirred layer compartments were adapted to $N$ according to (64) and (65). The extracellular bulk solution contained $25 \mathrm{mM}$ $\mathrm{HCO}_{3}{ }^{-}$at $\mathrm{pH} 7.4$ and the proton efflux was $-10^{-6}$ mole $\mathrm{m}^{-2} \mathrm{~s}^{1}$. 

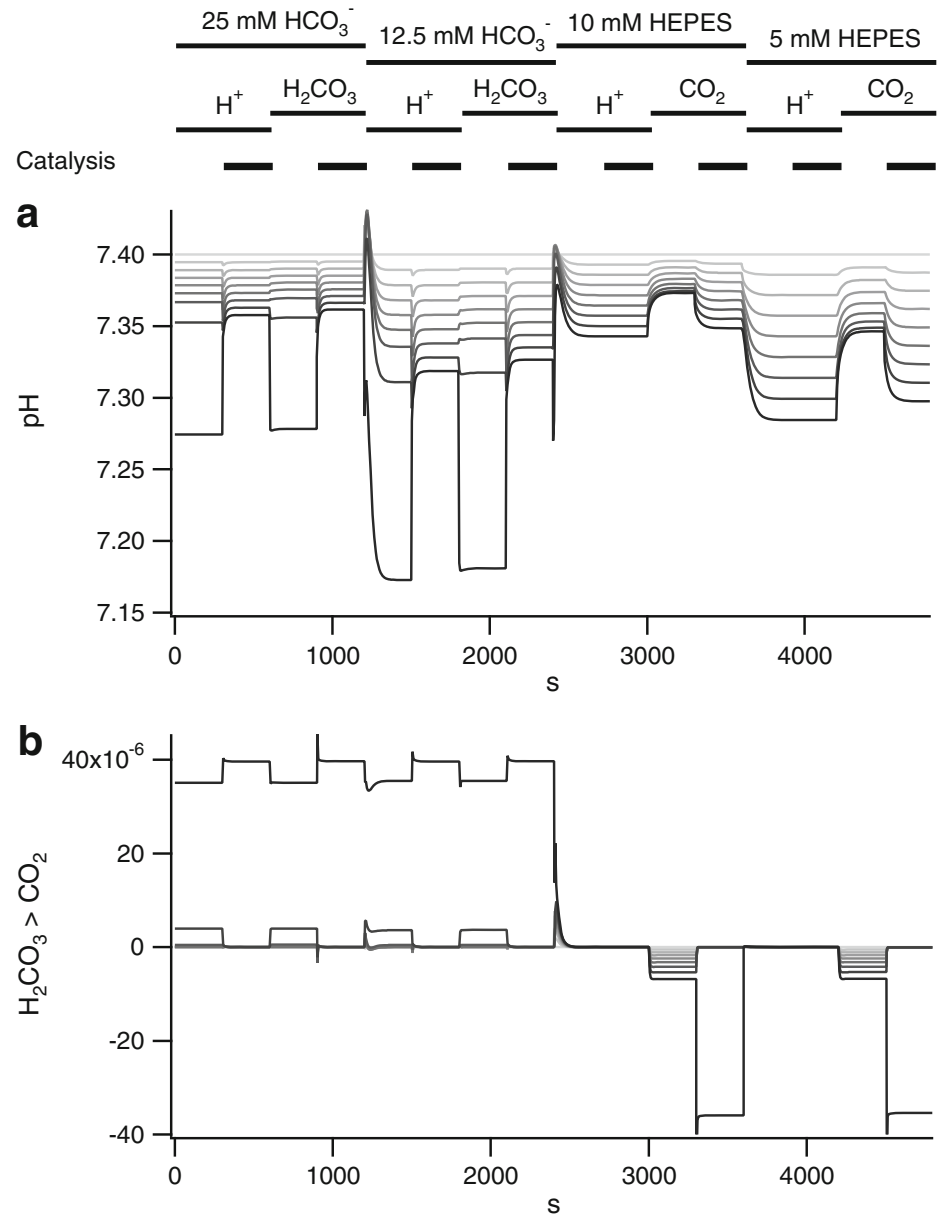

Fig. 5 Influence of the mobile buffer concentration. Initially the extracellular bulk solution was buffered with $25 \mathrm{mM}$ bicarbonate at $\mathrm{pH} 7.4$ and there was a constant efflux $\left(-10^{-6}\right.$ mole $\left.\mathrm{m}^{-2} \mathrm{~s}^{-1}\right)$ of $\mathrm{H}^{+}$or $\mathrm{H}_{2} \mathrm{CO}_{3}$. Then the bicarbonate concentration was reduced to $12.5 \mathrm{mM}$ at constant $\mathrm{pH} 7.4$ (with a simultaneous reduction in $\mathrm{CO}_{2}$ concentration) and the same fluxes were applied. Thereafter, the bicarbonate buffer in the bulk solution was replaced by $10 \mathrm{mM}$ HEPES at $\mathrm{pH} 7.4$ and there was an efflux $\left(-10^{-6} \mathrm{~mole} \mathrm{~m}^{-2} \mathrm{~s}^{-1}\right)$ of $\mathrm{H}^{+}$or $\mathrm{CO}_{2}$. Then the HEPES concentration was reduced to $5 \mathrm{mM}$ and the same fluxes were applied. For each situation this was simulated first without catalysis of the Deh reaction in the unstirred layer and thereafter with infinite catalysis (or equilibrium) of the Deh reaction in the unstirred layer compartment $N$, but without catalysis in the other unstirred layer compartments (lower thick horizontal bars). The unstirred layer was subdivided into eight compartments. a Calculated $\mathrm{pH}$ in the bulk compartment ( $\mathrm{pH}$ 7.4) and in the different unstirred layer compartments versus simulation time. The darker color corresponds to a higher compartment number. b Rate of the dehydration reaction $\left(D_{\text {ehydr, }}\right)$ in each compartment $j$

If the Deh reaction is infinitely catalyzed in compartment $N$ (or in the entire unstirred layer) the steady-state unstirred layer $\mathrm{pH}$ in compartment $N$ is independent of $N$ (empty circles in Fig. 6). However, if the Deh reaction is not catalyzed in the unstirred layer, $\mathrm{pH}_{N}$ is clearly more acid and the disequilibrium $\mathrm{pH}$ is larger when $N$ is larger (full circles in Fig. 6). 
Table 4 Parameters used in the simulations

\begin{tabular}{lll}
\hline Constant & Value & Reference \\
\hline$d$ & $200 \mu \mathrm{m}$ & {$[17,30,31]$} \\
$D_{H}$ & $9.210^{-9} \mathrm{~m}^{2} \mathrm{~s}^{-1}$ & {$[51]$} \\
$D_{O H}$ & $9.210^{-9} \mathrm{~m}^{2} \mathrm{~s}^{-1}$ & \\
$D_{H A}$ & $10^{-9} \mathrm{~m}^{2} \mathrm{~s}^{-1}$ & \\
$D_{A}$ & $10^{-9} \mathrm{~m}^{2} \mathrm{~s}^{-1}$ & {$[37]$} \\
$D_{H B}$ & $6.210^{-10} \mathrm{~m}^{2} \mathrm{~s}^{-1}$ & {$[52]$} \\
$D_{B}$ & $6.210^{-10} \mathrm{~m}^{2} \mathrm{~s}^{-1}$ & \\
$D_{C O 2}$ & $1.6410^{-9} \mathrm{~m}^{2} \mathrm{~s}^{-1}$ & {$[53]$} \\
$D_{H 2 C O 3}$ & $10^{-9} \mathrm{~m}^{2} \mathrm{~s}^{-1}$ & \\
$D_{H C O 3}$ & $8.710^{-10} \mathrm{~m}^{2} \mathrm{~s}^{-1}$ & {$[54]$} \\
$D_{C O 3}$ & $4.110^{-10} \mathrm{~m}^{2} \mathrm{~s}^{-1}$ & {$[34]$} \\
$K_{1}{ }^{\prime}$ & $10^{-6.12} \mathrm{M}$ & {$[20]$} \\
$K_{1}$ & $10^{-3.456} \mathrm{M}$ & {$[55]$} \\
$K_{2}$ & $10^{-10.277} \mathrm{M}$ & {$[56]$} \\
$k_{1}$ & $0.11 \mathrm{~s}^{-1}$ & {$[16]$} \\
$k_{-1}$ & $50.63 \mathrm{~s}^{-1}$ & Calculated from $k_{1}\left(K_{1}-K_{1}{ }^{\prime}\right) / K_{1}{ }^{\prime}$ \\
$k_{4}$ & $27000 \mathrm{M}^{-1} \mathrm{~s}^{-1}$ & {$[16]$} \\
$k_{-4}$ & $0.000355 \mathrm{~s}^{-1}$ & Calculated from $k_{4} K_{w}\left(K_{1}-K_{1}{ }^{\prime}\right) /\left(K_{1} K_{1}{ }^{\prime}\right)$ \\
\hline
\end{tabular}

For $D_{A}$ the diffusion coefficient of lactate was used. Because the dissociation constants $K_{1}$ and $K_{1}{ }^{\prime}$ and the velocity constants $k_{1}, k_{-1}, k_{4}$ and $k_{-4}$ are related to each other, the values of $k_{-1}$ and $k_{-4}$ were calculated to be consistent with $K_{1}$ and $K_{1}{ }^{\prime} . K_{w}$ is the ionic product of water $\left(10^{-14}\right)$.

The following parameters have no influence on the simulations in flux clamp mode. The intracellular metabolic $\mathrm{CO}_{2}$ production $\left(M_{C O 2}\right)$ was $8.310^{-6} \mathrm{M} \mathrm{s}^{-1} . M_{H 2 C O 3}$ and $M_{H A}$ were assumed to be 0 . The membrane potential $(E)$ was $-80 \mathrm{mV}$. Membrane permeabilities (in m s${ }^{-1}$ ): $P_{H A, i}=1.410^{-5}, P_{A, i}=$ $410^{-10}, P_{H B, i}=0, P_{B, i}=0, P_{C O 2, i}=10^{-4}, P_{H 2 C O 3, i}=210^{-5}, P_{H C O 3, i}=410^{-10}, P_{C O 3, i}=210^{-10}$, $P_{H, i}=1.810^{-7}, P_{O H, i}=1.810^{-7}$. The used values for the membrane permeabilities of $\mathrm{HA}, \mathrm{CO}_{2}$ and $\mathrm{H}_{2} \mathrm{CO}_{3}$ were smaller than the respective permeabilities of the plasma membrane to take into account the diffusion resistance in series by the intracellular unstirred layer, which is not incorporated in this model.

To simulate a bi-directional proton extrusion pump depending on both the intracellular and extracellular $\mathrm{pH}$ [7], the following generic equation was used for the active proton flux:

$$
J_{\text {Hactive }}=-P_{\max }\left[\frac{2}{10^{P_{n}\left(\mathrm{pH}_{i}-P_{1} \mathrm{pH}_{N}-P_{2}\right)}+1}-1\right]
$$

where $P_{\max }=510^{-7}$ mole $\mathrm{m}^{-2} \mathrm{~s}^{-1}, P_{n}=0.3, P_{1}=0.237$ and $P_{2}=5.504$.

The intracellular intrinsic buffer capacity $\left(\beta^{\prime}{ }_{i}\right)$ was $-0.0196 \mathrm{pH}_{i}+0.16 \mathrm{M}$ [27]. The unstirred layer intrinsic buffer capacity $\left(\beta^{\prime}{ }_{j}\right)$ was $3.510^{-4} \mathrm{M}$ in Figs. $1,2,3,4,5,6,7,8,9$ and 10 and $10^{-5} \mathrm{M}$ in Figs. 11 and 12

If the Deh reaction is infinitely catalyzed in compartment $N, D_{\text {ehydr,N }}$ is doubled when $N$ is doubled (empty triangles in Fig. 6), because the same amount of moles of $\mathrm{H}_{2} \mathrm{CO}_{3}$ have to go through this reaction per unit of time in a compartment volume which is two times smaller. If the Deh reaction is not catalyzed in the unstirred layer, $D_{\text {ehydr }, N}$ does not increase so much (full triangles). This induces the larger disequilibrium $\mathrm{pH}$ in compartment $N$ when $N$ is doubled. However, diffusion of solutes between the unstirred layer compartments limits a further increase of the disequilibrium $\mathrm{pH}$ at higher values of $N$, because the permeability of the diffusion barrier between the unstirred layer compartments is also doubled when $N$ is doubled (64).

To know how large $N$ has to be for an accurate estimation of the unstirred layer $\mathrm{pH}$ in the immediate vicinity of the cell membrane during a proton efflux, the relationship between $\mathrm{pH}_{\mathrm{N}}$ and $N$ was fitted to a double exponential equation and extrapolated to higher values of $N$. This shows that the extrapolated $\mathrm{pH}_{\mathrm{N}}$ approaches asymptotically $\mathrm{pH} 7.15$, which can be 


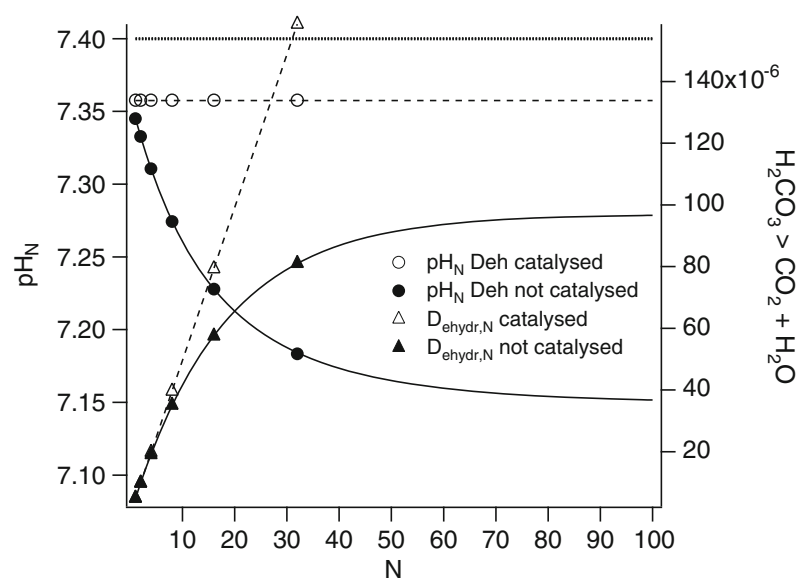

Fig. 6 Influence of the number of unstirred layer compartments. The extracellular bulk solution was buffered with $25 \mathrm{mM}$ bicarbonate at $\mathrm{pH}$ 7.4. The transmembrane proton efflux was $-10^{-6}$ mole $\mathrm{m}^{-2} \mathrm{~s}^{-1}$. The steady state was calculated in different simulations, in which the number of unstirred layer compartments $(N)$ was $1,2,4,8,16$ or 32 . The thickness of the unstirred layer $(d)$ was kept constant. The steady-state $\mathrm{pH}$ in the unstirred layer compartment closest to the cell membrane $\left(\mathrm{pH}_{\mathrm{N}}\right.$ : circles, left axis) and the corresponding rate of the Deh reaction ( $D_{\text {ehydr, }}$ : triangles, right axis) are plotted as a function of the total number of unstirred layer compartments used in the simulation. Full symbols: no catalysis of the Deh reaction. Empty symbols: infinite catalysis of the Deh reaction in compartment $N$, but no catalysis in the other compartments

considered as the correct unstirred layer $\mathrm{pH}$ at the cell membrane with this proton efflux, if the Deh reaction is not catalyzed. This extrapolation also shows that with 64 or 128 unstirred layer compartments $\mathrm{pH}_{\mathrm{N}}$ would be very close to the correct value. In the next simulations $N$ was limited to 32 , because this gives already a good idea of the order of magnitude of the disequilibrium $\mathrm{pH}_{\mathrm{N}}$ and larger values for $N$ dramatically increase the calculation time.

If the Deh reaction is infinitely catalyzed in compartment $N$, the steady state $\mathrm{pH}_{\mathrm{N}}$ is independent of $N$. This is true for any combination of solute fluxes, and not only in flux clamp simulations but for any type of steady-state simulation with this multicompartment model. If the Deh reaction is not catalyzed in the unstirred layer, but the rate of the Deh reaction is very small, then the disequilibrium $\mathrm{pH}_{\mathrm{N}}$ is also very small and the steady-state $\mathrm{pH}_{\mathrm{N}}$ is very little dependent on $N$. However, if transient $\mathrm{pH}$ and concentration changes are calculated, it is more accurate to use a larger number of unstirred layer compartments also when the Deh reaction is infinitely catalyzed. The necessary number of unstirred layer compartments is determined by distance related concentration differences in the unstirred layer, e.g., due to diffusion of solutes, and is thus smaller when the thickness of the unstirred layer is smaller.

Simulations with a lower number of unstirred layer compartments can still be useful to obtain a qualitative insight in some processes and directions of fluxes and changes, but to get a more accurate $\mathrm{pH}_{\mathrm{N}}$ it is important to choose $N$ large enough.

\subsection{Contribution of the uncatalyzed Deh reaction}

If the extracellular bulk solution contains $25 \mathrm{mM} \mathrm{HCO}_{3}{ }^{-}$at $\mathrm{pH} 7.4$ without other buffers and the Deh reaction is infinitely catalyzed, the calculated steady-state $\mathrm{pH}_{\mathrm{N}}$ with a proton 
flux of $-10^{-6}$ mole $\mathrm{m}^{-2} \mathrm{~s}^{-1}$ is 7.36 (see Section 3.5). If the Deh reaction is not catalyzed, the extrapolated $\mathrm{pH}_{\mathrm{N}}$ is 7.15 . To estimate how large the contribution of the uncatalyzed Deh reaction is in proton transport in the unstirred layer, one can exceptionally use $K_{1}$ $\left(10^{-3.46}\right)$ instead of $K_{1}{ }^{\prime}\left(10^{-6.12}\right)$ in all equations leading to (26) and (29a), which has the same effect as excluding completely the Deh reaction, even the uncatalyzed one. When one then integrates (26) and (29a), one obtains that the same proton efflux would acidify the $\mathrm{pH}$ close to the membrane to $\mathrm{pH} 5.84$, thus much lower than $\mathrm{pH} 7.15$. This shows that the proton transport capacity of a pure bicarbonate buffer is very small without the contribution of the Deh reaction, and that even the uncatalyzed Deh reaction plays a significant role in proton transport in a bicarbonate buffer.

\subsection{Influence of the degree of catalysis}

For these simulations the unstirred layer was subdivided into 32 compartments. The Deh reaction was not catalyzed in compartments 1 to 31 . The degree of catalysis of the Deh reaction in compartment 32 next to the cell membrane $\left(C_{a t a, N}\right)$, was varied from 1 (no catalysis) to 256 and finally infinite catalysis (equilibrium).

In the first simulation the extracellular bulk solution was buffered with $25 \mathrm{mM}$ bicarbonate at $\mathrm{pH} 7.4$ and there was a transmembrane proton efflux of $-10^{-6}$ mole $\mathrm{m}^{-2} \mathrm{~s}^{-1}$ (Fig. 7a, b, c). When the Deh reaction is infinitely catalyzed in compartment $32(N)$, the steady-state unstirred layer $\mathrm{pH}$ changes gradually from $7.4(0 \mu \mathrm{m}$, the bulk) to 7.358 (200 $\mu \mathrm{m}$, compartment $N$ ), see dashed line in Fig. 7a. If the Deh reaction is not catalyzed, the $\mathrm{pH}$ in the part of the unstirred layer between 0 and $120 \mu \mathrm{m}$ from the bulk compartment is about the same as that during infinite catalysis. It is only closer to the cell membrane that the $\mathrm{pH}$ starts deviating and becomes more acidic than in the case of infinite catalysis. This deviation starts thus about $62 \mu \mathrm{m}$ from the cell membrane, if $200 \mu \mathrm{m}$ is used as unstirred layer thickness.

Even a low $C_{a t a, N}$ has already a large impact on the disequilibrium $\mathrm{pH}_{\mathrm{N}}$ in a pure bicarbonate buffer (Fig. 7a), because the proton transport capacity of the bicarbonate buffer without the contribution of the Deh reaction is very small.

For a proton efflux in a bicarbonate buffered medium the $\mathrm{pH}$ profile at different values of $C_{a t a, N}$ is closely related to the profile of $\left[\mathrm{H}_{2} \mathrm{CO}_{3}\right]$ in the unstirred layer (Fig. 7a and b). The relative change of the bicarbonate and $\mathrm{CO}_{2}$ concentrations as a function of the distance from the bulk is then small. If the Deh reaction is infinitely catalyzed in compartment $N$, the rate of the Deh reaction is very low in the other unstirred layer compartments (Fig. 7c). In contrast, if the Deh reaction is little or not catalyzed in compartment $N$, the reaction has to proceed further in the other compartments, because $\mathrm{H}_{2} \mathrm{CO}_{3}$ diffusing from compartment $N$ is not yet completely equilibrated with $\mathrm{CO}_{2}$.

In the second simulation the extracellular bulk solution was buffered with $12.5 \mathrm{mM}$ bicarbonate and $5 \mathrm{mM}$ HEPES at $\mathrm{pH} 7.4$ and there was a proton efflux of $-10^{-6}$ mole $\mathrm{m}^{-2}$ $\mathrm{s}^{-1}$ (Fig. 7d, lower curves). Owing to the non-bicarbonate buffer, the disequilibrium $\mathrm{pH}$ is spread from the cell membrane down to compartment 1 , if the Deh reaction is not catalyzed (see separation of the corresponding $\mathrm{pH}$ profile from the dashed line). This is also the case when $C_{a t a, N}$ is increased. Due to the HEPES buffer the total proton transport capacity is already large without the Deh reaction and then a low $C_{a t a, N}$ has much less impact on the disequilibrium $\mathrm{pH}_{\mathrm{N}}$ (compare with Fig. 7a).

Similar results are obtained with a $\mathrm{CO}_{2}$ efflux of $-10^{-6}$ mole $\mathrm{m}^{-2} \mathrm{~s}^{-1}$ (Fig. $7 \mathrm{~d}$, upper curves) in the same buffer. Not only $\left[\mathrm{H}_{2} \mathrm{CO}_{3}\right]$ but also $\left[\mathrm{CO}_{2}\right],\left[\mathrm{HCO}_{3}{ }^{-}\right],\left[\mathrm{CO}_{3}{ }^{2-}\right]$ and the 
a

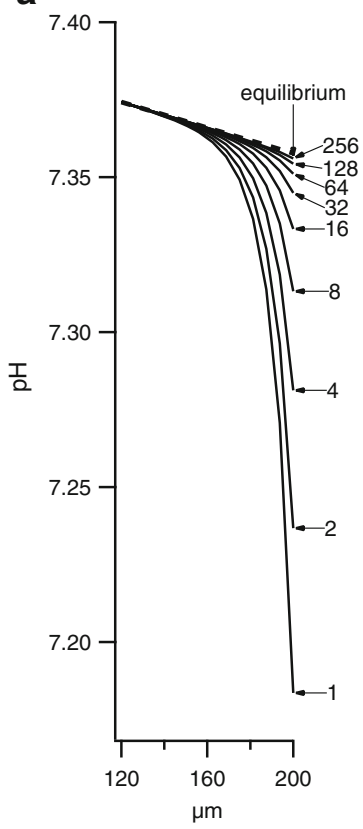

b

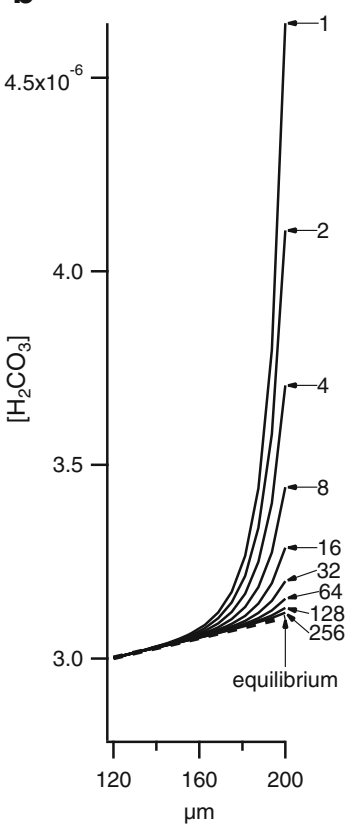

C

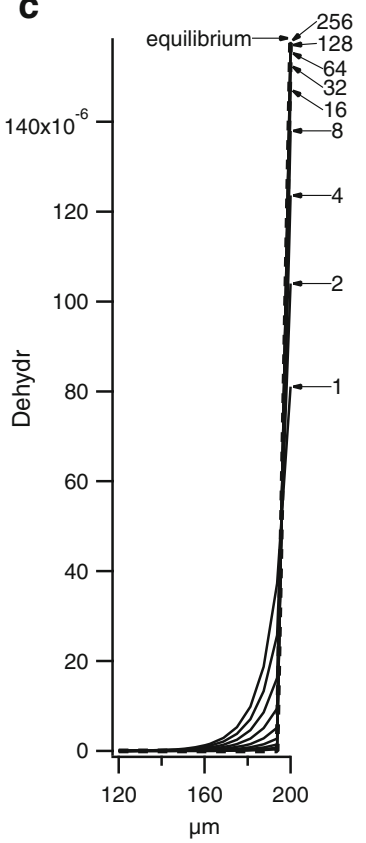

d

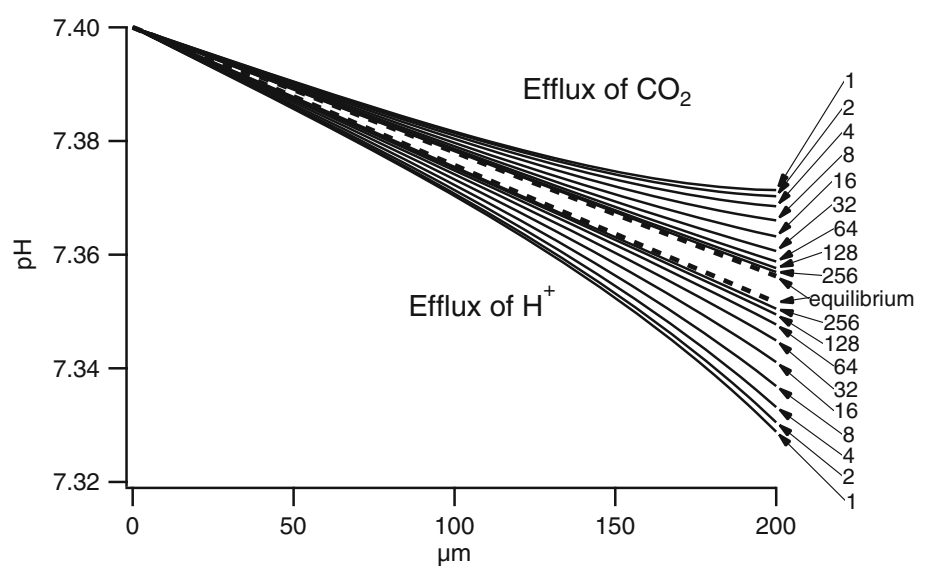

Fig. 7 Influence of the degree of catalysis of the Deh reaction. The unstirred layer was subdivided into 32 compartments. The Deh reaction was not catalyzed in compartments 1-31. The degree of catalysis in compartment $32\left(C_{a t a, N}\right)$ was varied from 1 (no catalysis) to 256, and finally infinite catalysis (equilibrium, dashed lines). The numbers besides the curves are $C_{a t a, N} \mathbf{a}, \mathbf{b}, \mathbf{c}$ The extracellular bulk solution was buffered with $25 \mathrm{mM}$ bicarbonate at $\mathrm{pH}$ 7.4. The graphs display $\mathrm{pH},\left[\mathrm{H}_{2} \mathrm{CO}_{3}\right]$ and the rate of the Deh reaction $\left(D_{\text {ehydr }, j}\right)$ versus the distance from the extracellular bulk compartment during a transmembrane proton flux of $-10^{-6}$ mole $\mathrm{m}^{-2} \mathrm{~s}^{-1}$. Only the simulation results from $120 \mu \mathrm{m}$ to $200 \mu \mathrm{m}$ (at cell membrane) are shown. d The extracellular bulk solution was buffered with $12.5 \mathrm{mM}$ bicarbonate and $5 \mathrm{mM}$ HEPES at $\mathrm{pH}$ 7.4. The graph displays $\mathrm{pH}$ versus the distance from the bulk compartment during a transmembrane flux $\left(-10^{-6}\right.$ mole $\left.\mathrm{m}^{-2} \mathrm{~s}^{-1}\right)$ of protons (lower curves) or $\mathrm{CO}_{2}$ (upper curves) 
concentrations of the acid and basic form of HEPES then change gradually as a function of the distance from the bulk.

\subsection{Importance of extracellular membrane-bound carbonic anhydrase}

To test the relative efficiency of catalysis of the Deh reaction in the different unstirred layer compartments, simulations were done whereby first the Deh reaction was not catalyzed; thereafter infinite catalysis (or equilibrium) of this reaction was chosen in gradually more compartments, starting from compartment 1 (Fig. 8). This was first simulated for a proton efflux $\left(-10^{-6}\right.$ mole $\left.\mathrm{m}^{-2} \mathrm{~s}^{-1}\right)$ with an extracellular bulk solution only buffered with $25 \mathrm{mM}$ bicarbonate at $\mathrm{pH} 7.4$ (Fig. 8a). In the absence of catalysis $\mathrm{pH}_{\mathrm{N}}$ was 7.184. Infinite catalysis in compartments 1 to 24, but not in the other compartments had very little effect. Catalysis in compartments $1-30$ had still only a minor effect $\left(\mathrm{pH}_{\mathrm{N}}=7.202\right)$. Catalysis in compartments 1-31 had already more effect $\left(\mathrm{pH}_{\mathrm{N}}=7.246\right)$, but catalysis in compartment $32(N)$ had by far most effect on $\mathrm{pH}_{\mathrm{N}}$ (7.358). Thus catalysis had most effect in the compartments closest to the cell membrane, because there the Deh reaction has to proceed more rapidly. Similar results were obtained for an efflux of $\mathrm{H}_{2} \mathrm{CO}_{3}$ and $\mathrm{HA}$ (and thus also lactic acid) in a bicarbonate buffered solution (results not shown).

In contrast, during a steady-state proton efflux in an extracellular solution buffered with $12.5 \mathrm{mM}$ bicarbonate and $5 \mathrm{mM}$ HEPES, the disequilibrium $\mathrm{pH}$ is extended to all unstirred layer compartments, so that catalysis of the Deh reaction in the compartments closer to the bulk solution also clearly influences $\mathrm{pH}_{\mathrm{N}}$ (Fig. 8b, lower curves). However, catalysis in compartments closer to the cell membrane has still more effect on $\mathrm{pH}_{\mathrm{N}}$. The same is true for an efflux of $\mathrm{CO}_{2}$ (Fig. 8b, upper curves), $\mathrm{H}_{2} \mathrm{CO}_{3}, \mathrm{HCO}_{3}{ }^{-}, \mathrm{CO}_{3}{ }^{2-}, \mathrm{HA}, \mathrm{A}, \mathrm{HB}$ and B (results not shown).

Infinite catalysis of the Deh reaction in unstirred layer compartment $N$ has the same effect on $\mathrm{pH}_{\mathrm{N}}$ as catalysis in the whole unstirred layer (Appendix), which shows the efficiency of the location of a membrane-bound CA with its catalytic site directed towards the outside of the cell. In addition, the simulation of Fig. 8a demonstrates that in a bicarbonate buffer catalysis in the unstirred layer compartments closest to the cell membrane is also more effective. This demonstrates that extracellular membrane-bound CA is located very strategically for reducing the $\mathrm{pH}$ gradient in the unstirred layer during an acid efflux in a bicarbonate buffer. By reducing the acidification in the extracellular unstirred layer next to the proton extrusion pump(s), extracellular membrane-bound CA should facilitate proton extrusion energetically and may protect the function of membrane proteins. This may explain why the extracellular membrane-bound CA IV has evolved to be more expressed in $\mathrm{H}^{+}$secreting cells and plays an important role in urinary acidification $[39,40]$. By reducing the extracellular acidification, extracellular membrane-bound CA also facilitates efflux of lactic acid [41]. Similarly, the intracellular membrane-bound CAII binds to and enhances activity of the $\mathrm{Na}^{+} / \mathrm{H}^{+}$exchanger [42].

\subsection{Influence of the size of the transmembrane proton flux on the disequilibrium $\mathrm{pH}$}

Figure 9a displays the influence of the size and direction of a clamped proton flux on the $\mathrm{pH}$ profile in an unstirred layer with 32 compartments, without catalysis of the Deh reaction (full lines) and with infinite catalysis of the Deh reaction only in the unstirred layer compartment closest to the cell membrane (dashed lines). The extracellular bulk solution was buffered with $25 \mathrm{mM}$ bicarbonate at $\mathrm{pH}$ 7.4. 

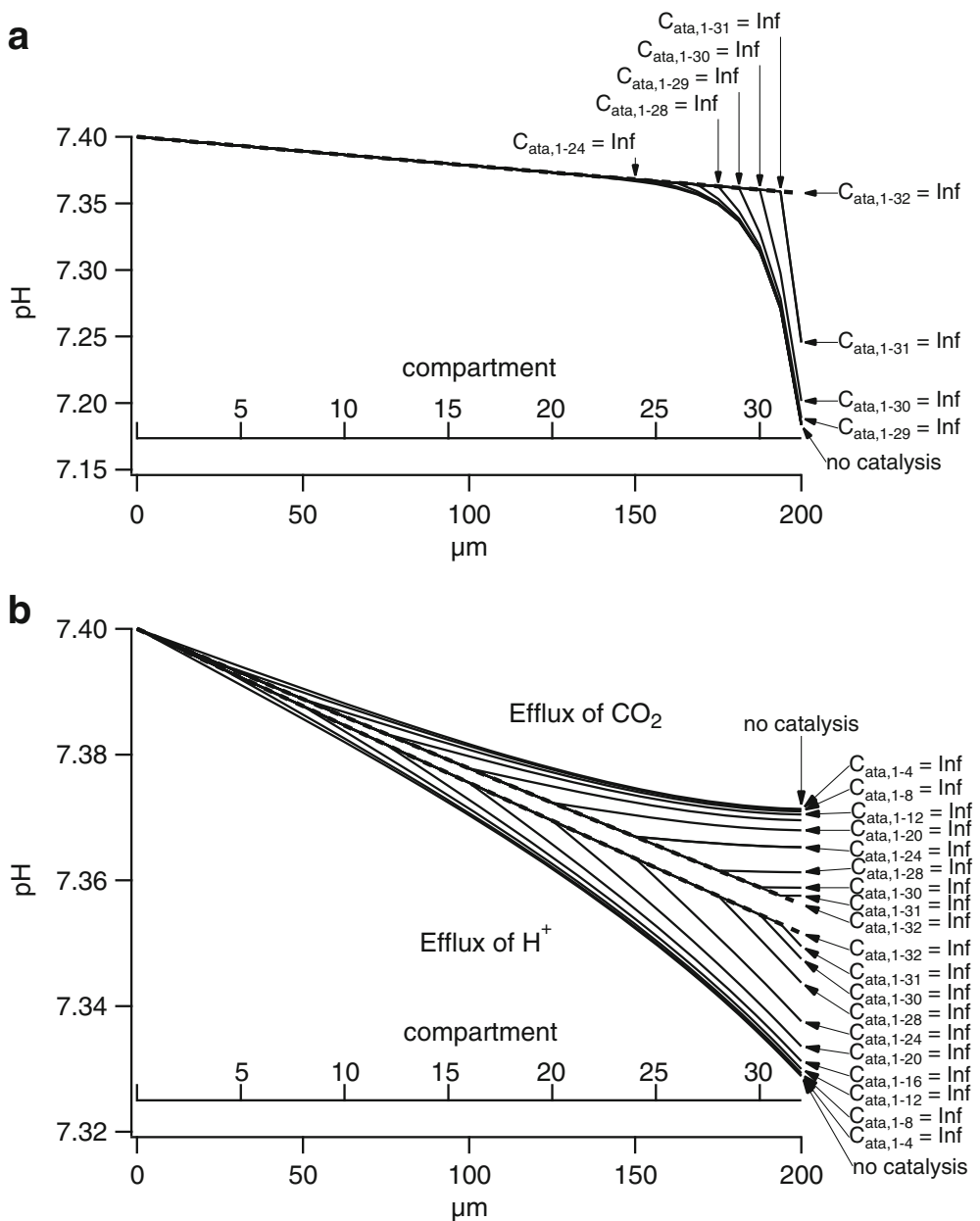

Fig. 8 Relative efficiency of membrane-bound carbonic anhydrase. The unstirred layer was subdivided into 32 compartments. The steady-state unstirred layer $\mathrm{pH}$ is displayed versus number of the unstirred layer compartment. At the bottom of the graph, a distance scale is also given from the extracellular bulk compartment to the cell membrane. a Extracellular bulk solution buffered with $25 \mathrm{mM}$ bicarbonate at $\mathrm{pH} 7.4$; clamped proton efflux $\left(-10^{6}\right.$ mole $\left.\mathrm{m}^{-2} \mathrm{~s}^{-1}\right)$. In this case, catalysis of the Deh reaction in compartments 1 to 24 has practically no effect. $C_{a t a, 1-31}=$ Inf: the Deh reaction is infinitely catalyzed in unstirred layer compartments 1 to 31 , but not catalyzed in compartment 32. $C_{a t a, 1-32}=$ Inf: infinite catalysis in all unstirred layer compartments (dashed line). Catalysis of the Deh reaction in compartment 32 (closest to the cell membrane) has by far the largest effect on $\mathrm{pH}_{\mathrm{N}}$. b Extracellular bulk solution buffered with $12.5 \mathrm{mM}$ bicarbonate and $5 \mathrm{mM}$ HEPES at $\mathrm{pH} 7.4$; clamped efflux $\left(-10^{-6}\right.$ mole $\left.\mathrm{m}^{-2} \mathrm{~s}^{-1}\right)$ of protons (lower curves) or $\mathrm{CO}_{2}$ (upper curves). In this case, catalysis of the Deh reaction in the unstirred layer compartments closer to the bulk compartment also influences $\mathrm{pH}_{\mathrm{N}}$

A small proton influx into the membrane $\left(10^{-6}\right.$ mole $\left.\mathrm{m}^{-2} \mathrm{~s}^{-1}\right)$ has about the opposite effect on the unstirred layer $\mathrm{pH}$ to that of a proton efflux of the same absolute size $\left(-10^{-6}\right.$ mole $\mathrm{m}^{-2} \mathrm{~s}^{-1}$ ). However, a large proton influx of $10^{-5}$ mole $\mathrm{m}^{-2} \mathrm{~s}^{-1}$ changes the unstirred layer $\mathrm{pH}$ much more than an efflux of $-10^{-5}$ mole $\mathrm{m}^{-2} \mathrm{~s}^{-1}$. When the Deh reaction is 
a

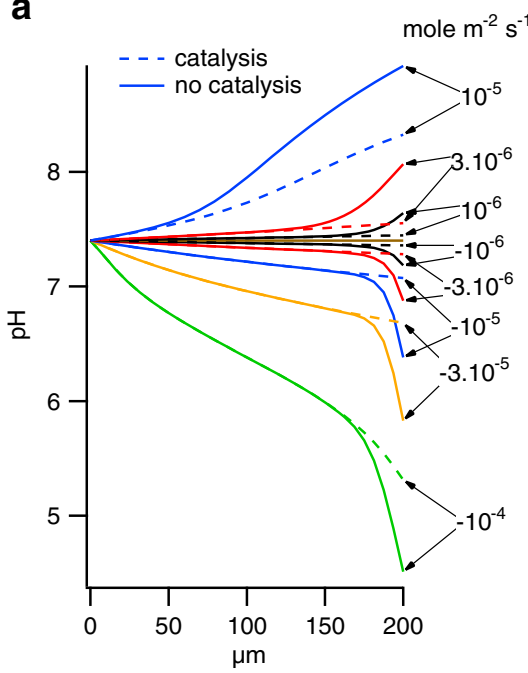

b mole $\mathrm{m}^{-2} \mathrm{~s}^{-1}$

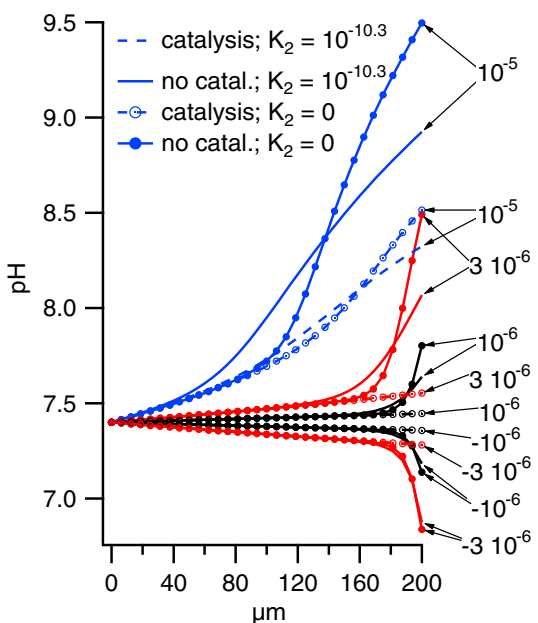

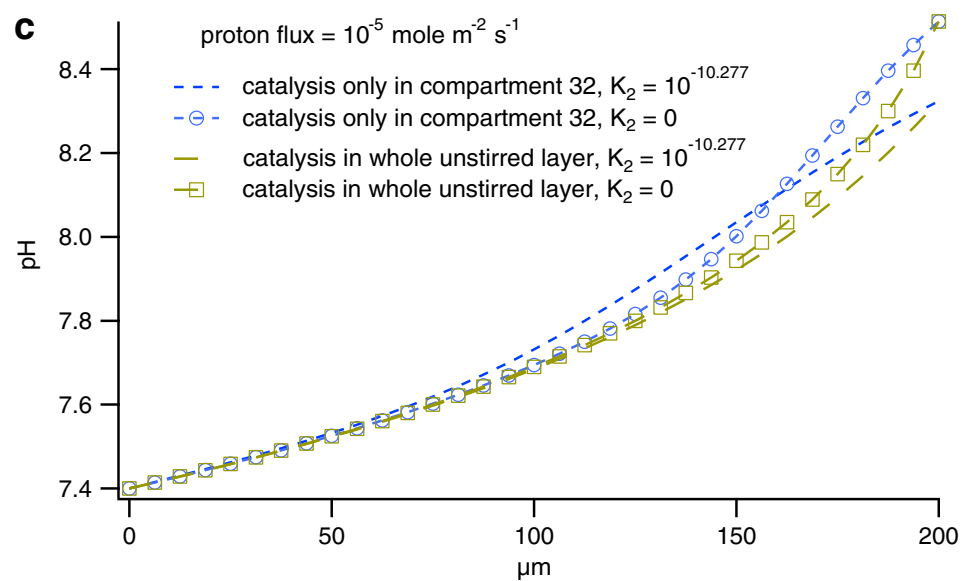

Fig. 9 Influence of size of clamped transmembrane proton flux and inclusion of second dissociation reaction of carbonic acid. The extracellular bulk solution was buffered with $25 \mathrm{mM}$ bicarbonate at $\mathrm{pH} 7.4$. The unstirred layer was subdivided into 32 compartments. The unstirred layer $\mathrm{pH}$ is plotted versus the distance from the extracellular bulk compartment. a Influence of size of the clamped transmembrane proton flux and catalysis on the steady-state $\mathrm{pH}$ in the unstirred layer. A proton influx (positive flux) increases the unstirred layer $\mathrm{pH}$ and a proton efflux (negative flux) decreases it. The size of the flux is indicated besides the graph. Full lines: no catalysis of the Deh reaction. Dashed lines infinite catalysis in compartment $32(N)$. b Influence of inclusion of the second dissociation reaction of carbonic acid in the equations. Full circles: second dissociation is neglected $\left(K_{2}=0\right)$ without catalysis of the Deh reaction. Empty circles: second dissociation is neglected with infinite catalysis of the Deh reaction in compartment 32 . The second dissociation of carbonic acid is included when $K_{2}=10^{-10.277}$. c Influence of infinite catalysis in the whole unstirred layer versus only in compartment $N$ closest to the cell membrane and of inclusion of the second dissociation reaction of carbonic acid. The clamped proton flux is $10^{-5}$ mole $\mathrm{m}^{-2} \mathrm{~s}^{-1}$. The second dissociation is included and simultaneously the Deh reaction is infinitely catalyzed in all unstirred layer compartments (long dashes) or only in compartment $N$ (short dashes). The second dissociation is not included and simultaneously the Deh reaction is catalyzed in all unstirred layer compartments (empty squares) or only in compartment $N$ (empty circles) 
in equilibrium, the proton transport capacity of the unstirred layer equals $F_{2}$ (29c). At the higher unstirred layer $\mathrm{pH}$ with a large proton influx the proton transport capacity of the bicarbonate buffer is smaller (Table 5, second column), which results in a larger $\mathrm{pH}$ gradient (29a) than with the proton efflux of $-10^{-5}$ mole $\mathrm{m}^{-2} \mathrm{~s}^{-1}$.

In addition, when the Deh reaction is not catalyzed, the $\mathrm{pH}$ disequilibrium is spread over a much larger distance in the unstirred layer with the large proton influx $\left(10^{-5}\right.$ mole $\left.\mathrm{m}^{-2} \mathrm{~s}^{-1}\right)$ than with the proton efflux $\left(-10^{-5}\right.$ mole $\left.\mathrm{m}^{-2} \mathrm{~s}^{-1}\right)$. This is because, in the compartments with a higher $\mathrm{pH}$ during the large proton influx, there is a larger proton transport by the $\mathrm{CO}_{3}{ }^{2-} / \mathrm{HCO}_{3}{ }^{-}$and $\mathrm{OH}^{-} / \mathrm{H}_{2} \mathrm{O}$ shuttles from these compartments towards the membrane, which induces a proton sink in these compartments, draws the reactions in the direction $\mathrm{H}^{+}+\mathrm{HCO}_{3}{ }^{-} \leftarrow \mathrm{H}_{2} \mathrm{CO}_{3} \leftarrow \mathrm{CO}_{2}+\mathrm{H}_{2} \mathrm{O}$ and induces a disequilibrium $\mathrm{pH}$. The proton transport by the $\mathrm{CO}_{3}{ }^{2-} / \mathrm{HCO}_{3}{ }^{-}$and $\mathrm{OH}^{-} / \mathrm{H}_{2} \mathrm{O}$ shuttles (which do not need the Deh reaction) extends thus the more alkaline disequilibrium $\mathrm{pH}$ to compartments farther from the cell membrane, similarly to the effect of HEPES on the spread of the disequilibrium $\mathrm{pH}$, compare Fig. 4a with Fig. 4b. This effect of the $\mathrm{CO}_{3}{ }^{2-} / \mathrm{HCO}_{3}{ }^{-}$and $\mathrm{OH}^{-} / \mathrm{H}_{2} \mathrm{O}$ shuttles decreases closer to the extracellular bulk compartment where the $\mathrm{pH}$ is less alkaline.

\subsection{Importance of including the second dissociation reaction of carbonic acid} in the models

In most articles with $\mathrm{pH}$ models the second dissociation reaction of carbonic acid $\left(\mathrm{HCO}_{3}{ }^{-} \leftrightarrows \mathrm{CO}_{3}{ }^{2-}+\mathrm{H}^{+}\right)$is neglected at physiological $\mathrm{pH}$. To estimate the error made by this simplification one can either use the correct value of its dissociation constant $K_{2}\left(10^{-10.277}\right)$ or replace its value by 0 , which corresponds to neglecting the second

Table 5 Proton transport capacity of a bicarbonate buffer

\begin{tabular}{lllllllr}
\hline $\mathrm{pH}$ & \multicolumn{2}{l}{ Deh reaction in equilibrium } & & \multicolumn{3}{l}{ Deh reaction not included } \\
\cline { 2 - 3 } & $K_{2}=10^{-10.277}$ & $K_{2}=0$ & Ratio & & $K_{2}=10^{-10.277}$ & $K_{2}=0$ & Ratio \\
\hline 6.00 & $6.16 \mathrm{E}-10$ & $6.16 \mathrm{E}-10$ & 1.00 & & $6.59 \mathrm{E}-12$ & $6.54 \mathrm{E}-12$ & 1.01 \\
6.50 & $6.22 \mathrm{E}-10$ & $6.22 \mathrm{E}-10$ & 1.00 & & $2.23 \mathrm{E}-12$ & $2.08 \mathrm{E}-12$ & 1.08 \\
7.00 & $3.53 \mathrm{E}-10$ & $3.52 \mathrm{E}-10$ & 1.00 & & $1.16 \mathrm{E}-12$ & $6.58 \mathrm{E}-13$ & 1.76 \\
7.40 & $1.72 \mathrm{E}-10$ & $1.71 \mathrm{E}-10$ & 1.01 & & $1.51 \mathrm{E}-12$ & $2.62 \mathrm{E}-13$ & 5.78 \\
8.00 & $5.28 \mathrm{E}-11$ & $4.79 \mathrm{E}-11$ & 1.10 & & $5.02 \mathrm{E}-12$ & $6.58 \mathrm{E}-14$ & 76.24 \\
8.50 & $3.09 \mathrm{E}-11$ & $1.55 \mathrm{E}-11$ & 1.99 & & $1.54 \mathrm{E}-11$ & $2.08 \mathrm{E}-14$ & 740.92 \\
9.00 & $5.11 \mathrm{E}-11$ & $4.95 \mathrm{E}-12$ & 10.32 & & $4.62 \mathrm{E}-11$ & $6.58 \mathrm{E}-15$ & 7027.48 \\
\hline
\end{tabular}

The first column is the unstirred layer $\mathrm{pH}$. The second column gives the contribution of the bicarbonate buffer to the unstirred layer proton transport capacity (see $(29 \mathrm{c})$ ), divided by $\left[T_{H 2 C}\right]$ and has the same dimension as a diffusion coefficient (in $\mathrm{m}^{2} \mathrm{~s}^{-1}$ ). The third column is the same, except that the second dissociation reaction of carbonic acid is not included $\left(K_{2}=0\right)$. The fourth column gives the ratio between the latter columns. The fifth column is the proton transport capacity of the $\mathrm{H}_{2} \mathrm{CO}_{3} / \mathrm{HCO}_{3}{ }^{-} / \mathrm{CO}_{3}{ }^{2-}$ buffer, divided by $\left[T_{\mathrm{H}_{2} \mathrm{CO} 3}\right]$ without the Deh reaction. This is calculated in the same way as the second column, except that here $K_{1}\left(=10^{-3.456}\right)$ is used as first dissociation constant instead of $K_{1}^{\prime}\left(=10^{-6.12}\right)$, to exclude the Deh reaction. The sixth column is the same, except that also the second dissociation reaction of carbonic acid is not included. The seventh column is the ratio of the fifth to the sixth column. The proton transport capacity of a bicarbonate buffer decreases at higher $\mathrm{pH}$ if the Deh reaction is in equilibrium. If the second dissociation reaction of carbonic acid is not included, the proton transport capacity of the bicarbonate buffer decreases more at higher $\mathrm{pH}$. This effect is much more pronounced if the Deh reaction is completely inactive than if the Deh reaction is in equilibrium (compare seventh to fourth column) 
dissociation of carbonic acid. This was tested for the same range of transmembrane fluxes as that displayed in Fig. 9a. The curves in which the second dissociation of carbonic acid was neglected are indicated with empty circles (infinite catalysis of the Deh reaction in compartment $N$ ) or with full circles (no catalysis), see Fig. 9b. With a $+10^{-5}$ mole $\mathrm{m}^{-2} \mathrm{~s}^{-1}$ proton flux and no catalysis, $\mathrm{pH}_{\mathrm{N}}$ is clearly lower if the second dissociation is included (compare curve with full line to curve with full circles). This is because then the $\mathrm{CO}_{3}{ }^{2-} / \mathrm{HCO}_{3}{ }^{-}$shuttle contributes to the proton transport and decreases the load to the Deh reaction and the corresponding disequilibrium $\mathrm{pH}$ closer to the cell membrane. However, the proton transport by the $\mathrm{CO}_{3}{ }^{2-} / \mathrm{HCO}_{3}{ }^{-}$shuttle simultaneously draws protons from the compartments farther from the cell membrane, for example around $120 \mu \mathrm{m}$, and thus extends the $\mathrm{pH}$ disequilibrium to these compartments. This is not the case if the second dissociation is not included (curve with full circles). This explains the marked effect of the second dissociation reaction on the shape of the $\mathrm{pH}$ profile in the absence of catalysis. When the second dissociation reaction is not included, the larger spread of the disequilibrium $\mathrm{pH}$ with the $+10^{-5}$ mole $\mathrm{m}^{-2} \mathrm{~s}^{-1}$ proton flux (than with $310^{-6}$ or $10^{-6}$ mole $\mathrm{m}^{-2} \mathrm{~s}^{-1}$ fluxes) is mainly due to the proton transport by the $\mathrm{OH}^{-} / \mathrm{H}_{2} \mathrm{O}$ shuttle.

Figure $9 \mathrm{~b}$ also illustrates that the error by not including the second dissociation becomes smaller when $\mathrm{pH}_{\mathrm{N}}$ is lower and the proton fluxes are less positive or more negative. This is because then the carbonate concentration is smaller and thus also its effect on the proton transport capacity (Table 5, (29c)).

The error by neglecting the second dissociation reaction of carbonic acid was much larger when the Deh reaction was not catalyzed than when it was catalyzed (Fig. 9b). To understand this one can consider the extreme case that the Deh reaction is completely inactive. Then the proton transport capacity by the bicarbonate buffer is much more influenced by inclusion of the second dissociation reaction than when the Deh reaction is in equilibrium (Table 5). If only the uncatalyzed Deh reaction is active, the sensitivity to inclusion of the second dissociation is intermediate between these two cases. When the Deh reaction is infinitely catalyzed, the error by neglecting the second dissociation of carbonic acid is still clearly visible in the $\mathrm{pH}$ profile with the $+10^{-5}$ mole $\mathrm{m}^{-2} \mathrm{~s}^{-1}$ proton flux, but the error is negligible with the other fluxes $\left(310^{-6}, 10^{-6},-10^{-6},-310^{-6},-10^{-5},-310^{-5}\right.$, $-10^{-4}$ mole $\mathrm{m}^{-2} \mathrm{~s}^{-1}$ ). However, when the Deh reaction is not catalyzed, there is a visible error with the fluxes $10^{-5}, 310^{-6}, 10^{-6},-10^{-6},-310^{-6}$ mole $\mathrm{m}^{-2} \mathrm{~s}^{-1}$ (Fig. 9b), and this error occurs also within the physiological $\mathrm{pH}$ range.

If the second dissociation is included, the proton transport capacity of the bicarbonate buffer is larger (Table 5). Then (29a) predicts that the slope of the steady-state pH-profile is smaller all over the unstirred layer, on the condition that the Deh reaction is infinitely catalyzed in all unstirred layer compartments (compare curves with empty squares and long dashes in Fig. 9c). However, if the Deh reaction is only catalyzed in compartment $N$, the disequilibrium $\mathrm{pH}$ in compartments 1 to $N-1$ makes that the slope of the $\mathrm{pH}$ profile is not necessarily smaller all over the unstirred layer when the second dissociation reaction is included (compare curves with empty circles and short dashes). Figure 9c also illustrates that, if the Deh reaction is infinitely catalyzed in compartment $N, \mathrm{pH}_{\mathrm{N}}$ is not influenced by catalysis in the other unstirred layer compartments (see Appendix).

Similar conclusions can be drawn from simulations of transient changes in unstirred layer $\mathrm{pH}$ e.g., after addition of propionate to a bulk solution buffered with $25 \mathrm{mM}$ bicarbonate at $\mathrm{pH} 7.4$ (results not shown). Although these transients are more complex than the steady state, the principles determining the steady-state $\mathrm{pH}_{\mathrm{N}}$ also influence the amplitude of the unstirred layer $\mathrm{pH}$ transients. When only a two-compartment model without unstirred layer 
is used and transients changes of the intracellular $\mathrm{pH}$ are simulated, the error by not including the second dissociation is small, because the large intrinsic buffer capacity of the cell decreases the relative contribution of the bicarbonate buffer to the total intracellular buffer capacity. However, if also the $\mathrm{pH}$ of a bicarbonate buffered extracellular unstirred layer is simulated, it is better to include the second dissociation reaction of $\mathrm{H}_{2} \mathrm{CO}_{3}$ if the Deh reaction is little or not catalyzed. The relative error by not including it decreases if a non-bicarbonate buffer is added (results not shown).

\subsection{Influence of a rapid addition of acid to the unstirred layer}

Figure 10 displays the time course of the initial changes in $\mathrm{pH},\left[\mathrm{H}_{2} \mathrm{CO}_{3}\right]$ and rate of the Deh reaction in compartment $32(N)$ after starting a proton efflux of $-10^{-6}$ mole m$^{-2} \mathrm{~s}^{-1}$. The extracellular bulk compartment was buffered with $25 \mathrm{mM}$ bicarbonate at $\mathrm{pH}$ 7.4. The proton efflux shifts the reactions $2 \mathrm{H}^{+}+\mathrm{CO}_{3}{ }^{2-} \rightarrow \mathrm{H}^{+}+\mathrm{HCO}_{3}{ }^{-} \rightarrow \mathrm{H}_{2} \mathrm{CO}_{3} \rightarrow$ $\mathrm{CO}_{2}+\mathrm{H}_{2} \mathrm{O}$ to the right, increases $\left[\mathrm{H}_{2} \mathrm{CO}_{3}\right]$, accelerates the Deh reaction and lowers the $\mathrm{pH}$ in compartment 32. There was little difference in $\mathrm{pH}_{\mathrm{N}}$ and $\left[\mathrm{H}_{2} \mathrm{CO}_{3}\right]_{N}$ between infinite catalysis (equilibrium) and a degree of catalysis of 256 after $1 \mathrm{~s}$ of proton efflux (Fig. 10a, b, c) or in steady state (Fig. 7a, b, c). However, during the first millisecond

a

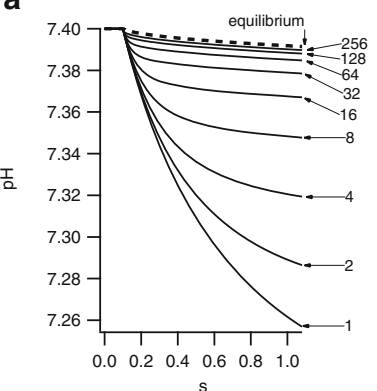

d

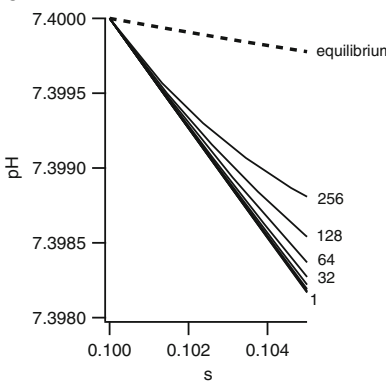

b

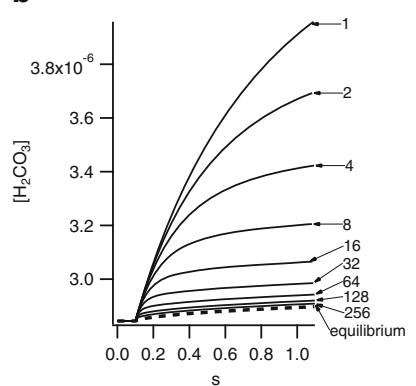

e

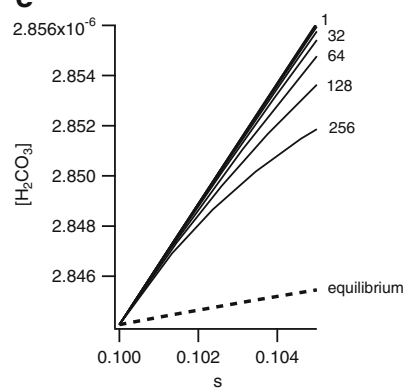

C

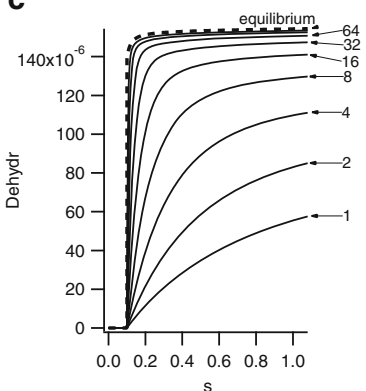

f

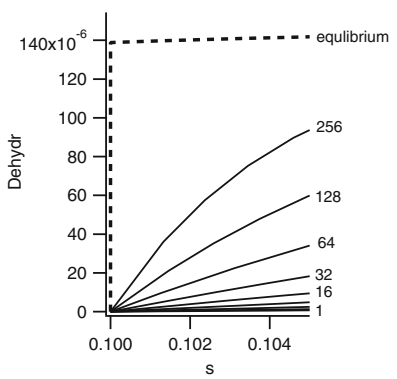

Fig. 10 Influence of a rapid addition of acid to the unstirred layer. The unstirred layer was subdivided into 32 compartments. The Deh reaction was not catalyzed in compartments 1-31. The degree of catalysis in compartment $32\left(C_{a t a, N}\right)$ was varied from 1 (no catalysis) to 256, and finally infinite catalysis (equilibrium, dashed lines). The numbers besides the curves are $C_{a t a, N}$. The extracellular bulk solution was buffered with $25 \mathrm{mM}$ bicarbonate at $\mathrm{pH}$ 7.4. Starting from $0.1 \mathrm{~s}$ there was a transmembrane proton efflux of $-10^{-6}$ mole $\mathrm{m}^{-2} \mathrm{~s}^{-1}$. a, b, c The graphs display $\mathrm{pH},\left[\mathrm{H}_{2} \mathrm{CO}_{3}\right]$ and the rate of the Deh reaction in compartment 32; d, e, f The same simulations are displayed during the first $5 \mathrm{~ms}$ of proton efflux 
of proton efflux $\mathrm{pH}_{\mathrm{N}},\left[\mathrm{H}_{2} \mathrm{CO}_{3}\right]_{N}$ and the rate of the Deh reaction with infinite catalysis were clearly separated from that with a degree of catalysis of 256, and there was little difference in $\left[\mathrm{H}_{2} \mathrm{CO}_{3}\right]_{N}$ between a degree of catalysis of 1 and 256 (Fig. 10d, e, f). This indicates that only a small fraction of the $\mathrm{H}_{2} \mathrm{CO}_{3}$, generated by the proton efflux, was converted to $\mathrm{CO}_{2}$ by the Deh reaction with this degree of catalysis within $1 \mathrm{~ms}$. Even without catalysis $\mathrm{pH}_{\mathrm{N}}$ was decreased by only $0.0004 \mathrm{pH}$ units after $1 \mathrm{~ms}$. The diffusion to the bulk compartment limits this decrease in $\mathrm{pH}$. If there was no diffusion between the unstirred layer and the bulk and if the unstirred layer had the same thickness as the width of a synaptic cleft $(20 \mathrm{~nm})$, the same proton efflux would decrease $\mathrm{pH}_{\mathrm{N}}$ within $1 \mathrm{~ms}$ already by 0.118 or $0.106 \mathrm{pH}$ units with a degree of catalysis of 1 or 256, respectively and by $0.015 \mathrm{pH}$ units with infinite catalysis. Such simulations could be done to estimate the acidification of the extracellular side of the cell membrane by vesicle fusion during synaptic transmission [15]. However, then a correct geometry of the compartments, buffering and a simultaneous efflux of the different acid-base components of the synaptic vesicles has to be used.

\subsection{Simulation of transient $\mathrm{pH}$ changes with the multicompartment model}

In the following simulations transient changes will be studied and the transmembrane fluxes are not clamped but determined by $\mathrm{pH}$ and concentrations in the bulk solution, membrane permeability of solutes, membrane potential, an acid extrusion mechanism, metabolic production of $\mathrm{CO}_{2}$ and the Deh reaction.

If one uses a model consisting of a stirred extracellular bulk solution, a flat unstirred layer $(d=200 \mu \mathrm{m})$ and only one layer of cells, then the simulated difference $\left(\mathrm{pH}_{\mathrm{N}}-\right.$ $\mathrm{pH}_{0}$ ) induced by metabolic production of $\mathrm{CO}_{2}$ or by addition of a salt of a weak acid like propionate is very small. In contrast, the observed difference between the surface $\mathrm{pH}$ of a multicellular muscle fiber and the bulk $\mathrm{pH}$, due to metabolic production [17] or addition of propionate $[12,14]$, is larger because the total surface area of the cells is then much larger than that of the outer surface of the unstirred layer in contact with the bulk. The geometry of the multicompartment model, described in this paper, is not complex enough to simulate precisely the surface $\mathrm{pH}$ of a multicellular preparation with its intercellular spaces. To study some aspects of the relationship between $\mathrm{pH}_{\mathrm{N}}$ transients and transmembrane fluxes with this simplified multicompartment model, the unstirred layer was subdivided into 16 compartments (Fig. 11). The following values were used for the surface to volume ratios (in $\mathrm{m}^{-1}$ ) of compartment $(j) 1$ to $15: \rho_{p, j}=810^{4}$ and $\rho_{n, j}=810^{4}$ (which results in a parallel unstirred layer); $\rho_{p, 16}=810^{4}$ but $\rho_{n, 16}$ is increased to $6.410^{6}$ to augment the surface area of cell membrane and thus obtain a larger effect of metabolic production of $\mathrm{CO}_{2}$ and transmembrane fluxes on $\left(\mathrm{pH}_{\mathrm{N}}-\mathrm{pH}_{0}\right)$, as in a multicellular preparation. The surface to volume ratio of the intracellular compartment $\left(\rho_{p, 17}\right)$ was $810^{5}$. The Deh reaction was not catalyzed in the unstirred layer, except during the period indicated with a thick horizontal bar, during which the Deh reaction was infinitely catalyzed in compartment $16(N)$. The intracellular Deh reaction was infinitely catalyzed.

The metabolic production of $\mathrm{CO}_{2}\left(8.310^{-6} \mathrm{M} \mathrm{s}^{-1}\right)$ makes that the starting steady-state $\mathrm{pH}_{\mathrm{N}}$ is lower than the bulk $\mathrm{pH}$ by a net cellular efflux of $\mathrm{CO}_{2}$ into the unstirred layer [17]. In addition, the efflux of bicarbonate, driven by the negative membrane potential $(-80 \mathrm{mV})$, and a proton efflux by the $\left(\mathrm{pH}_{0}\right.$ and $\mathrm{pH}_{\mathrm{i}}$ dependent) proton extrusion pump produces $\mathrm{H}_{2} \mathrm{CO}_{3}$ in the unstirred layer. This induces a disequilibrium $\mathrm{pH}$ in the absence of catalysis of the Deh reaction, and further lowers the steady-state $\mathrm{pH}$ in the unstirred layer. 

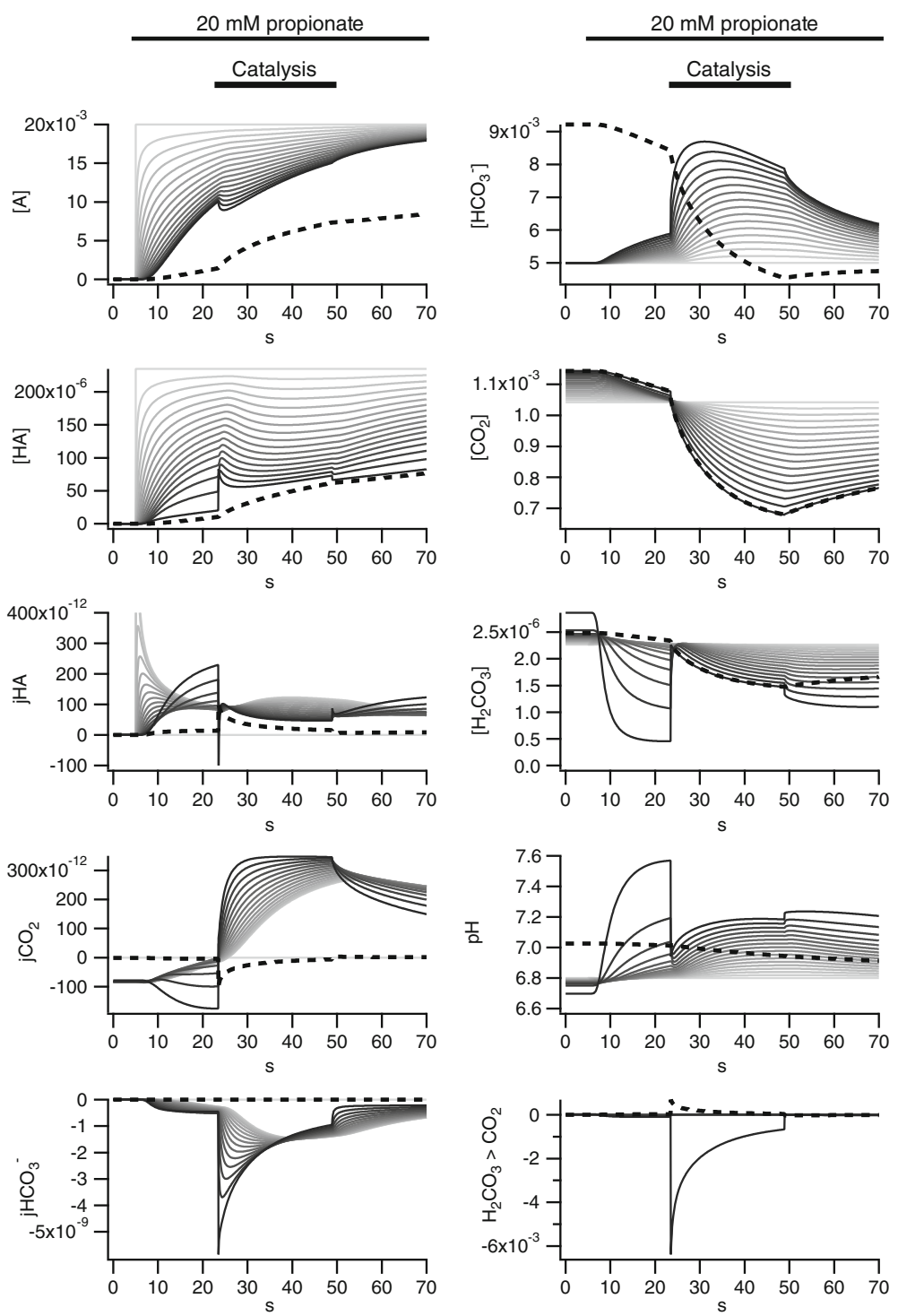

Fig. 11 Transient changes after addition of an anion of a weak acid. The extracellular bulk solution was buffered with $5 \mathrm{mM}$ bicarbonate at $\mathrm{pH}$ 6.8. Twenty $\mathrm{mM} \mathrm{Cl}^{-}$was replaced by $20 \mathrm{mM}$ propionate (A) in the bulk solution, as indicated with a horizontal line. The unstirred layer was subdivided into 16 compartments. The Deh reaction was not catalyzed in the unstirred layer, except during a period indicated with the thick horizontal line, wherein the Deh reaction was catalyzed infinitely in compartment $16(N)$. The Deh reaction was infinitely catalyzed (in equilibrium) in the intracellular compartment. The graphs display the time course of $[\mathrm{A}],[\mathrm{HA}],\left[\mathrm{HCO}_{3}^{-}\right],\left[\mathrm{CO}_{2}\right],\left[\mathrm{H}_{2} \mathrm{CO}_{3}\right], \mathrm{pH}$, the fluxes $j_{\mathrm{HA}}, j_{\mathrm{CO}}, j_{\mathrm{HCO}}$ and the rate of the Deh reaction in all compartments during the first $70 \mathrm{~s}$ of the simulation. The darker-grey color corresponds to a higher compartment number. The dashed curves represent the time course of the intracellular concentrations or $\mathrm{pH}$, fluxes through the cell membrane or the time rate of the intracellular Deh reaction 
The simulation illustrates the initial transients induced by the replacement of $20 \mathrm{mM}$ $\mathrm{Cl}^{-}$by $20 \mathrm{mM}$ of an anion of a weak acid (for example propionate, $K_{H A}=10^{-4.87}$ ) in a bulk solution buffered with $5 \mathrm{mM}$ bicarbonate at $\mathrm{pH}$ 6.8. The cell membrane is much more permeable to the uncharged propionic acid (HA) than to propionate (A). Influx of $\mathrm{HA}$ into the cell drives the reaction $\mathrm{H}^{+}+\mathrm{A}^{-} \rightarrow \mathrm{HA}$ to the right in compartment $N$ and the disappearing protons are partly replenished by the reactions $\mathrm{CO}_{2}+\mathrm{H}_{2} \mathrm{O} \rightarrow \mathrm{H}_{2} \mathrm{CO}_{3} \rightarrow$ $\mathrm{HCO}_{3}{ }^{-}+\mathrm{H}^{+} \rightarrow \mathrm{CO}_{3}{ }^{2-}+2 \mathrm{H}^{+}$and by the intrinsic unstirred layer buffer capacity, and $\mathrm{pH}_{\mathrm{N}}$ increases initially. After arrival in the cell most of $\mathrm{HA}$ dissociates to $\mathrm{A}^{-}$and $\mathrm{H}^{+}$. These protons bind partly to the intrinsic intracellular buffer and to the intracellular bicarbonate and carbonate, which decreases the intracellular $\mathrm{pH}$ and drives the following reactions to the left in the cell: $\mathrm{CO}_{2}+\mathrm{H}_{2} \mathrm{O} \leftarrow \mathrm{H}_{2} \mathrm{CO}_{3} \leftarrow \mathrm{HCO}_{3}{ }^{-}+\mathrm{H}^{+} \leftarrow \mathrm{CO}_{3}{ }^{2-}+2 \mathrm{H}^{+}$. The intracellular acidification, together with the increase in extracellular $\mathrm{pH}$, increases the activity of the proton extrusion pump $[2,7,43]$. Interestingly, although the above reaction produces $\mathrm{CO}_{2}$ in the cell, the intracellular $\mathrm{CO}_{2}$ concentration decreases. This is due to an efflux $\mathrm{CO}_{2}$ from the cell, as a consequence of the large sink in $\left[\mathrm{CO}_{2}\right]$ in the unstirred layer: because the small intrinsic unstirred layer buffer capacity cannot give off much protons, most of the protons needed there for the formation of $\mathrm{HA}$ come from $\mathrm{H}_{2} \mathrm{CO}_{3} / \mathrm{CO}_{2}$ and the bicarbonate $/ \mathrm{CO}_{2}$ shuttle, which decreases $\left[\mathrm{CO}_{2}\right]_{N}$. In the absence of catalysis of the Deh reaction the transmembrane fluxes (mainly the influx of $\mathrm{HA}$ ) generate a clear disequilibrium $\mathrm{pH}$ in the unstirred layer compartments closest to the cell membrane with a pronounced decrease in $\left[\mathrm{H}_{2} \mathrm{CO}_{3}\right]_{N}$ and only a slow decrease of $\left[\mathrm{CO}_{2}\right]_{N}$. When the Deh reaction is switched to infinite catalysis in compartment $\mathrm{N}$, the disequilibrium $\mathrm{pH}$ disappears and $\mathrm{pH}_{\mathrm{N}}$ becomes less alkaline. Consequently $[\mathrm{HA}]_{N}$ and the influx of HA increase again and the unstirred layer and intracellular $\left[\mathrm{CO}_{2}\right]$ decrease more rapidly. The opposite happens when catalysis of the Deh reaction is switched off again.

The addition of $\mathrm{A}$ in the bulk solution thus caused an initial influx of HA into the cell, which generated secondary transmembrane fluxes of e.g., $\mathrm{CO}_{2}, \mathrm{H}_{2} \mathrm{CO}_{3}$ and protons, and all these fluxes influence the intracellular and unstirred layer $\mathrm{pH}$ simultaneously.

\subsection{Interpretation of the amplitude of the unstirred layer $\mathrm{pH}$ transients}

In the next simulations the following questions were addressed: 1) Can the principles, analyzed in the steady-state flux clamp simulations, also help in the explanation of the amplitude of $\mathrm{pH}_{\mathrm{N}}$ transients? 2) What is the influence of the total buffer capacity of the unstirred layer (of mobile + immobile buffers) and the buffer capacity of the immobile buffers alone on the amplitude of the unstirred layer transients?

Figure 12 displays the transient changes in simulated unstirred layer and intracellular $\mathrm{pH}$ after replacement of $20 \mathrm{mM} \mathrm{Cl}^{-}$by $20 \mathrm{mM}$ propionate at constant $\mathrm{pH}_{0} 6.8$ in an extracellular bulk solution buffered with $5 \mathrm{mM}$ bicarbonate, and after returning to the original solution. The unstirred layer was subdivided into 16 compartments. The same surface to volume ratios were used as in Fig. 11.

To test the relationship between the transmembrane fluxes and $\mathrm{pH}_{N}$ the transmembrane fluxes were saved at different time points (full circles). After the simulation the steadystate $\mathrm{pH}_{\mathrm{N}}$ was calculated with the multicompartment model in flux clamp mode using the transmembrane fluxes saved at these time points and the same parameters $\left(\mathrm{pH}_{\mathrm{NSF}}\right.$, full circles). If the difference $\left(\mathrm{pH}_{\mathrm{NSF}}-\mathrm{pH}_{0}\right)$ is larger and the used parameters and extracellular bulk solution remain the same, a higher steady-state $\mathrm{pH}$ difference is needed to transport these acids and bases through the unstirred layer and thus the 'net transmembrane influx of 

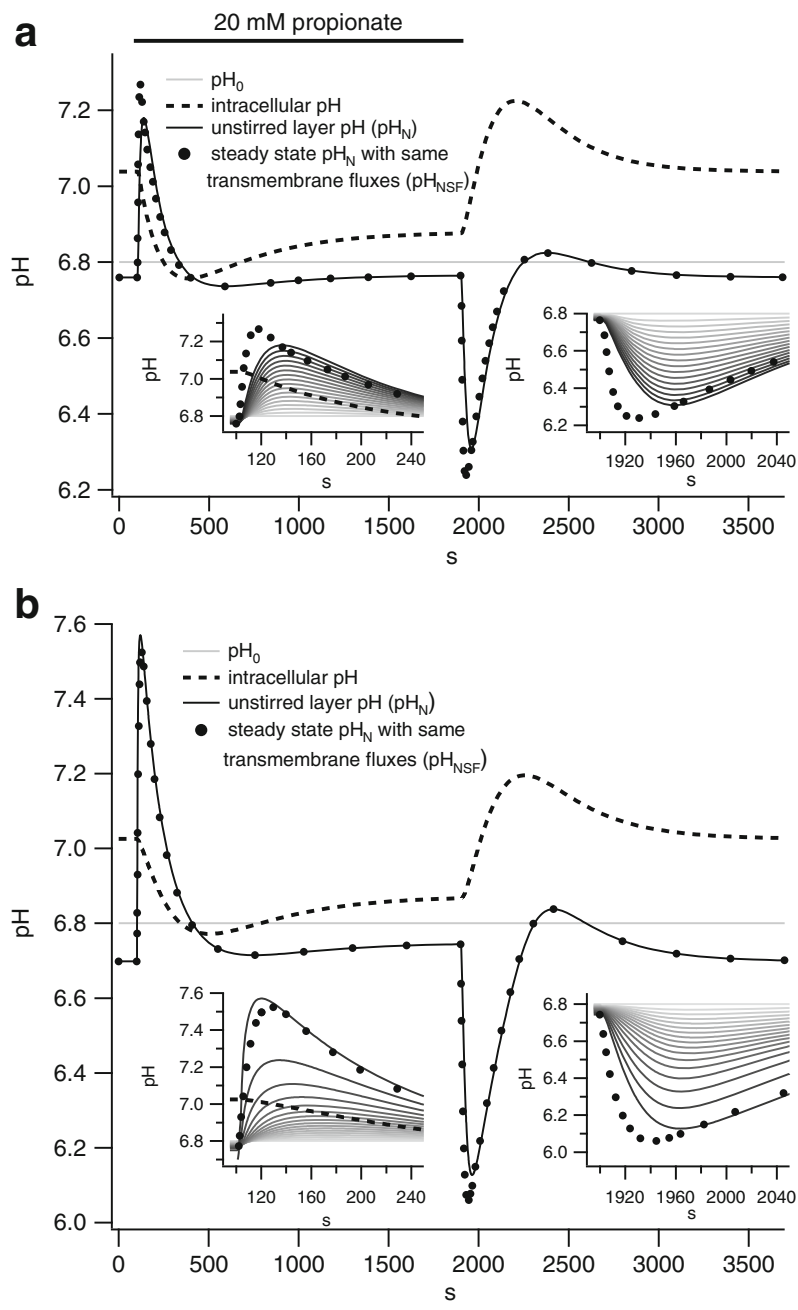

Fig. 12 Interpretation of the unstirred layer $\mathrm{pH}$ transients. The extracellular bulk solution was buffered with $5 \mathrm{mM}$ bicarbonate at $\mathrm{pH} 6.8$. Twenty $\mathrm{mM} \mathrm{Cl}^{-}$was replaced by $20 \mathrm{mM}$ propionate in the bulk solution during $1800 \mathrm{~s}$, as indicated with a horizontal line. The unstirred layer was subdivided into 16 compartments. The graphs displays the $\mathrm{pH}$ in the extracellular bulk compartment $\left(\mathrm{pH}_{0}\right.$, grey), the $\mathrm{pH}$ in compartment 16 close to the cell membrane $\left(\mathrm{pH}_{\mathrm{N}}\right.$, black curve) and the intracellular $\mathrm{pH}$ (dashed curve) as a function of time. The $\mathrm{pH}$ of compartments $1-15$ is not displayed. The full circles represent the steady-state $\mathrm{pH}_{\mathrm{N}}$, calculated with the multicompartment model in flux clamp mode with the same transmembrane fluxes and extracellular bulk concentrations as during the simulation at that time point. The insets display the same at a more expanded time scale and also the time course of the $\mathrm{pH}$ in all unstirred layer compartments. The same simulation parameters were used as in Fig. 11, see also Table 4. The intracellular Deh reaction was catalyzed infinitely. a The Deh reaction was catalyzed infinitely in compartment $16(N)$, but not catalyzed in the other unstirred layer compartments. b The Deh reaction was not catalyzed in the unstirred layer

acids' (related to the term between square brackets in (29b) in the case of infinite catalysis of the Deh reaction) should be larger. Initially after the solution change $\mathrm{pH}_{\mathrm{N}}$ deviates from $\mathrm{pH}_{\mathrm{NSF}}$, but later $\mathrm{pH}_{\mathrm{N}}$ becomes closer to $\mathrm{pH}_{\mathrm{NSF}}$ as the system approaches more a steady 
state. A condition for steady state in the unstirred layer compartment $N$ is that $\mathrm{dpH}_{N} / \mathrm{d} t=$ 0 , which is true at the maxima and minima of $\mathrm{pH}_{\mathrm{N}}$. Interestingly, at its maxima and minima $\mathrm{pH}_{\mathrm{N}}$ was close to $\mathrm{pH}_{\mathrm{NSF}}$ (see insets in Fig. 12) when the extracellular bulk solution was only buffered with bicarbonate and the immobile buffer concentration of the unstirred layer was low. This was true not only when the Deh reaction was catalyzed infinitely in all unstirred layer compartments (Table 6 case 5), but also when the Deh reaction was catalyzed infinitely in compartment $N$ but not catalyzed in the other unstirred layer compartments (Fig. 12a, Table 6 case 6 ) and when the Deh reaction was not catalyzed in the whole unstirred layer (Fig. 12b, Table 6 case 7). Similarly, $\mathrm{pH}_{\mathrm{N}}$ at the initial maximum after addition of propionate $\left(\mathrm{pH}_{\mathrm{Nmax}}\right)$ was also close to $\mathrm{pH}_{\mathrm{NSF}}$ in a $25 \mathrm{mM}$ bicarbonate buffer at $\mathrm{pH}_{0} 7.4$ or at $\mathrm{pH}_{0} 6.8$ with a higher $\left[\mathrm{CO}_{2}\right]_{0}$ (Table 6 cases $\left.1-4\right)$.

When the unstirred layer $\mathrm{pH}$ changes, the total buffer capacity of the unstirred layer slows down these $\mathrm{pH}$ changes. Consequently, the $\mathrm{pH}_{\mathrm{N}}$ maximum after addition of propionate comes mostly later than the moment of maximal net transmembrane acid influx, which is approximately the moment of the maximum of $\mathrm{pH}_{\mathrm{NSF}}$ (see first inset in Fig. 12a). When the

Table 6 Comparison of transient $\mathrm{pH}_{\mathrm{N}}$ maximum with steady-state $\mathrm{pH}_{\mathrm{N}}$ with same transmembrane fluxes

\begin{tabular}{|c|c|c|c|c|c|c|c|c|c|c|c|c|}
\hline Case & Time & $\mathrm{pH}_{0}$ & $\mathrm{pH}_{\mathrm{Nmax}}$ & $\mathrm{pH}_{\mathrm{NSF}}$ & $\%$ diff. & $\beta$, & {$\left[\mathrm{HCO}^{-}\right]_{0}$} & {$\left[T_{H B}\right]_{0}$} & $p K_{H B}$ & $D_{H B / B}$ & Catalysis & Other \\
\hline 1 & 44.7 & 7.4 & 7.487 & 7.485 & 2.2 & 0.01 & 25 & 0 & & & $N$ & \\
\hline 2 & 22.2 & 7.4 & 7.766 & 7.761 & 1.5 & 0.01 & 25 & 0 & & & - & \\
\hline 3 & 32.9 & 6.8 & 6.897 & 6.900 & -3.5 & 0.01 & 25 & 0 & & & $N$ & \\
\hline 4 & 17.8 & 6.8 & 7.160 & 7.141 & 5.2 & 0.01 & 25 & 0 & & & - & \\
\hline 5 & 37.0 & 6.8 & 7.180 & 7.170 & 2.5 & 0.01 & 5 & 0 & & & all & \\
\hline 6 & 37.0 & 6.8 & 7.180 & 7.171 & 2.5 & 0.01 & 5 & 0 & & & $N$ & \\
\hline 7 & 20.2 & 6.8 & 7.571 & 7.498 & 9.5 & 0.01 & 5 & 0 & & & - & \\
\hline 8 & 38.8 & 6.8 & 7.123 & 7.169 & -14.5 & 3.85 & 5 & 0 & & & all & \\
\hline 9 & 38.9 & 6.8 & 7.118 & 7.167 & -15.3 & 0.01 & 5 & 15 & 6.12 & $1 \mathrm{E}-22$ & all & \\
\hline 10 & 30.0 & 6.8 & 7.047 & 7.057 & -4.1 & 0.01 & 5 & 15 & 6.12 & $1.25 \mathrm{E}-9$ & all & \\
\hline 11 & 22.2 & 6.8 & 7.482 & 7.967 & -71.0 & 3.85 & 5 & 0 & & & - & \\
\hline 12 & 26.3 & 6.8 & 7.272 & 7.397 & -26.7 & 0.01 & 0 & 10 & 6.8 & $6.20 \mathrm{E}-10$ & all & \\
\hline 13 & 23.5 & 6.8 & 7.180 & 7.213 & -8.5 & 0.01 & 0 & 10 & 6.8 & $1.25 \mathrm{E}-9$ & all & \\
\hline 14 & 48.0 & 6.8 & 7.306 & 7.467 & -31.9 & 3.85 & 5 & 0 & & & - & * \\
\hline 15 & 61.4 & 6.8 & 7.189 & 7.226 & -9.5 & 0.01 & 0 & 10 & 6.8 & $6.20 \mathrm{E}-10$ & all & $*$ \\
\hline
\end{tabular}

Results from 15 different simulations in which $20 \mathrm{mM}$ propionate was added to the extracellular bulk compartment. The extracellular unstirred layer was subdivided into 16 compartments. The first column is the number of the simulation, to which is referred in Section 3.13. The second column is the time of the $\mathrm{pH}_{\mathrm{N}}$ maximum after addition of propionate (in s). The third column is the $\mathrm{pH}$ of the extracellular bulk compartment. The fourth column is the $\mathrm{pH}_{\mathrm{N}}$ maximum after addition of propionate. The fifth column is the steady-state $\mathrm{pH}_{\mathrm{N}}$ calculated in flux clamp mode with the same transmembrane fluxes as at the moment of the $\mathrm{pH}_{\mathrm{N}}$ maximum. The sixth column represents the $\%$ difference between $\mathrm{pH}_{\mathrm{Nmax}}$ and $\mathrm{pH}_{\mathrm{NSF}}$ or $\left(\mathrm{pH}_{\mathrm{Nmax}}-\right.$ $\left.\mathrm{pH}_{\mathrm{NSF}}\right) /\left(\mathrm{pH}_{\mathrm{Nmax}}-\mathrm{pH}_{0}\right) \times 100 \%$. Seventh column: $\beta$ ' is the used intrinsic unstirred layer buffer capacity (in $\mathrm{mM}$ ), which in this model behaves as an immobile buffer. Eighth column: bicarbonate concentration $(\mathrm{mM})$ in the extracellular bulk compartment. Ninth column: total concentration of the HB/B buffer (mM) in the extracellular bulk compartment. This buffer cannot cross the cell membrane. Tenth column: $\mathrm{pK}$ of $\mathrm{HB} / \mathrm{B}$ buffer. Eleventh column: diffusion coefficient of HB and B $\left(\mathrm{m}^{2} \mathrm{~s}^{-1}\right)$. Twelfth column: catalysis of the Deh reaction in the unstirred layer; - : no catalysis in unstirred layer; $N$ : infinite catalysis in compartment $N$ but no catalysis in the other unstirred layer compartments; all: infinite catalysis in all unstirred layer compartments. Thirteenth column: if empty, then the used membrane permeability of propionate $\left(P_{m H A}\right)$ was $1.410^{-5} \mathrm{~m} \mathrm{~s}^{-1}$ and the ratio of the surface area of the cell membrane to the intracellular volume $\left(\rho_{p, i}\right)$ was $810^{5} \mathrm{~m}^{-1}$. If this column contains and asterisk, then $P_{m H A}$ was decreased to $310^{-6} \mathrm{~m} \mathrm{~s}^{-1}$ and $\rho_{p, i}$ was decreased to 4 $10^{5} \mathrm{~m}^{-1}$, to slow down the $\mathrm{pH}_{\mathrm{N}}$ transient and increase the time to the $\mathrm{pH}_{\mathrm{N}}$ maximum 
Deh reaction is not catalyzed, the $\mathrm{pH}_{\mathrm{N}}$ maximum after addition of propionate comes earlier (20.2 s after the solution change) than when it is infinitely catalyzed (37 s after solution change), due to the rapidly rising disequilibrium $\mathrm{pH}$ close to the cell membrane. During the $\mathrm{pH}_{\mathrm{N}}$ changes, e.g., after the $\mathrm{pH}_{\mathrm{N}}$ maximum, the difference $\left(\mathrm{pH}_{\mathrm{N}}-\mathrm{pH}_{\mathrm{NSF}}\right)$ is larger when the rate of the $\mathrm{pH}_{\mathrm{N}}$ change and the total buffer capacity of the unstirred layer are larger, but depends also on the degree of catalysis of the Deh reaction (compare insets of Fig. 12a and b), which influences the buffer capacity of the bicarbonate buffer and the disequilibrium $\mathrm{pH}$. After the initial $\mathrm{pH}_{\mathrm{N}}$ maximum there is a slow $\mathrm{pH}_{\mathrm{N}}$ minimum. One can thus expect that this is close to a maximum of the net cellular acid efflux. This fits with the fact that the slope of the simulated intracellular $\mathrm{pH}$ recovery was then approximately maximal. The inverse is seen around $2420 \mathrm{~s}$ in Fig. 12a. We have observed such relationships between the intracellular and unstirred layer $\mathrm{pH}$ repeatedly in experiments on superfused preparations. The difference between unstirred layer $\mathrm{pH}$ and bulk $\mathrm{pH}$ can thus give useful information about net transmembrane acid-base fluxes.

In steady state the difference $\left(\mathrm{pH}_{\mathrm{N}}-\mathrm{pH}_{0}\right)$ corresponds to the $\mathrm{pH}$ difference needed to transport the protons, generated by the transmembrane fluxes of acids and bases, by the mobile buffers in cooperation with the Deh reaction through the unstirred layer. With the exception of the initial period after the solution changes, the time course of these transient $\mathrm{pH}_{\mathrm{N}}$ changes was very similar to that of $\mathrm{pH}_{\mathrm{NSF}}$ in Fig. 12. This indicates that then during such $\mathrm{pH}_{\mathrm{N}}$ transients the difference $\left(\mathrm{pH}_{\mathrm{N}}-\mathrm{pH}_{0}\right)$ can be interpreted roughly as the $\mathrm{pH}$ difference needed to transport the protons, generated as a consequence of the transmembrane fluxes, through the unstirred layer by the mobile buffers in cooperation with the Deh reaction. This then occurs mainly according to the principles of the steadystate $\mathrm{pH}_{\mathrm{N}}$, analyzed more accurately by means of clamped transmembrane fluxes in this paper.

In the steady state, an immobile buffer in the unstirred layer has no influence on the difference $\left(\mathrm{pH}_{\mathrm{N}}-\mathrm{pH}_{0}\right)$, see Section 3.4. However, an immobile buffer contributes to reduce the amplitude of the $\mathrm{pH}_{\mathrm{N}}$ transient after addition of e.g., propionate and does it in another way than by proton transport, which is indicated by the fact that it lowers $\mathrm{pH}_{\mathrm{Nmax}}$ versus $\mathrm{pH}_{N S F}$ and makes thus the percent difference between $\mathrm{pH}_{\mathrm{Nmax}}$ and $\mathrm{pH}_{\mathrm{NSF}}$ (\% diff) more negative (Table 6 , compare cases 8 and 9 with case 5 ). In case 8 the intrinsic buffer capacity of the unstirred layer $\left(\beta^{\prime}\right)$ was increased, which in the multicompartment model acts as an immobile buffer with a constant buffer capacity. In case 9 a $15 \mathrm{mM} \mathrm{HB} / \mathrm{B}$ buffer with an extremely low diffusion coefficient $\left(10^{-22} \mathrm{~m}^{2} \mathrm{~s}^{-1}\right)$ was added to the unstirred layer as immobile buffer; its $p K_{H B}$ was 6.12 (same as $p K_{1}{ }^{\prime}$ ) which allows to compare its effect with that of a $\mathrm{CO}_{2}$ /bicarbonate buffer. The buffer capacity of the immobile unstirred layer buffer $\beta^{\prime}$ in case 8 is the same as the mean buffer capacity of the immobile buffer HB/B in case 9 (obtained by integrating its buffer capacity between $\mathrm{pH}_{0} 6.8$ and $\mathrm{pH}_{\mathrm{Nmax}}$ 7.118); the effect of the immobile buffer on $\mathrm{pH}_{\mathrm{Nmax}}, \mathrm{pH}_{\mathrm{NSF}}$ and $\%$ difference was similar in cases 8 and 9 . That an immobile buffer capacity in the unstirred layer decreases $\mathrm{pH}_{\mathrm{Nmax}}$ versus $\mathrm{pH}_{\mathrm{NSF}}$ suggests that also the buffer capacity of a mobile buffer contributes to decrease $\mathrm{pH}_{\mathrm{Nmax}}$ and not only its acid transport capacity.

When the added HB/B buffer was mobile with a diffusion coefficient comparable to that of a $\mathrm{CO}_{2}$ /bicarbonate buffer, $\mathrm{pH}_{\mathrm{Nmax}}$ was even lower (Table 6, compare case 10 with case 9). This illustrates the role of the proton transport by a mobile buffer in the lowering of $\mathrm{pH}_{\mathrm{Nmax}}$. Because a mobile buffer affects both $\mathrm{pH}_{\mathrm{Nmax}}$ and $\mathrm{pH}_{\mathrm{NSF}}$ partly in a similar way (via proton transport), adding a mobile buffer induces less discrepancy between 
$\mathrm{pH}_{\mathrm{Nmax}}$ and $\mathrm{pH}_{\mathrm{NSF}}$, which results in a less negative $\%$ diff, than adding an immobile buffer (Table 6, cases 9 and 10).

The lowering of $\mathrm{pH}_{\mathrm{Nmax}}$ versus $\mathrm{pH}_{\mathrm{NSF}}$ by an immobile buffer is much more pronounced when the Deh reaction is not catalyzed in the bicarbonate buffered unstirred layer and thus the proton transport capacity of the bicarbonate buffer is small (Table 6, compare cases 7 and 11). In general, when the proton transport capacity of the unstirred layer is smaller, an immobile buffer makes a larger relative contribution to the lowering of $\mathrm{pH}_{\mathrm{Nmax}}$. At the $\mathrm{pH}_{\mathrm{N}}$ maximum $\mathrm{dpH} / \mathrm{d} t$ is zero in compartment $N$, but at the same time in the lower numbered unstirred layer compartments the $\mathrm{pH}$ is still increasing (especially when the immobile buffer concentration is larger). There the immobile buffer releases protons which react with bicarbonate to form $\mathrm{H}_{2} \mathrm{CO}_{3}$, which diffuses towards the cell membrane and reduces the alkaline disequilibrium $\mathrm{pH}$ in compartment $N$ (caused by the influx of propionic acid), and thus lowers $\mathrm{pH}_{\mathrm{Nmax}}$ versus $\mathrm{pH}_{\mathrm{NSF}}$. Normally in an aqueous unstirred layer the immobile buffer capacity can be expected to be low and not to induce a large difference between $\mathrm{pH}_{\mathrm{Nmax}}$ and $\mathrm{pH}_{\mathrm{NSF}}$.

When the extracellular solution was not buffered with bicarbonate but with $10 \mathrm{mM} \mathrm{HB} / \mathrm{B}$ buffer $\left(p K_{H B}=6.8\right)$ with a diffusion coefficient similar to that of HEPES, $\mathrm{pH}_{\mathrm{Nmax}}$ was again clearly lower than $\mathrm{pH}_{\mathrm{NSF}}$ (Table 6 case 12). This is mainly related to the lower mobility of the $\mathrm{HB} / \mathrm{B}$ buffer, because $\mathrm{pH}_{\mathrm{Nmax}}$ was much closer to $\mathrm{pH}_{\mathrm{NSF}}$ when a larger diffusion coefficient similar to that of $\mathrm{CO}_{2} /$ bicarbonate was used (Table 6 case 13). Thus when the buffer has a lower mobility (case 12 ) it decreases $\mathrm{pH}_{\mathrm{Nmax}}$ more by its buffer capacity and less by its proton transport capacity and behaves thus intermediately between a very mobile and an immobile buffer.

The parameters such as $\mathrm{pH}_{0}$, membrane permeability of the weak acid $\left(P_{H A, i}\right)$ and the ratio of the surface area of the cell membrane to the intracellular volume $\left(\rho_{p, i}\right)$ were chosen to obtain faster $\mathrm{pH}_{\mathrm{N}}$ transients, which allows to distinguish better any difference between $\mathrm{pH}_{\mathrm{Nmax}}$ and $\mathrm{pH}_{\mathrm{NSF}}$. When a smaller $P_{H A, i}$ and $\rho_{p, i}$ were used, the $\mathrm{pH}_{\mathrm{N}}$ transient was slower and the difference between $\mathrm{pH}_{\mathrm{Nmax}}$ and $\mathrm{pH}_{\mathrm{NSF}}$ was smaller (Table 6, compare case 11 with 14 and case 12 with 15 ). In general, the slower the $\mathrm{pH}$ transient, the smaller the relative contribution of the buffer capacity and the larger the contribution of the proton transport capacity of the buffers to the decrease of the amplitude of the $\mathrm{pH}_{\mathrm{N}}$ transients, and the more their amplitude is determined by the principles governing the steady-state $\mathrm{pH}$ difference with the same transmembrane fluxes $\left(\mathrm{pH}_{\mathrm{NSF}}-\mathrm{pH}_{0}\right)$. Very fast transients in the unstirred layer $[15,44]$ are too far from the steady-state situation and can be analyzed best with a multicompartment model for transient changes or another mathematical approach.

\subsection{Influence of extracellular $\mathrm{pH}$ gradients on intracellular $\mathrm{pH}$ dynamics}

Extracellular $\mathrm{pH}$ gradients affect the intracellular $\mathrm{pH}$ [43] by changing the extracellular $\mathrm{pH}$ at the surface of the cell membrane. When the extracellular $\mathrm{pH}$ is decreased, effluxes of acid from the cell via acid extruders (such as a proton ATP-ase, $\mathrm{Na} / \mathrm{H}$ exchanger, $\mathrm{Na}$-driven $\mathrm{Cl} / \mathrm{HCO}_{3}$ exchanger and a $\mathrm{Na} / \mathrm{HCO}_{3}$ cotransporter with a $1 / 2$ stoichiometry) slow down by a decrease in their driving force and influxes of acid via acid loaders (such as a $\mathrm{Cl} / \mathrm{HCO}_{3}$ exchanger, $\mathrm{Na} / \mathrm{HCO}_{3}$ cotransporter with a $1 / 3$ stoichiometry and passive fluxes of protons, $\mathrm{OH}^{-}$and bicarbonate) increase [2, 3]. This tends to lower the intracellular $\mathrm{pH}[2,3,7,14]$. In addition, a decrease of the unstirred layer $\mathrm{pH}$ shifts the local acid-base equilibria and augments the concentration of uncharged weak acids, such as $\mathrm{CO}_{2}$ or $\mathrm{HA}$ (which can cross 
the cell membrane easily) and decreases the concentration of an uncharged weak base, such as $\mathrm{NH}_{3}$. This changes the transmembrane fluxes of these uncharged weak acids and weak bases, which also contributes to a decrease in intracellular $\mathrm{pH}$ [10]. The opposite can be expected during a rise of the extracellular $\mathrm{pH}$.

\subsection{Intracellular unstirred layer}

Many principles about an extracellular unstirred layer, discussed in this paper, can also be applied to an intracellular unstirred layer. The intracellular medium is normally buffered by a bicarbonate buffer together with mobile and immobile non-bicarbonate buffers. Consequently, catalysis of the Deh reaction by intracellular membrane-bound CA affects the $\mathrm{pH}$ close to the intracellular membrane during all these fluxes $\left(\mathrm{H}^{+}, \mathrm{HA}, \mathrm{A}, \mathrm{HB}, \mathrm{B}\right.$, $\mathrm{H}_{2} \mathrm{CO}_{3}, \mathrm{CO}_{2}, \mathrm{HCO}_{3}{ }^{-}$or $\mathrm{CO}_{3}{ }^{2-}$ ) and also free cytosolar CA decreases the intracellular $\mathrm{pH}$ deviation close to the cell membrane during these fluxes (analogously to in Fig. 8b). The high concentrations of intracellular mobile buffers also reduce the intracellular $\mathrm{pH}$ deviation at the membrane surface during large transmembrane proton fluxes, e.g., during proton secretion.

\subsection{Limitations of the multicompartment model}

The multicompartment model does not contain intracellular compartments, although the intracellular $\mathrm{pH}$ and solute concentrations are not equally distributed in the cell due to organelles or externally imposed gradients [9] or when very large cells such as Xenopus oocytes are simulated [45]. This is outside the scope of this work and has no influence on the conclusions made in this paper.

However, if one wants to add intracellular unstirred layer compartments to the model, one can use for them the equations described for an extracellular unstirred layer compartment and add the term(s) related to the metabolic production, already used in the equations of the intracellular compartment. For example, to calculate $\mathrm{d}\left[\mathrm{CO}_{2}\right]_{j} / \mathrm{d} t$ of an intracellular unstirred layer compartment one can use (40) to which $M_{C O 2}$ is added; to calculate the total proton load of an intracellular unstirred layer compartment one can use (49a) to which the proton load by the metabolic production $\left[f_{H A, j} M_{H A}+\left(f_{H C O 3, j}+2 f_{C O 3, j}\right) M_{H 2 C O 3}\right]$ is added. Depending on the biological systems which one wants to simulate, the geometry and position of the compartments and the surface area to volume ratios may have to be adapted. If more than three compartments interact and exchange with each other, equations like (39), (40) and (49a) have to be extended.

\subsection{Comparison with other computer models}

In the multicompartment model equations are derived to calculate the rate of change of the intracellular and unstirred layer $\mathrm{pH}$ and the rate of the Deh reaction when it is not assumed to be in equilibrium (36)-(48) and also for the case that the Deh reaction is in equilibrium or infinitely catalyzed (52)-(57), (62), (63). The second dissociation reaction of carbonic acid is included in these equations.

Several computer models have already been described to simulate transient $\mathrm{pH}$ and concentration changes $[10,37,44-50]$. These models were built differently, depending on 
the biological system studied or the questions which one wanted to answer. Boron and De Weer were the first to simulate the time course of intracellular $\mathrm{pH}$ changes during transmembrane fluxes of the charged and uncharged form of a weak acid or base in a twocompartment model [10]. To calculate $\mathrm{d}\left[\mathrm{H}^{+}\right]_{i} / \mathrm{d} t$ they divided the rate at which protons are added in this way to the cell $(\mathrm{d} Q / \mathrm{d} t)$ by its intrinsic buffer capacity. Keifer and Roos [46] pointed out that part of the protons added to a cell after an influx of a weak acid HA are taken up again by the buffer capacity of HA/A $\left(\beta_{H A, i}\right)$ during the decrease of the intracellular $\mathrm{pH}$. Therefore they divided a smaller proton load, corrected for this, by the intrinsic intracellular buffer capacity to calculate $\mathrm{d}\left[\mathrm{H}^{+}\right]_{i} / \mathrm{d} t$ (see their Eq. A4). This method was proven in a complex way for a single acid-base system HA/A. See also an analogous (26) in the review by Roos and Boron [1] for the calculation of $\mathrm{d}\left[\mathrm{H}^{+}\right]_{i} / \mathrm{d} t$ by transmembrane movements of $\mathrm{NH}_{4}+/ \mathrm{NH}_{3}$. However, it is difficult to extend such equations for different simultaneous acid-base systems.

In the present paper equations are derived to calculate $\mathrm{dpH} / \mathrm{d} t$ in a different and more straightforward way (as a two-step process), valid immediately for many simultaneous transmembrane fluxes of weak acids and bases and with possible contribution of the Deh reaction and metabolic production of acids. This showed that, to calculate $\mathrm{dpH} / \mathrm{d} t$, the rate of the proton load $\left(\mathrm{d} Q_{j} / \mathrm{d} t\right)$ calculated at constant $p H$ has to be divided by the total buffer capacity for a closed system of the compartment $\left(\beta_{T, j}\right)$, which is larger than the intrinsic buffer capacity $\left(\beta_{j}^{\prime}\right)$. See (51) and (45), (48) and (49a) (if the Deh reaction is not assumed to be in equilibrium) or (53), (55) and (56) (if the Deh reaction is in equilibrium). This formulation looks very different from Eqs. A4 and A9 by Keifer and Roos [46] or (26) of Roos and Boron [1]. However, if (45), (48) and (50) are reduced to a single acid-base system HA/A without metabolic acid production and Deh reaction and rearranged, these equations become identical to theirs.

In several computer models the transient $\mathrm{pH}$ changes due to acid-base fluxes were not calculated completely correctly: 1) The proton load by the Deh reaction, not assumed to be in equilibrium, was not multiplied with $\left(f_{\mathrm{HCO}, j}+2 f_{\mathrm{CO}, j}\right),(48)$ or $(49 \mathrm{a})[48,49]$. This error is mostly small. 2) $\mathrm{dpH}_{j} / \mathrm{d} t$ (or $\mathrm{d}\left[\mathrm{H}^{+}\right]_{j} / \mathrm{d} t$ ) was often calculated by dividing the uncorrected proton load by the intrinsic buffer capacity $\left(\beta_{j}^{\prime}\right)$ of the compartment instead of by the total buffer capacity $\left(\beta_{T, j}\right)[10,48,49]$. The magnitude of this error depends on the ratio of the total to the intrinsic buffer capacity of the compartment, and is thus larger when the Deh reaction is assumed to be in equilibrium, because then the bicarbonate buffer capacity is higher and thus also $\beta_{T, j}$ (compare (45) and (56)). The error is also larger when $\left[T_{H A}\right]_{j}$ is higher and the $\mathrm{pK}$ of HA/A is closer to $\mathrm{pH}_{j}$, because then $\beta_{H A, j}$ is larger and contributes more to $\beta_{T, j}$. If one has only considered transmembrane proton fluxes, there is no error in the calculation of the intracellular $\mathrm{pH}$ by division by $\beta_{j}^{\prime}$, because $\beta_{H, i}$ is extremely small at physiological $\mathrm{pH}$ and is included in the large $\beta_{i}^{\prime}$. However, if fluxes of weak acids or bases are simulated, the error by division by $\beta_{j}^{\prime}$ (instead of $\beta_{T, j}$ ) can be serious when $\mathrm{pH}$ changes in the extracellular unstirred layer are simulated, because $\beta_{j}^{\prime}$ of the extracellular unstirred layer is normally small.

In the multicompartment model the unstirred layer is subdivided into $N$ compartments, of which the solute concentrations are used directly to calculate the diffusion between the compartments. As an alternative method to simulate $\mathrm{pH}$ and concentration gradients in the unstirred layer also the finite element method [37] or finite difference method $[45,50]$ can be used. 


\section{Conclusions}

The derived analytical expression (29a) shows how the steady-state $\mathrm{pH}$ gradient in the unstirred layer depends on the size of the transmembrane fluxes of (weak) acids and bases, the dissociation constant (via $f_{X}$ ) and diffusion coefficient of these solutes and the buffer capacity and diffusion coefficients of the mobile buffers, if the Deh reaction is assumed to be in equilibrium in the unstirred layer. This $\mathrm{pH}$ gradient can be interpreted as the net flux of protons through a sheet of the unstirred layer (due to these transmembrane acid-base fluxes after dissociation and association reactions at the local $\mathrm{pH}$ ), divided by the proton transport capacity of its mobile buffers. Numerical integration of (29a), (26), (18) (and analogue for $\mathrm{HB} / \mathrm{B}$ ) from the bulk solution to the cell membrane makes it possible to calculate the $\mathrm{pH}$ profile in the unstirred layer.

If the Deh reaction is not in equilibrium in the unstirred layer, a disequilibrium $\mathrm{pH}$ is superimposed on the latter $\mathrm{pH}$ profile. In this paper a multicompartment model is described, which allows simulation of the unstirred layer and intracellular $\mathrm{pH}$ changes also when the Deh reaction is not in equilibrium. Simulations with this model in flux clamp mode demonstrated that the steady-state unstirred layer $\mathrm{pH}_{\mathrm{N}}$ at the surface of the cell membrane during the efflux of a (weak) acid or base depends on the type of solute efflux and on catalysis of the Deh reaction in the compartment $N$ closest to the cell membrane (which mimics the activity of extracellular membrane-bound CA). The influence of catalysis on $\mathrm{pH}_{\mathrm{N}}$ is larger when the Deh reaction has to proceed faster during the transmembrane solute flux. The effect of catalysis is also different when the extracellular buffer contains both a bicarbonate and a non-bicarbonate buffer, like HEPES. The non-bicarbonate buffer spreads the disequilibrium of the Deh reaction over the unstirred layer. Similarly the $\mathrm{CO}_{3}{ }^{2-} / \mathrm{HCO}_{3}{ }^{-}$and $\mathrm{OH}^{-} / \mathrm{H}_{2} \mathrm{O}$ shuttles extend the disequilibrium $\mathrm{pH}$ over different unstirred layer compartments, especially at more alkaline $\mathrm{pH}$ values.

During a proton efflux in a pure bicarbonate buffer already low degrees of catalysis in compartment $N$ have a clear effect on $\mathrm{pH}_{\mathrm{N}}$, in contrast to in a mixed bicarbonate/nonbicarbonate buffer. Infinite catalysis in compartment $N$ has the same effect on the steadystate $\mathrm{pH}_{\mathrm{N}}$ as catalysis in the whole unstirred layer. Varying the location of the catalysis of the Deh reaction showed that catalysis has more effect closer to the cell membrane. This shows that extracellular membrane-bound CA is located very strategically for reducing the $\mathrm{pH}$ gradient in the unstirred layer during an acid efflux in a bicarbonate buffer. The presence of a non-bicarbonate mobile buffer, which spreads the disequilibrium $\mathrm{pH}$ over the unstirred layer, increases the contribution of dissolved CA to the decrease of the disequilibrium $\mathrm{pH}$ at the surface of the cell membrane during an acid efflux.

According to these models an immobile buffer has no influence on the $\mathrm{pH}$ gradient in the unstirred layer in steady state. However, the total buffer capacity (including that of the immobile buffers) slows down transient $\mathrm{pH}$ changes and contributes to decrease their amplitude. This contribution is larger when the proton transport capacity of the mobile buffers is lower and/or the $\mathrm{pH}_{\mathrm{N}}$ transient is faster. When the $\mathrm{pH}$ changes are not too fast, the difference between the extracellular $\mathrm{pH}$ close to the cell membrane and the bulk $\mathrm{pH}_{0}$ $\left(\mathrm{pH}_{\mathrm{N}}-\mathrm{pH}_{0}\right)$ in a bicarbonate buffer can be interpreted mainly as the $\mathrm{pH}$ difference needed to transport the net flux of acid, due to the transmembrane acid-base fluxes, through the unstirred layer.

It is recommended to choose the number of unstirred layer compartments large enough to obtain an accurate simulation of the unstirred layer. It is also more accurate to include the second dissociation constant of carbonic acid in the equations, especially when the Deh 
reaction is not catalyzed in the unstirred layer and little or no other buffers are added to the extracellular bicarbonate buffer.

Acknowledgements I wish to thank professor Alex de Hemptinne for his contribution to the computer model of intracellular and extracellular $\mathrm{pH}$ changes and for the stimulating discussions. I thank him also for reading the manuscript and for his comments.

\section{Appendix: Steady state with the Deh reaction in equilibrium in one of the unstirred layer compartments}

Calculations with the multicompartment model showed that, if the Deh reaction is in equilibrium (or infinitely catalyzed) in unstirred layer compartment $j$ (but not necessarily in the other unstirred layer compartments), then the steady-state $\mathrm{pH}_{j},\left[T_{H A}\right]_{j}$ and $\left[T_{H 2 C}\right]_{j}$ are exactly the same as in the situation whereby the Deh reaction is in equilibrium in all unstirred layer compartments. This is true not only for the steady state in the normally used multicompartment model but also when the model is used in the flux clamp or concentration clamp mode. This can be explained briefly in the following way:

Suppose that in the bulk solution there is a HA/A and a bicarbonate buffer, and that there are transmembrane movements of $\mathrm{H}^{+}, \mathrm{OH}^{-}, \mathrm{HA}, \mathrm{A}, \mathrm{CO}_{2}, \mathrm{H}_{2} \mathrm{CO}_{3}, \mathrm{HCO}_{3}{ }^{-}$and $\mathrm{CO}_{3}{ }^{2-}$, a metabolic production of $\mathrm{HA}, \mathrm{CO}_{2}$ or $\mathrm{H}_{2} \mathrm{CO}_{3}$ and the Deh reaction. Then there are four independent variables in each compartment $j:\left[T_{H A}\right]_{j},\left[T_{H 2 C}\right]_{j}, \mathrm{pH}_{j}$ and the ratio $\left[\mathrm{H}_{2} \mathrm{CO}_{3}\right]_{j} /$ $\left[\mathrm{CO}_{2}\right]_{j}$.

1) In the steady state, the combination of $\left[T_{H A}\right]_{0}$ (in bulk solution) together with the principles which govern the mass balance of $\left[T_{H A}\right]$ (fluxes and metabolic production) give one set of restrictions which decreases the degrees of freedom in each compartment.

2) In the steady state, the combination of $\left[T_{H 2 C}\right]_{0}$ together with the principles which govern the mass balance of $\left[T_{H 2 C}\right]$ (fluxes and metabolic production) give a second set of restrictions.

3) In the steady state, the combination of $\mathrm{pH}_{0}$ together with the principles which govern the flux of acid equivalents between the compartments give a third set of restrictions.

4) If the Deh reaction is in equilibrium in compartment $j$, the concentration ratio is constant: $\left[\mathrm{H}_{2} \mathrm{CO}_{3}\right]_{j} /\left[\mathrm{CO}_{2}\right]_{j}=1 /\left(K_{1} / K_{1}^{\prime}-1\right)$

where $K_{1}$ and $K_{1}{ }^{\prime}$ are the dissociation constants of $\mathrm{H}_{2} \mathrm{CO}_{3}$ and $\mathrm{CO}_{2}{ }^{\prime}\left(=\mathrm{CO}_{2}+\mathrm{H}_{2} \mathrm{CO}_{3}\right)$, respectively. This then provides the fourth restriction in this compartment.

Consequently, with 4 independent variables and 4 equations (restrictions) there should be only one solution for the values of $\mathrm{pH}_{j},\left[T_{H A}\right]_{j}$ and $\left[T_{H 2 C}\right]_{j}$, and this solution should thus be the same when the Deh reaction is infinitely catalyzed in compartment $j$ (but not necessarily in the other unstirred layer compartments) as when the Deh reaction is infinitely catalyzed in all unstirred layer compartments.

For example, if the Deh reaction is catalyzed infinitely in compartment $N$ (closest to the cell membrane), but not in compartments 1 to $\mathrm{N}-1$, the unstirred layer $\mathrm{pH}_{\mathrm{N}}$ is in steady state exactly the same as $\mathrm{pH}_{\mathrm{N}}$ in the situation whereby the Deh reaction is infinitely catalyzed in all unstirred layer compartments. But then the $\mathrm{pH}$ in the other unstirred layer compartments (than compartment $N$ ) can be different from that in the situation whereby the Deh reaction is catalyzed infinitely in all unstirred layer compartments. 


\section{Glossary}

For the derivation of the expression of the unstirred layer $\mathrm{pH}$ gradient in steady state.

This model consists of a cell membrane, covered by an unstirred layer in contact with the bulk of the extracellular solution. $\mathrm{CO}_{2}$ is assumed to be in equilibrium with $\mathrm{H}_{2} \mathrm{CO}_{3}$.

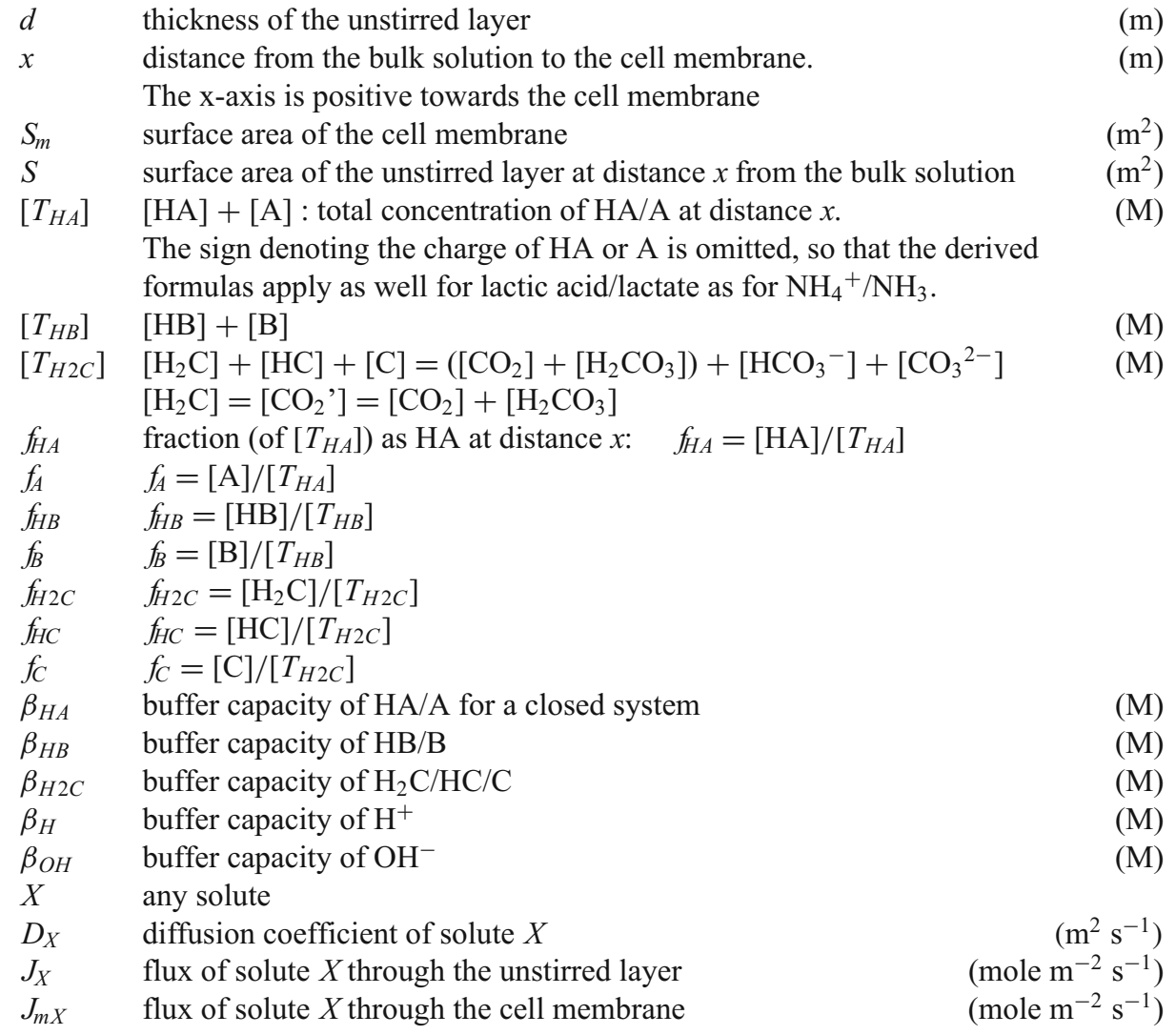

For the multicompartment model

Equilibrium of the dehydration reaction of $\mathrm{H}_{2} \mathrm{CO}_{3}$ is not required.

$N \quad$ total number of unstirred layer compartments

$j \quad$ index for compartment number ascending from bulk (0) to cell

$(N+1)$

$o \quad$ index for extracellular bulk compartment outside the unstirred layer

$i \quad$ index for intracellular compartment $(i=N+1)$

$V_{j} \quad$ volume of compartment number $j$

$S_{j} \quad$ surface area between compartment number $j-1$ and $j$ 
Surface area to volume ratios of compartment $\dot{j}$.

\begin{tabular}{|c|c|c|}
\hline$\rho_{p, j}$ & $\begin{array}{l}S_{j} / V_{j} \text { uses area of surface in contact with previous } \\
\text { compartment }\end{array}$ & $\left(\mathrm{m}^{-1}\right)$ \\
\hline$\rho_{n, j}$ & $\begin{array}{l}S_{j+1} / V_{j} \text { uses area of surface in contact with next } \\
\text { compartment }\end{array}$ & $\left(\mathrm{m}^{-1}\right)$ \\
\hline$t$ & time & $(\mathrm{s})$ \\
\hline$P_{X, j}$ & permeability of surface area $j$ to solute $X$ & $\left(\mathrm{~m} \mathrm{~s}^{-1}\right)$ \\
\hline$J_{X, j}$ & $\begin{array}{l}\text { net flux of solute } X \text { from compartment } j-1 \text { to } \\
\text { compartment } j\end{array}$ & $\left(\right.$ mole $\left.\mathrm{m}^{-2} \mathrm{~s}^{-1}\right)$ \\
\hline$z$ & valence of solute $X$ & \\
\hline$E$ & membrane potential & (V) \\
\hline$R$ & universal gas constant & $\left(\mathrm{VC} \mathrm{mole}^{-1} \mathrm{~K}^{-1}\right)$ \\
\hline$T$ & absolute temperature & $(\mathrm{K})$ \\
\hline$F$ & Faraday constant & $\left(\mathrm{C} \mathrm{mole}^{-1}\right)$ \\
\hline$[X]_{j}$ & concentration of solute $X$ in compartment $j$ & (M) \\
\hline$\left[T_{H A}\right]_{j}$ & $=[\mathrm{HA}]_{j}+[\mathrm{A}]_{j}$ & (M) \\
\hline$\left[T_{\mathrm{H} 2 \mathrm{CO}}\right]_{j}$ & $=\left[\mathrm{H}_{2} \mathrm{CO}_{3}\right]_{j}+\left[\mathrm{HCO}_{3}^{-}\right]_{j}+\left[\mathrm{CO}_{3}^{2-}\right]_{j}$ & (M) \\
\hline$\left[T_{\mathrm{CO}^{\prime}}\right]_{j}$ & $=\left(\left[\mathrm{CO}_{2}\right]_{j}+\left[\mathrm{H}_{2} \mathrm{CO}_{3}\right]_{j}\right)+\left[\mathrm{HCO}_{3}^{-}\right]_{j}+\left[\mathrm{CO}_{3}^{2-}\right]_{j}$ & (M) \\
\hline$\left[\mathrm{CO}_{2}^{\prime}\right]_{j}$ & $\begin{aligned}= & {\left[\mathrm{CO}_{2}\right]_{j}+\left[\mathrm{H}_{2} \mathrm{CO}_{3}\right]_{j} \text {. The symbol } \mathrm{CO}_{2} \text { ' is only } } \\
& \text { used when the dehydration reaction of } \mathrm{H}_{2} \mathrm{CO}_{3} \text { is } \\
& \text { assumed to be in equilibrium. }\end{aligned}$ & (M) \\
\hline$f_{H A, j}$ & $\begin{array}{l}\text { fraction (of }\left[T_{H A}\right] \text { ) as HA in compartment } j \text { : } \\
\qquad f_{H A, j}=[\mathrm{HA}]_{j} /\left[T_{H A}\right]_{j}\end{array}$ & \\
\hline$f_{A, j}$ & $f_{A, j}=[\mathrm{A}]_{j} /\left[T_{H A}\right]_{j}$ & \\
\hline
\end{tabular}

If the dehydration reaction of $\mathrm{H}_{2} \mathrm{CO}_{3}$ is not in equilibrium:

$f_{\mathrm{H} 2 \mathrm{CO}, j}$ fraction (of $\left[T_{\mathrm{H}_{2} \mathrm{CO}}\right]$ ) as $\mathrm{H}_{2} \mathrm{CO}_{3}$ in compartment $j$ :

$$
f_{\mathrm{H} 2 \mathrm{CO}, j}=\left[\mathrm{H}_{2} \mathrm{CO}_{3}\right]_{j} /\left[T_{\mathrm{H}_{2} \mathrm{CO} 3}\right]_{j}
$$

$f_{\mathrm{HCO}, j} \quad f_{\mathrm{HCO}, j}=\left[\mathrm{HCO}_{3}{ }^{-}\right]_{j} /\left[T_{\mathrm{H}_{2} \mathrm{CO} 3}\right]_{j}$

$f_{\mathrm{CO}, j} \quad f_{\mathrm{CO}, j}=\left[\mathrm{CO}_{3}{ }^{2-}\right]_{j} /\left[T_{\mathrm{H} 2 \mathrm{CO}}\right]_{j}$

If $\left[\mathrm{CO}_{2}\right]$ and $\left[\mathrm{H}_{2} \mathrm{CO}_{3}\right]$ are assumed to be in equilibrium:

$$
\begin{aligned}
& f_{\mathrm{H} 2 \mathrm{C}, j} \quad \text { fraction (of }\left[\mathrm{T}_{\mathrm{CO}^{\prime}}\right] \text { ) as }\left(\mathrm{CO}_{2}+\mathrm{H}_{2} \mathrm{CO}_{3}\right) \text { in compartment } j \text { : } \\
& f_{\mathrm{H} 2 \mathrm{C}, j}=\left[\mathrm{CO}_{2}{ }^{\prime}\right]_{j} /\left[T_{\mathrm{CO}^{\prime}}\right]_{j} \\
& f_{\mathrm{HC}, j} \quad f_{\mathrm{HC}, j}=\left[\mathrm{HCO}_{3}{ }^{-}\right]_{j} /\left[\mathrm{T}_{\mathrm{CO}^{\prime}}\right]_{j} \\
& f_{C, j} \quad f_{C, j}=\left[\mathrm{CO}_{3}{ }^{2-}\right]_{j} /\left[T_{\mathrm{CO}^{\prime}}\right]_{j} \\
& K_{H A} \quad \text { dissociation constant of HA: } K_{H A}=\left[\mathrm{H}^{+}\right][\mathrm{A}] /[\mathrm{HA}] \\
& K_{H B} \quad \text { dissociation constant of HB: } K_{H B}=\left[\mathrm{H}^{+}\right][\mathrm{B}] /[\mathrm{HB}] \\
& K_{1}=K_{\mathrm{H} 2 \mathrm{CO} 3} \quad \text { dissociation constant of } \mathrm{H}_{2} \mathrm{CO}_{3} \text { : } \\
& K_{1}=\left[\mathrm{H}^{+}\right]\left[\mathrm{HCO}_{3}^{-}\right] /\left[\mathrm{H}_{2} \mathrm{CO}_{3}\right]=10^{-3.46} \\
& K_{1}^{\prime}=K_{H 2 C} \quad \text { dissociation constant of } \mathrm{CO}_{2}{ }^{\prime} \text { : } \\
& K_{1}^{\prime}=\left[\mathrm{H}^{+}\right]\left[\mathrm{HCO}_{3}{ }^{-}\right] /\left[\mathrm{CO}_{2}{ }^{\prime}\right]=10^{-6.12} \\
& K_{1}^{\prime} \text { or } K_{H 2 C} \text { is only used when }\left[\mathrm{CO}_{2}\right] \text { and }\left[\mathrm{H}_{2} \mathrm{CO}_{3}\right] \text { are } \\
& \text { assumed to be in equilibrium. } \\
& K_{2}=K_{\mathrm{HCO} 3} \quad \text { dissociation constant of } \mathrm{HCO}_{3}{ }^{-} \text {: } \\
& K_{2}=\left[\mathrm{H}^{+}\right]\left[\mathrm{CO}_{3}{ }^{2-}\right] /\left[\mathrm{HCO}_{3}{ }^{-}\right]=10^{-10.277}
\end{aligned}
$$




$K_{w}$
$\beta_{H A, j}$
$\beta_{H 2 C O 3, j}$
$\beta_{H 2 C, j}$
$\beta_{j}^{\prime}{ }_{j}$
$\beta_{T, j}$
$M_{H A}$
$M_{C O 2}$
$M_{H 2 C O 3}$
$D_{e h y d r, j}$
$k_{1}$
$k_{-1}$
$k_{4}$
$k_{-4}$
$C_{a t a, j}$
$C_{a t b, j}$
$U$

CA

Deh reaction

\section{$\mathrm{pH}_{\mathrm{N}}$} $\mathrm{pH}_{\mathrm{NSF}}$

$\mathrm{pH}_{0}$

$$
K_{w}=\left[\mathrm{H}^{+}\right]\left[\mathrm{OH}^{-}\right]=10^{-14}
$$$$
\begin{aligned}
& \text { buffer capacity of the system } \mathrm{H}_{2} \mathrm{CO}_{3} / \mathrm{HCO}_{3}{ }^{-} / \mathrm{CO}_{3}{ }^{2-} \\
& \text { buffer capacity of the system } \mathrm{CO}_{2}{ }^{\prime} / \mathrm{HCO}_{3}{ }^{-} / \mathrm{CO}_{3}{ }^{2-}
\end{aligned}
$$$$
\text { intrinsic buffer capacity of compartment } j(=\text { by other }
$$

total buffer capacity of compartment $j$

metabolic production of HA by cell

metabolic production of $\mathrm{CO}_{2}$

metabolic production of $\mathrm{H}_{2} \mathrm{CO}_{3}$

rate of production of $\mathrm{CO}_{2}$ via dehydration of

$\mathrm{H}_{2} \mathrm{CO}_{3}$ and $\mathrm{HCO}_{3}{ }^{-}$in compartment $j$

velocity constant of the reaction: $\mathrm{CO}_{2}+\mathrm{H}_{2} \mathrm{O} \rightarrow \mathrm{H}_{2} \mathrm{CO}_{3}$

velocity constant of the reaction: $\mathrm{CO}_{2}+\mathrm{H}_{2} \mathrm{O} \leftarrow \mathrm{H}_{2} \mathrm{CO}_{3}$

catalysis factor of the dehydration reaction via

$\mathrm{H}_{2} \mathrm{CO}_{3} \leftrightarrows \mathrm{CO}_{2}+\mathrm{H}_{2} \mathrm{O}$ in compartment $j$ (see (38))

catalysis factor of the dehydration reaction via

$$
\mathrm{HCO}_{3}{ }^{-} \leftrightarrows \mathrm{CO}_{2}+\mathrm{OH}^{-}
$$

Unit conversion factor.

$U=1,000$ if this hybrid unit system is used (see above glossary)

$U=1$ if $\mathrm{m}$ is used consistently as basic unit of distance,

so that concentrations and buffer capacities are expressed

in mole $\mathrm{m}^{-3}$, and $M_{\mathrm{HA}}, M_{\mathrm{CO} 2}, M_{\mathrm{H} 2 \mathrm{CO} 3}$, and $D_{e h y d r, j}$ in mole $\mathrm{m}^{-3} \mathrm{~s}^{-1}$.

Carbonic anhydrase

Dehydration-hydration reaction of $\mathrm{CO}_{2}$ or sum of the

reactions $\mathrm{H}_{2} \mathrm{CO}_{3} \leftrightarrows \mathrm{CO}_{2}+\mathrm{H}_{2} \mathrm{O}$ and

$\mathrm{HCO}_{3}^{-} \leftrightarrows \mathrm{CO}_{2}+\mathrm{OH}^{-}$catalyzed or not and going

in the direction of dehydration or hydration.

$\mathrm{pH}$ in unstirred layer compartment $N$ next to the cell membrane

Steady-state $\mathrm{pH}$ in unstirred layer compartment $N$, calculated in

flux clamp mode with the same transmembrane fluxes and parameters, see Section 3.13.

$\mathrm{pH}$ in extracellular bulk compartment

\section{References}

1. Roos, A., Boron, W.F.: Intracellular pH. Physiol. Rev. 61, 296-434 (1981)

2. Boron, W.F.: Regulation of intracellular pH. Adv. Physiol. Educ. 28, 160-179 (2004)

3. Vaughan-Jones, R.D., Spitzer, K.W., Swietach, P.: Intracellular pH regulation in heart. J. Mol. Cell. Cardiol. 46, 318-331 (2009)

4. Thomas, R.C.: Intracellular $\mathrm{pH}$ of snail neurones measured with a new pH-sensitive glass mircoelectrode. J. Physiol. 238, 159-180 (1974)

5. de Hemptinne, A.: Intracellular $\mathrm{pH}$ and surface $\mathrm{pH}$ in skeletal and cardiac muscle measured with a double-barrelled pH microelectrode. Pflügers Arch. 386, 121-126 (1980)

6. Loiselle, F.B., Casey, J.R.: Measurement of intracellular pH. Methods Mol. Biol. 637, 311-331 (2010) 
7. Boron, W.F., McCormick, W.C., Roos, A.: pH regulation in barnacle muscle fibers: dependence on intracellular and extracellular pH. Am. J. Physiol. 237, C185-C193 (1979)

8. Szatkowski, M.S., Thomas, R.C.: The intrinsic intracellular $\mathrm{H}^{+}$buffering power of snail neurones. J. Physiol. 409, 89-101 (1989)

9. Swietach, P., Leem, C.H., Spitzer, K.W., Vaughan-Jones, R.D.: Experimental generation and computational modeling of intracellular pH gradients in cardiac myocytes. Biophys. J. 88, 3018-3037 (2005)

10. Boron, W.F., De Weer, P.: Intracellular $\mathrm{pH}$ transients in squid giant axons caused by $\mathrm{CO}_{2}, \mathrm{NH}_{3}$, and metabolic inhibitors. J. Gen. Physiol. 67, 91-112 (1976)

11. Marrannes, R., de Hemptinne, A., Leusen, I.: pH aspects of transient changes in conduction velocity in isolated heart fibers after partial replacement of chloride with organic anions. Pflügers Arch. 389, 199-209 (1981)

12. de Hemptinne, A., Marrannes, R., Vanheel, B.: Influence of organic acids on intracellular pH. Am. J. Physiol. 245, C178-C183 (1983)

13. Kaila, K., Saarikoski, J., Voipio, J.: Mechanism of action of GABA on intracellular pH and on surface pH in crayfish muscle fibres. J. Physiol. 427, 241-260 (1990)

14. de Hemptinne, A., Marrannes, R., Vanheel, B.: Surface $\mathrm{pH}$ and the control of intracellular $\mathrm{pH}$ in cardiac and skeletal muscle. Can. J. Physiol. Pharm. 65, 970-977 (1987)

15. Chesler, M.: Regulation and modulation of $\mathrm{pH}$ in the brain. Physiol. Rev. 83, 1183-1221 (2003)

16. Maren, Th.: The kinetics of $\mathrm{HCO}_{3}{ }^{-}$synthesis related to fluid secretion, $\mathrm{pH}$ control, and $\mathrm{CO}_{2}$ elimination. Annu. Rev. Physiol. 50, 695-717 (1988)

17. de Hemptinne, A., Hughuenin, F.: The influence of muscle respiration and glycolysis on surface and intracellular $\mathrm{pH}$ in fibres of the rat soleus. J. Physiol. 347, 581-592 (1984)

18. Thomas, R.C.: Changes in the surface $\mathrm{pH}$ of voltage-clamped snail neurones apparently caused by $\mathrm{H}^{+}$ fluxes through a channel. J. Physiol. 398, 313-327 (1988)

19. Musa-Aziz, R., Chen, L.M., Pelletier, M.F., Boron, W.F.: Relative $\mathrm{CO}_{2} / \mathrm{NH}_{3}$ selectivities of AQP1, AQP4, AQP5, AmtB, and RhAG. Proc. Natl. Acad. Sci. U. S. A. 106, 5406-5411 (2009)

20. Putnam, R.W., Roos, A.: Which value for the first dissociation constant of carbonic acid should be used in biological work? Am. J. Physiol. 260, C1113-C1116 (1991)

21. Roos, A., Boron, W.F.: The buffer value of weak acids and bases: origin of the concept, and first mathematical derivation and application to physico-chemical systems. The work of M. Koppel and K. Spiro (1914). Respir. Physiol. 40, 1-32 (1980)

22. Van Slyke, D.D.: On the measurement of buffer values and on the relationship of buffer value to the dissociation constant of the buffer and the concentration and reaction of the buffer solution. J. Biol. Chem. 52, 525-570 (1922)

23. Kildenberg, P.: Acid-base status of biological fluids: amount of acid, kind of acid, anion-cation difference, and buffer value. Scand. J. Clin. Lab. Invest. 43, 103-109 (1983)

24. Urbansky, E.T., Schock, M.R.: Understanding, deriving and computing buffer capacity. J. Chem. Educ. 77, 1640-1644 (2000)

25. Goldman, D.E.: Potential, impedance, and rectification in membranes. J. Gen. Physiol. 27, 37-60 (1943)

26. Hodgkin, A.L., Katz, B.: The effect of sodium ions on the electrical activity of giant axon of the squid. J. Physiol. 108, 37-77 (1949)

27. Vaughan-Jones, R.D., Wu, M.L.: $\mathrm{pH}$ dependence of intrinsic $\mathrm{H}^{+}$buffering power in the sheep cardiac Purkinje fibre. J. Physiol. 425, 429-448 (1990)

28. Press, H., Flannery, B.P., Teukolsky, S.A., Vetterling, W.T.: Numerical Recipes. The Art of Scientific Computing. Cambridge University Press, Cambridge (1986)

29. Walter, A., Hastings, D., Gutknecht, J.: Weak acid permeability through lipid bilayer membranes. Role of chemical reactions in the unstirred layer. J. Gen. Physiol. 79, 917-933 (1982)

30. Antonenko, Y.N., Pohl, P., Denisov, G.A.: Permeation of ammonia across bilayer lipid membranes studied by ammonium ion selective microelectrodes. Biophys. J. 72, 2187-2195 (1997)

31. Pohl, P., Saparov, S.M., Antonenko, Y.N.: The size of the unstirred layer as a function of the solute diffusion coefficient. Biophys. J. 75, 1403-1409 (1998)

32. Gutknecht, J., Tosteson, F.C.: Diffusion of weak acids across lipid bilayer membranes: effects of chemical reactions in the unstirred layers. Science 182, 1258-1261 (1973)

33. Engasser, J.-M., Horvath, C.: Buffer facilitated proton transport. pH profile of bound enzymes. Biochim. Biophys. Acta 358, 178-192 (1974)

34. Gros, G., Mol, W.: Facilitated diffusion of $\mathrm{CO}_{2}$ across albumin solutions. J. Gen. Physiol. 64, 356-371 (1974)

35. Antonenko, Y.N., Denisov, G.A., Pohl, P.: Weak acid transport across bilayer lipid membrane in the presence of buffers. Theoretical and experimental $\mathrm{pH}$ profiles in the unstirred layers. Biophys. J. 64, $1701-1710(1993)$ 
36. Spitzer, K.W., Skolnick, R.L., Peercy, B.E., Keener, J.P., Vaughan-Jones, R.D.: Facilitation of intracellular $\mathrm{H}^{+}$ion mobility by $\mathrm{CO}_{2} / \mathrm{HCO}_{3}^{-}$in rabbit ventricular myocytes is regulated by carbonic anhydrase. J. Physiol. 541, 159-167 (2002)

37. Swietach, P., Zaniboni, M., Stewart, A.K., Rossini, A., Spitzer, K.W., Vaughan-Jones, R.D.: Modelling intracellular $\mathrm{H}^{+}$ion diffusion. Prog. Biophys. Mol. Biol. 83, 69-100 (2003)

38. Stewart, A.K., Boyd, C.A.R., Vaughan-Jones, R.D.: A novel role for carbonic anhydrase: cytoplasmic $\mathrm{pH}$ gradient dissipation in mouse small intestinal enterocytes. J. Physiol. 516, 209-217 (1999)

39. Schwartz, G.J., Kittelberger, A.M., Barnhart, D.A., Vijayakumar, S.: Carbonic anhydrase IV is expressed in $\mathrm{H}^{+}$-secreting cells of rabbit kidney. Am. J. Physiol. Renal. Physiol. 278, F894-F904 (2000)

40. Purkerson, J.M., Schwartz, G.J.: Expression of membrane-associated carbonic anhydrase isoforms IV, IX, XII, and XIV in the rabbit: induction of CA IV and IX during maturation. Am. J. Physiol., Regul. Integr. Comp. Physiol. 288, R1256-R1263 (2005)

41. Wetzel, P., Hasse, A., Papadopoulos, S., Voipio, J., Kaila, K., Gros, G.: Extracellular carbonic anhydrase activity facilitates lactic acid transport in rat skeletal muscle fibres. J. Physiol. 531, 743-756 (2001)

42. Li, X., Alvarez, B., Casey, J.R., Reithmeier, R.A., Fliegel, L.: Carbonic anhydrase II binds to and enhances activity of the $\mathrm{Na}^{+} / \mathrm{H}^{+}$exchanger. J. Biol. Chem. 277, 36085-36091 (2002)

43. Vanheel, B., de Hemptinne, A., Leusen, I.: Influence of surface $\mathrm{pH}$ on intracellular $\mathrm{pH}$ regulation in cardiac and skeletal muscle. Am. J. Physiol. 250, C748-C760 (1986)

44. Tong, C.-K., Chen, K., Chesler, M.: Kinetics of activity-evoked $\mathrm{pH}$ transients and extracellular $\mathrm{pH}$ buffering in rat hippocampal slices. J. Neurophysiol. 95, 3686-3697 (2006)

45. Somersalo E., Occhipinti R., Boron W.F., Calvetti D.: A reaction-diffusion model of $\mathrm{CO}_{2}$ influx into an oocyte. J. Theor. Biol. 309, 185-203 (2012)

46. Keifer, D.W., Roos, A.: Membrane permeability to the molecular and ionic forms of DMO in barnacle muscle. Am. J. Physiol. 240, C73-C79 (1981)

47. Verkman, A.S., Alpern, R.J.: Kinetic transport model for cellular regulation of $\mathrm{pH}$ and solute concentration in the renal proximal tubule. Biophys. J. 51, 533-546 (1987)

48. Heming, T.A., Stabenau, E.K., Vanoye, C.G., Moghadasi, H., Bidani, A.: Roles of intra- and extracellular carbonic anhydrase in alveolar-capillary $\mathrm{CO}_{2}$ equilibration. J. Appl. Physiol. 77, 697-705 (1994)

49. Geers, C., Gros, G.: Carbon dioxide transport and carbonic anhydrase in blood and muscle. Physiol. Rev. 80, 681-715 (2000)

50. Weinstein, A.M., Krahn, T.A.: A mathematical model of rat ascending Henle limb. II. Epithelial function. Am. J. Physiol. Renal. Physiol. 298, F525-F542 (2010)

51. Kortüm, G.: Lehrbuch der Elektrochemie. Verlag Chemie, Weinheim/Bergstra (1972)

52. Donini, A., Donnell, M.J.: Analysis of $\mathrm{Na}^{+}, \mathrm{Cl}^{-}, \mathrm{K}^{+}, \mathrm{H}^{+}$and $\mathrm{NH}_{4}{ }^{+}$concentration gradients adjacent to the surface of anal papillae of the mosquito Aedes aegypti: application of self-referencing ion-selective microelectrodes. J. Exp. Biol. 208, 603-610 (2005)

53. Gros, G., Moll, W., Hoppe, H., Gros, H.: Proton transport by phosphate diffusion-A mechanism of facilitated $\mathrm{CO}_{2}$ transfer. J. Gen. Physiol. 67, 773-790 (1976)

54. Landolt, H., Börnstein, R.: Zahlenwerte und Funktionen, vol. 2. Springer, Berlin (1960)

55. Forster, R.E.: Methods for the measurement of carbonic anhydrase activity. In: Dodgson, S.J., Tashian, R.E., Gros, G., Carter, N.D. (eds.) The Carbonic Anhydrases. Cellular Physiology and Molecular Genetics, pp. 79-97. Plenum Press, London (1991)

56. Park, S.N., Kim, H., Kim, K., Lee, J.: Spectroscopic measurement of the acid dissociation constant of 2-naphthol and the second dissociation constant of carbonic acid at elevated temperatures. Phys. Chem. Chem. Phys. 1, 1893-1898 (1999) 